University of Louisville

ThinkIR: The University of Louisville's Institutional Repository

Electronic Theses and Dissertations

$12-2011$

\title{
That terrifying center : poetry, language, and embodied subjectivities.
}

Yalonda J. D. Green 1980-

University of Louisville

Follow this and additional works at: https://ir.library.louisville.edu/etd

\section{Recommended Citation}

Green, Yalonda J. D. 1980-, "That terrifying center : poetry, language, and embodied subjectivities." (2011). Electronic Theses and Dissertations. Paper 528.

https://doi.org/10.18297/etd/528

This Doctoral Dissertation is brought to you for free and open access by ThinkIR: The University of Louisville's Institutional Repository. It has been accepted for inclusion in Electronic Theses and Dissertations by an authorized administrator of ThinkIR: The University of Louisville's Institutional Repository. This title appears here courtesy of the author, who has retained all other copyrights. For more information, please contact thinkir@louisville.edu. 
THAT TERRIFYING CENTER:

POETRY, LANGUAGE, AND EMBODIED SUBJECTIVTIES

By

Yalonda JD Green

B.A., Kentucky State University, 2002

M.A., Wake Forest University, 2004

\section{A Dissertation \\ Submitted to the Faculty of the}

College of Arts and Sciences of the University of Louisville in Partial Fulfillment of the Requirements

for the Degree of

Doctor of Philosophy

Department of Humanities

University of Louisville

Louisville, Kentucky

December 2011 
THAT TERRIFYING CENTER:

POETRY, LANGUAGE, AND EMBODIED SUBJECTIVITIES

By

Yalonda JD Green

B.A., Kentucky State University, 2002

M.A., Wake Forest University, 2004

A Dissertation Approved on

November 22, 2011

By the following Dissertation Committee:

Karen Chandler

Dissertation Director

Alan Golding

Simona Bertacco

Nancy M. Theriot 


\section{DEDICATION}

To those damned poets, straggling bands, junkies

never quite touching the earth anti-gravity verses in their pockets disguised as holes

From another damn junkie, one more itinerant ne'er-do-

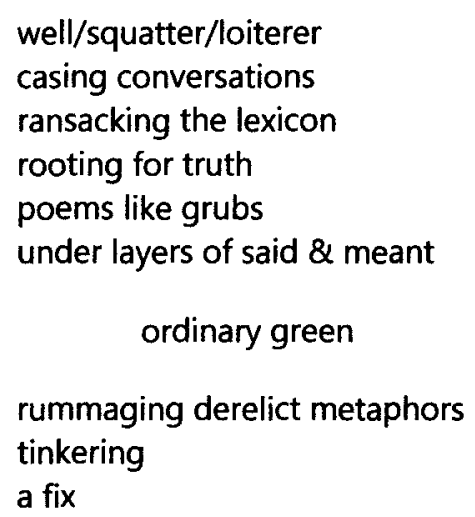




\section{ACKNOWLEDGMENTS}

Without the loving support of my husband, AJ Green, this project would simply not be.

Whether he meant to or not, whether he liked me or not, whether he knew it or not, he shared with me daily the practical magic of grace. My daddy, my puppies, my colleagues, my kindred, and my kin-I am thankful to God for them all.

Deepest thanks to my dissertation committee for allowing me the room to play in these pages, while keeping me honest in my poetry and my prose.

To Dr. Nancy Theriot-for embracing my work and managing to make my committee even more amazing;

To Dr. Alan Golding - for having the perfect book ever in reach, and double for adding my manuscript to the maze. Triple for introducing me to Harvest and Harryette Mullen. And baconflavored everything;

To Dr. Simona - for the space to consider what bodies, and language, and M. NourbeSe Philip, what pain and poem can mean;

To Dr. Estella - for adding me to your constellation, for showing me how to live and shine and the ten and the five;

To Dr. Karen-for sticking with me, for checking on me, for letting me talk out the madness of this dissertation, then making me write it out, for your painstaking comments, for your kindness, and your presence;

To Ma—for dreaming me up and teaching me to believe my own stories:

Thank you. 


\section{ABSTRACT \\ THAT TERRIFYING CENTER: \\ POETRY, LANGUAGE, AND EMBODIED SUBJECTIMTIES \\ Yalonda JD Green}

November 22, 2011

That Terrifying Center is a creative and philosophical experiment in the transmission of corporeal experiences and socio-cultural knowledge through poetry. I am bringing together the seemingly disparate threads of my studies into one creative-theoretical project: a collection of original poems exploring the development of multiple subjectivities, the terror of self-examination, and the scrutiny of memory; it is also a collection of poems that bear witness, that simply tell stories. These are poems that talk about what it's like to live in a body; they ask questions and translate answers related to becoming woman, demystifying fear, investigating genealogies of pain, and narrating family histories. As the title of the project suggests, That Terrifying Center's creative synthesis is fearsome work and the discursive chapters of this project are also part of the experiment. My poems interrogate language and somatic realities, this is not just what the body says-or how it is read by outsiders- but how it interprets, interacts with space, location, and geography. I see the body as a repository of memory and possibility. Consciously, I want to cultivate a poetics of hybridity-experimentation with language and form, while keeping a narrative voice (or voices) telling the story, using absences, space, shifts in time, and memory to translate and even reproduce the sensations of being human.

The creative dissertation consists of a critical introduction and two conceptual halves. The first half is a collection of original poetry, divided into the following sections: The Bottom Line, Absurdity, Conjure Woman, and Sunterblooms Ik Tew. The second half of the project consists of four discursive 
chapters. Chapter one presents the cultural and creative framework(s) that prefigure my treatment of "many-selvedness," and black women's embodiment as they draw from M. NourbeSe Philip's concepts "s/place," "dis place" and "bodymemory." This chapter also considers "writing the body" and the reconceptualization of creativity in the poetry and essays of Audre Lorde. Chapter two presents my work as an in-process, prismatic poetics (of parallels and intersection, of reflection) —of language and sounds, but also of space and embodied experimentation that uses poetry as an epistemological tool. Taking a cue from poet Barbara Henning's statement that Mullen adopts a kind of "verbal scat" in her poetry, I consider how the vocal scat in jazz is a particularly resonant metaphor for considering improvisation, language, and the role of "sound image" in the discussion of poetic experimentation in work by Harryette Mullen and others. Chapter three retraces the process of locating the thematic, formal and conceptual centers of the poetry manuscript. This chapter also presents some of the challenges involved in writing critically about my own poetry. In particular, I explore my desire for a poetics of hybridity and the conflicting pull to write conventional criticism and to write creatively in the discursive parts of That Terrifying Center, while considering the genesis and overall design of the creative-theoretical project. Chapter four is a lyric essay that meditates on my personal interaction with these poems, speaking frankly about the ways in which grief, illness, and memory informed the earliest conceptions of this project, its shifts and its detours. In this final chapter, I reflect on the nature of my project: the poignancy of what it has meant to translate the language of my innermost selves, to plumb my own memories, to offer up the flesh and wonder of my own terrifying poems. 


\section{TABLE OF CONTENTS}

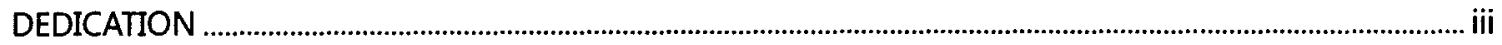

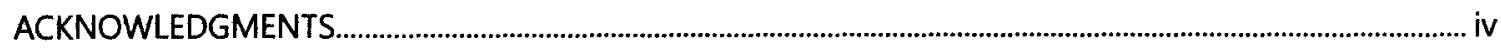

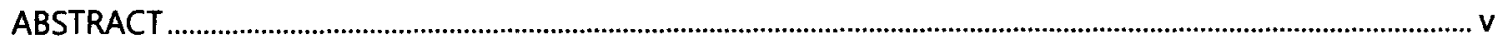

UST OF FIGURES

\section{CRITCALINTRODUCTION}

That Terrifying Center: Poetry, Language, and Embodied Subjectivities ............................................ 1

POEMS.

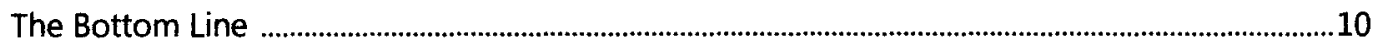

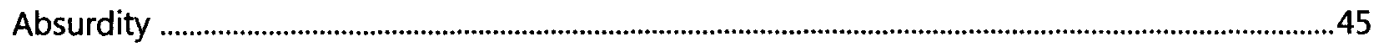

Conjure Woman ................................................................................................................

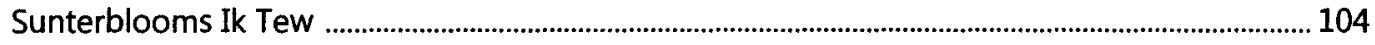

\section{CHAPTERS}

1. TRANSLATIONS:

S/Place, Embodiment, and That Terrifying Center

I. RIFFING:

Hand-Me-Down Hybridity, Sensuality, and Poetic Strategy

III. LANGSCAPES:

Minding the Gaps and Mapping That Terrifying Center.

IV. SHIFTING:

Getting from There to Here; Or, Weird Women: A Meditation

REFERENCES 


\section{TABLE OF ILLUSTRATIONS}

FIGURE

1. Illustration 1 : Six hundred most common words with ampersand.

2. Illustration 2 : Ninety-nine most frequently used words with ampersand. 150

3. Illustration 3: Handwritten draft of "Last Night" referenced in Chapter 1....................................... 202

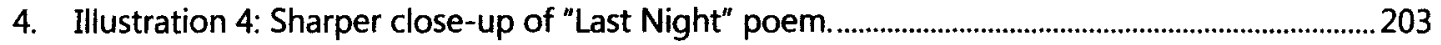

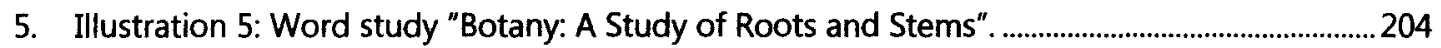

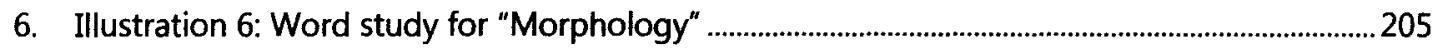

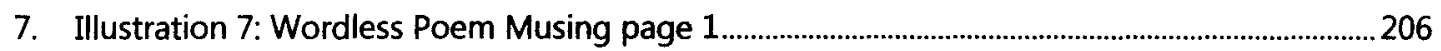

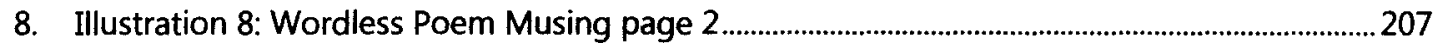

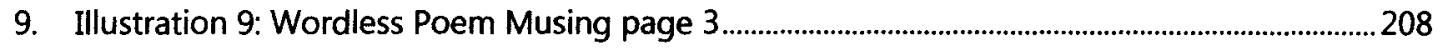

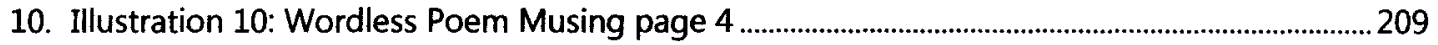

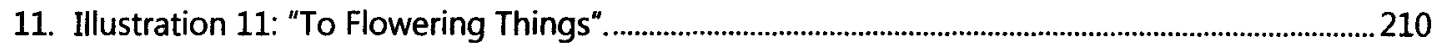

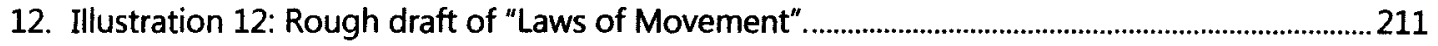

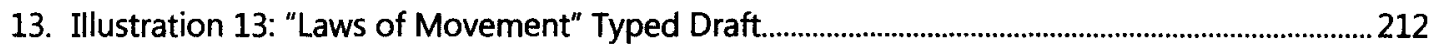

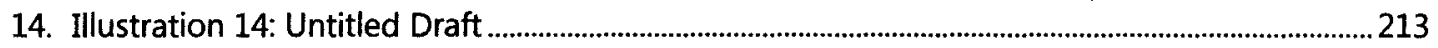

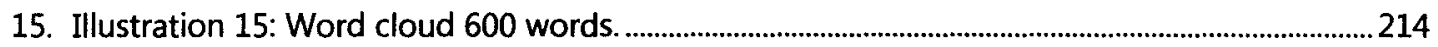

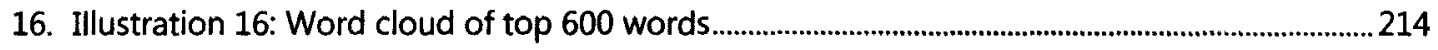

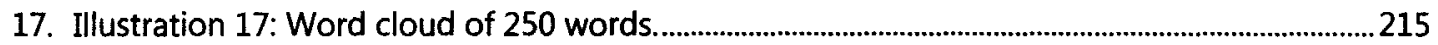

18. Illustration 18: Word cloud of 250 words.......................................................................................215

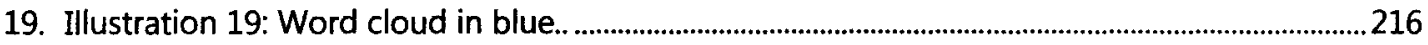

20. Illustration 20: Word cloud conjunctions, prepositions and articles................................................216

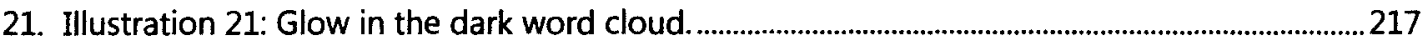




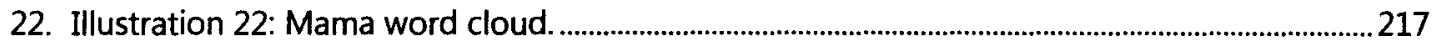

23. Illustration 23: "Epistemology" within the context of my class notes...........................................218

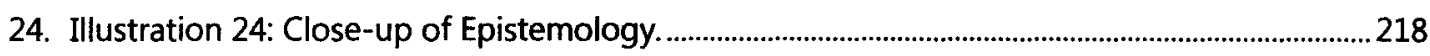

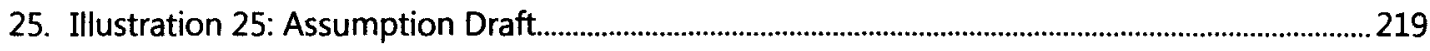

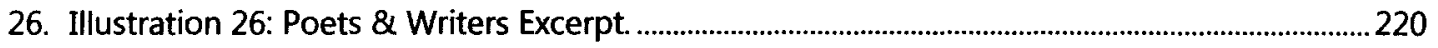




\section{INTRODUCTION}

We drink from many bowls, synthesizing knowledge gained from varied experiences that eventually converge and coalesce into personalities that we become.

--Ingrid Reneau, Introduction to Blessings for a New World

But poems are like dreams: in them you put what you don't know you know. --Adrienne Rich, "When We Dead Awaken"

In their 1990 interview, Pilar E. Rodriguez Aranda asks Chicana poet and novelist, Sandra Cisneros, an ostensibly mundane question: whether Cisneros considers an audience when she writes. In response, Cisneros provides an insight into poetry that still prickles my skin. She explains that with fiction, yes, she considers an audience, but in poetry, considering audience-even oneself-censors the work. "The scariest thing to me," she continues, "is writing poetry, because you're looking at yourself desnuda... You're always looking at the part of you that you don't show anybody. And that center, that terrifying center, is a poem" (Cisneros, Interview 75). Cisneros's words invoke the artist's delicate and "terrifying" task of interrogating her innermost "selves." In poetry, we're working toward the "piece of gold" that shocks ourselves (75). In order to get to the truths we must write, the truths that we do not yet know, the truths that will become poems, we must not be afraid to dig—or, more accurately, to mine. "That's why it's so horrible," Cisneros says; "you've got to go beyond censorship ...

you've got to go deeper, to a real subterranean level to get at that core of truth.... When you think: my goodness, I didn't know I felt that!' that's when you stop.... That's a poem" (75-76). Within the tangle of that marrow, the seams of the most primal parts of an artist's selves, lay poetry. Though this intense self-examination may cause us to shock ourselves, the object is not necessarily to then write poems about ourselves, or for our own benefit. It is the process of interrogation that is most significant 
because "poetry is a mode of knowing and of exploring the cultural and ideological processes of knowing" (Simpson x). What Cisneros presents in her response is a metaphor for understanding poetry as a powerful epistemological tool.

Cisneros' words serve as the perfect introduction to the project that I undertake in my dissertation project, and ultimately inspire its title, That Terrifying Center. This project is dedicated to the transmission of corporeal experiences and socio-cultural knowledge through poetry. I am bringing together the seemingly disparate threads of my studies into one creative-theoretical project: a collection of original poems exploring the development of multiple subjectivities, the terror of selfexamination, and the scrutiny of memory; it is also a collection of poems that bear witness, that simply tell stories. These are poems that talk about what it's like to live in a body, they ask questions and translate answers related to becoming woman, demystifying fear, investigating genealogies of pain, and narrating family histories.

\section{About the Poems}

Thematically, the poems serve as a kind of interpretive exercise looking at the (female) body (of color) as the site of cultural and creative conflict. What does it mean to live in/as a black woman's body in contexts that seek not only to erase and negate her subjectivity, but to devour hermetaphorically and sexually? The terrains of memory and urban black girlhood, of sexuality and the changing, developing body make up much of That Terrifying Center's thematic geography. These poems follow the adolescent girl who must balance her coming of age with the taunting by boys at school. As her body changes and develops, she must be savy as she responds to the advances and catcalls of men. She must always be aware of her surroundings and her behavior, she must navigate the streets and her exchanges. She must not be raped. She must not be murdered. And somehow, she must manage her fear. These poems follow the movement of girls and women through public space: their vulnerabilities as selves-in-process within the urban landscape, such as rape, murder, and sexual predation. Poems such as "Oversight \#1," "October 2009," "Of Fences," "Rose," "Little Detroit Red" and 
"The 6" expose and interrogate the cultural location of "black girl selves" and "black woman selves" in the urban landscape, focusing on her sense of s/place, vulnerability, and visibility as she moves through physical and cultural space in a racially marked black/brown female body. These poems invoke, and sometimes even mourn, the freedom to just 'be'- to experience life, not as a potential victim, but as a member of society who is able to enjoy life and its pleasures.

While some pieces are more harrowing in their subjects, other poems consider the daily lessons in the coming-of-age of girls. These poems explore social mores and constructions of femininity. An example of this examination is the brief poem, "Flash":

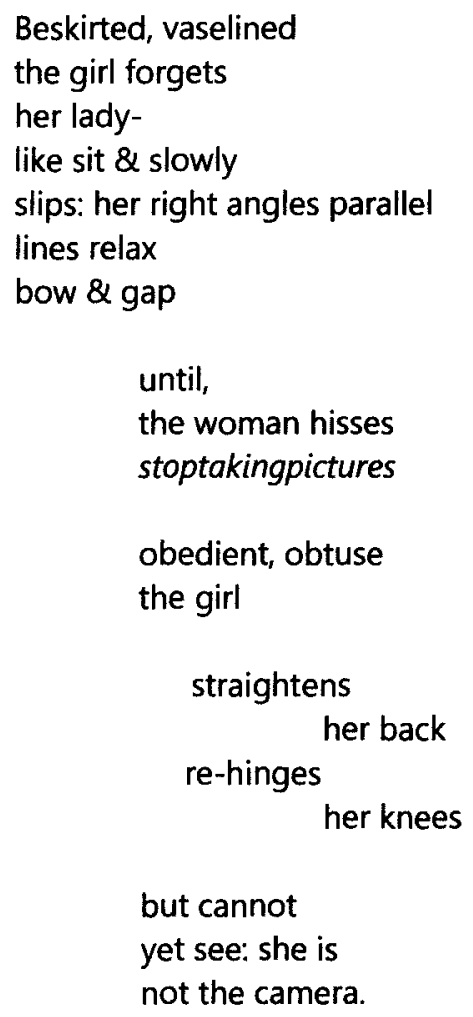

In the poem above, a young girl momentarily forgets the proper way to sit in a dress; instead of sitting up straight with her knees together, perhaps ankles gently crossed, she has begun to relax and her underskirt is exposed. When reminded by her mother (or similar female elder), the child resumes the proper posture, but is unclear on just what is meant by the admonition to "stop taking pictures." The 
girl believes that what is under her dress is the camera - both the mother and the adult speaker who is reflecting on the exchange realize that the girl's body is subject to the outside gaze of others. Though undergoing socialization to become a "lady," the girl ' $I$ ' is unfamiliar with the cultural restrictions placed on femaleness, and is even less aware of the consumption of the female form by "others."

As in "Flash," That Terrifying Center's poems consider girlhood and womanhood under scrutiny. Still others are reflections by a young woman growing into maturity after her mother's death from stomach cancer. In these pieces, the voices oscillate between the positions of child and woman. The poems in this collection examine "selves" from multiple perspectives through memory and shifting personae; in the body as it changes, aches, ails, and dies; in crisis (e.g. grief and loss). They capture how selves develop, change, and present themselves-not in a vacuum, but in ever-shifting personal and cultural contexts. . In the critical and creative sections of this dissertation, I refer often to "selves." I have opted uniformly to render reflexive pronouns as plural to demonstrate the multiplicity of selves that we all have (i.e. 'herselves,' 'myselves' and 'oneselves').

Embodiment-e.g. the flesh and bone of a black-girl-body or sick-body or always-hurtingbody - identity, memory, language, and s/place constitute much of the thematic terrain of That Terrifying Center. The nucleus of this project is the excavation of interiors and attempts to narrate my discoveries. The poems within this collection grapple with self-investigation and crisis; the conflict and revelation of each piece pivots on critical engagement with one's cultural landscape(s). In these poems, I experiment with language and form to express the shifting, multiple selves of women and attempt to reproduce the fluidity of the subject-in-process. These poems translate the relationship between our "selves" and our "bodies"; they prod and undermine the conception of identities as static and crystallized—and suggest, instead, that they may be both/and (i.e. bodyselves). These poems attempt to articulate shifting relationships of bodies to memory, experiences to genealogies of pain and illness, as we are shaped by ethnic and gender identities. 
Inspired by the myriad ways in which women of color have sought to articulate, confound, obscure, and explicate the body in their art, my engagement with and visualization of the body also includes elements of the kinesthetic and the musical as part of a creative-philosophical approach defining "myselves" through poetry. This project incorporates the crises of the performer by constructing the body as instrument and exploring notions of disclosure, composure, and selfportraiture by the artist/narrator/persona who is simultaneously viewer, subject, and auteur.

\section{Articulating the Poems and Framing the Discussion}

As I wrote and read, I began to recognize similar canvases of the personal and autobiographical, of embodiment and identity; I was fascinated by work of other colored women artists and their depictions of interlocking, multiple "selves" through lenses of ethnic and gender experience. The experimental forms of "self-portraiture" in the literary, visual, and mixed media art of Frida Kahlo, Carla Williams, Lucille Clifton, Adrian Piper, Betye Saar, and other women artists of color prefigure my own complicated exploration of subjectivity. Their creative iterations of selfhood and embodiment aided me as I shifted from studying "the body" to articulating "mybody," from attempts to understand constructions of "the self" to the translation of "myselves" in my poems. Therefore, the creative framework I employ draws self-consciously from the creative and critical work of several artisttheorists. Using terminology and concepts posited by poets Marlene NourbeSe Philip, Audre Lorde, and Sandra Cisneros; strategies for putting oneselves in the work, like in the work of Howardena Pindell or obscuring and coding one's presence as in pieces by Betye Saar and Frida Kahlo; formal experimentation inspired by NourbeSe Philip and Harryette Mullen as conceptual guides, my poems tinker with the dynamics of exposure, disclosure, and degrees of openness through a poetics of hybridity and experimentation in language and form.

As I began to compile a collection of poems, it was first necessary to consider how various artistic elements would come together in what is ostensibly a literary document that must be at home within an interdisciplinary humanities program. While the guidelines for creative dissertations require a 
document with "two distinct and equally important parts,"-one creative, one critical-I set out to test the elasticity of poetry and theory. In creating a project that explores the shifting selves and interstices that a woman occupies throughout her life, and in particular, the multiple consciousnesses of a CWA within her art, I necessarily use a variety of creative perspectives; but simply determining how to classify—or even explain —-this kind of a project required its own appropriately nuanced vocabulary. For many, many months I tried to hyphenate, slash, and stitch my own lexicon for discussing Lorde's, Philip's, Mullen's, and my own poetry, but it was all too nebulous to nail down.

Thankfully, Megan Simpson's Poetic Epistemologies: Gender and Knowing in Women's Language-Oriented Writing supplied critical vocabulary and modes of inquiry necessary to talk about my project. Language-oriented feminist epistemology provides a valid and appropriate context for discussing alternative/experimental/formally innovative poetries by women without invoking binary classifications of poetic conventions that only serve to further essentialize and/or marginalize work by women poets. Language-oriented poetry is a "poetics of possibility" fueled by imagination to breach conventional boundaries of "valid" and "legitimate" modes of knowledge : "To this end, these writers enact a variety of playful transgressions in their writing, breaching boundaries between the creative and the analytical, writing and reading, subjectivity and objectivity, one identity and another, male and female, poetry and other genres, and, most important, art and knowledge" (Simpson ix). In addition, this is a feminist epistemological project because it "seeks to disclose and change the operations of power in discourse that have limited and fixed notions of gender and other differences among people" (11). The thrust of this dissertation project is experimentation-it is an exploration of the tissues that connect life and art; it is an exploration of the "interplay and overlap between the theoretical and the creative" (xviii); it is an exploration of ways to voice what our bodies experience, but our selves struggle to express. 
Discursive Style and Arrangement of the Dissertation

As the title of the project suggests, That Terrifying Center's creative synthesis is fearsome work and the discursive chapters of this project are also part of the experiment. That Terrifying Center is a multidisciplinary chimera of sorts, moving toward a synthesis of theory and art that draws from the realms of literature, philosophy, mixed-media and visual art, medical and illness narrative, performance studies, and autoethnography. Poring over the essays, artists' statements and theoretical treatments of their own work by M. NourbeSe Philip, Audre Lorde, and Harryette Mullen, in particular, has challenged my understanding of what constitutes critical and creative, and encouraged efforts to articulate the unity of theory and poetry in my dissertation: "Theory is not separate from or commentary on the poetry; rather, poetry and theory are equally vital parts of each writer's continually developing poeticphilosophical project" (Simpson xvii). In many ways, this project is necessarily hybrid and multivalentit is building a kind of conceptual bridge between the diametrical constructions of body and self, sensation and language, narrative and experimentation, critique and creativity through the hazy, hazardous, process-oriented terrain of the borderlands-located simultaneously at the "margins" and the "center" of contemporary feminist language-oriented poetry.

That Terrifying Center, a creative dissertation, consists of a critical introduction, and two conceptual halves. The first is a collection of original poetry, divided into the following sections: "The Bottom Line," "Absurdity," "Conjure Woman," and "Sunterblooms Ik Tew." The second half of the project consists of four discursive chapters:

- Chapter 1: Translations: S/Place, Embodiment, and That Terrifying Center-presents the cultural and creative framework(s) for conceiving of "many-selvedness," and writing my body and as they draw from M. NourbeSe Philip's concepts of "s/place," "dis place" and "bodymemory"; considers "writing the body" and the reconceptualization of creative in the work of Audre Lorde, and demonstrates how the works of these two artist-theorists help me to navigate the treacherous conceptual terrain of the internal and external worlds in the poems of That Terrifying Center. 
- Chapter 2: Riffing: Hand-Me-Down Hybridity, Sensuality, and Poetic Strategy—presents my work as an in-process, prismatic poetics (of parallels and intersection, of reflection) —of language and sounds, but also of space and embodied experimentation that uses poetry as an epistemological tool. I'm most fascinated by the ways that poets manipulate and conceive of voice and language in verse. Taking a cue from poet Barbara Henning's statement that Harryette Mullen adopts a kind of "verbal scat" in her poetry, I consider how the vocal scat in jazz is a particularly resonant metaphor for considering improvisation, language, and the role of "sound image" in the discussion of poetic experimentation in work by Mullen and others.

- Chapter 3: Landscapes: Minding the Gaps \& Mapping That Terrifying Center-presents thematic and formal analysis of That Terrifying Center's poems, discusses strategies for creating the manuscript, and walks the reader through the shaping and organization of the final creative document. Chapter three retraces the process of locating the thematic, formal and conceptual centers of the poetry manuscript. This chapter also presents some of the challenges involved in writing critically about my own poetry. In particular, I explore my desire for a poetics of hybridity and the conflicting pull to write conventional criticism and to do something more creative in the discursive parts of That Terrifying Center, while also considering the genesis and overall design of the creative-theoretical project.

\section{- Chapter 4: Shifting: Getting from There to Here; Or, Weird Women: A Meditation-} reflects my thoughts on That Terrifying Center's real world genesis and emotional challenges. Chapter four is a lyric essay that meditates on my personal interaction with these poems, speaking frankly about the ways in which grief, illness, and memory informed the earliest conceptions of this project, and plots its shifts and its detours. In this final chapter, I reflect on the nature of my project: the poignancy of what it has meant to translate the language of my innermost selves, to plumb my own memories, to offer up the flesh and wonder of my own terrifying poems 
THAT TERRIFYING CENTER: POEMS

\author{
Bananas \\ Young, unsweet \\ stiff with our own greenness \\ certain that we are unbendable \\ unbreakable, few want us \\ Firm, thick with \\ freshness, but supple \\ meat creamy, white \\ few do not \\ Softening with time \\ peels tender as skin \\ though the meat is splotchy \\ the fruit is sweetest \\ Smelling of earth \\ ever-browning, covering $\&$ flesh \\ separate \\ juice \& kindling coexist \\ we are water, we are earth \\ seeping desiccating withering \\ rejoining the everything \\ that has always been
}


THE BOTTOM LNE

--for ma

A lady

always wears

the right kinda

draws. 
Flash

Beskirted, vaselined

the girl forgets

her lady-

like sit \& slowly

slips: her right angles parallel

lines relax

bow \& gap

until,

the woman hisses

stoptakingpictures

obedient, obtuse

the girl

straightens

her back

re-hinges

her knees

but cannot

yet see: she is

not the camera. 
Hush

in the dark

under covers

whispers

shhhhh
giggles
questions

half-truths

$\&$ bald-faced lies

little girls

sweet

curious

naïve

afraid

learn how

to make a

shhhhh first he puts mouth on you

then he climbs on top of you

then there's something about a snake...

a snake!?

no, i heard he pees in there

who? him or the snake?

eww, then i ain't never

what about the watermelon seeds?

everybody knows

ain't no watermelon seeds

it's grapes...

but ain't there blood?

blood? blood?

it might hurt a little

but nothing will happen

if it's just your first time

if you do it standing up

under water

if you don't want it to

$$
\text { it just means }
$$

\author{
he loves you \\ but he gives you a \\ when he gives you a
}

baby. 
Elementary Lessons

To Ms. Rybinski who may not be dead

I remember all sorts of things

from my fifth/sixth grade science classes

cataloging

observing

snakes shedding skins

absorbing daily servings of expository reading

pinhole camera from a grits box

eruption of baking soda \& vinegar

potato impaled on toothpicks

in water

suspended in a jelly jar, half in/half out

immersed breathing

Beans in petrie dishes

our nostrils full with

the must of creation

of sprouting growing things

power inside

a pinto or lima

something we'd have for dinner

dressed with rice, sweet cornbread

Dry beans would last forever,

she says

lying dormant, she says

but add water-

life from a legume,

she says

$\&$ we watched them grow

with growing wonder:

the mysteries of potential

impressed upon our

pudgy brown faces

\& smudged

grasping hands. 
from what i remember,

it took some doing

we had to practice

\& i needed steps

directions

$\&$ your willingness eased

my smile

was it over a course of days? a week.

each day, after school, your auntie in the probe

we in the kitchen, smiling serious

ready for the lesson

a peck, hmmm was it nowandlaters or blow pops?

$\mathrm{mmmm}$ apple nowandlaters, yes

so, yes a long peck

lingering lips \& green candy smiles

tickle of sweet

\& sour

riffle of filas, damaged or was used in style then?

doesn't matter, only je penney jeans, for me

over the murmured

scandals of ricki lake

as we hug hug

\& practice unfolding over days

dedicated study

delicate lessons

between horn beeps

rap of rhinestoned fingertips on

the wrought iron of my kitchen door

signaling time for you to go

kisses still new, tentative

savory \& green

taut as school pants in september

squeak of brand new nikes

blinding white

bounding on the first real day

of detroit spring 
While everyone keeps watch for grown men with nasty thoughts

$\&$ nastier hands,

no one is watching the 6th grade boy give candy to the 2 nd grade girl while they wait for the sleepy hollow bus,

ply her with nowandlaters, barter for hugs \& pats

$\&$ if she don't tell, maybe a kiss

tell her she my girlfriend | my secret.

While we generate code words for our mothers

in case Miz So\&So says she's picking us up from school

\& mama said it's okay

memorize how to run $\&$ whom to call

to tell | scream <in a nice loud voice>

about the bad touch,

while we are sharpened | keened | hipped

to the advances, the lures

of strange men | of kissy uncles | of funny women

assured that it is not our

fault when grown ups

take $\&$ do

there are no coloring books

no stickers

there are no visits from officer smiley or his real badge--

no directions for sounding it all out

No words

when they bump me in the hall

Scuse me | oops | sorry

then next time

brush | smack | pinch |

what to do when they mock

my flatness $\mid$ my roundness

what to do after I've stood my ground--

No freaky friday | No hump day

not here No.

but then they circle me after school

pouncing | arching like hyenas: 
large prey / big game

fifth grade

they taunt $\&$ wait

for me | her| it

to falter to

tell | break | cry

or better yet

to let. 
Women's Studies

There's something to be said for squatting

something mystical \& practical

in the female bondingness

in the sheer strength

$\&$ balance of the hover

Little sister hasn't learned to squat

poor baby still manages to dribble

on sandaled toes

piddles on the panties

$\&$ blue jeans gathered at her quavering feet

$\&$ sometimes she falls

\section{Learning}

the proper proportion

of paper to seat

approximating without skimping

or clogging

so as to preserve the sanctity

the pristine beauty

of a

southwest

amtrak

greyhound

or waffle house

john

I remember crouching with mama

around the uncovered drain of a belle isle men's room

seven years old $\&$ nowhere else to go

that drain was the cleanest spot in the whole damn place

following her lead

I unbuttoned

got low

\& pissed

like a lady

down the throat of open sewage

as mama held me steady

$\&$ daddy stood sentry outside the rusted doors 
What Mama Taught Me With A Razor

I'd kneel in front of her

upturned waiting open

as she took a straight blade to my face

$\&$ made me beautiful

Begin with what's already there

see the obvious $\&$ the invisible

watch the line $\&$ don't stray

unless you are sure you're sure

With tweezers in my right hand

leaning into the mirror, I learned

to trust my eye

\& make my hand obey

keep steady, tune it fine

but sometimes just walk away-

Secrets hide in the tiny

decision

before grasp

see what it will be

\& firmly, gently

but quickly tug

one smooth movement

rush $\&$ regret it:

look at a woman's eyes $\&$ see her mistakes

On knees, my trusting chin in her palm

Mama keened line angle arc

imparted wisdom balance illusion. 
Size 6 Slim: A Flashback

i.

ma flips through racks

of clothes for me to--eventually--

wear

calls me from my cave,

my dark \& awesome lair

inside the circular scraping skeletal nests

of shifting stone wash jeans

noisy jackets, scratchy sweaters

plaid jumpers

\& ill-fitting turtlenecks

t-shirts \& ruffles, lord

racks of the brightest white, pink or red heart-bubbled,

cupcaked, or

butterflied tights,

she orders me to stand \& not sway.

ii.

yal- yalonda, come here

put these on

the these in question is

a pair of hot pink jeans circa 1986

stirrups are involved

\& sparkles

definitely sparkles

but, i do not like sparkles

or butterflies, but mama does

\& so i am bedecked

in glitter $\&$ winged bugs

$h m$, they just fit; let's get them a size up... remember 6 slim...

stand up straight, baby; try this jacket on.

so i do.

mama is singing

anita baker, unconcerned

searching for a top

to hold up to my back, for a quick

$\&$ scientific fit

ooo you gon be sharp

\& so i am:

yellow \& glinting

skinny in the girls' section of

kingsway or kresge's or k-mart

\& mama's still caught up

in the rapture of the search. 


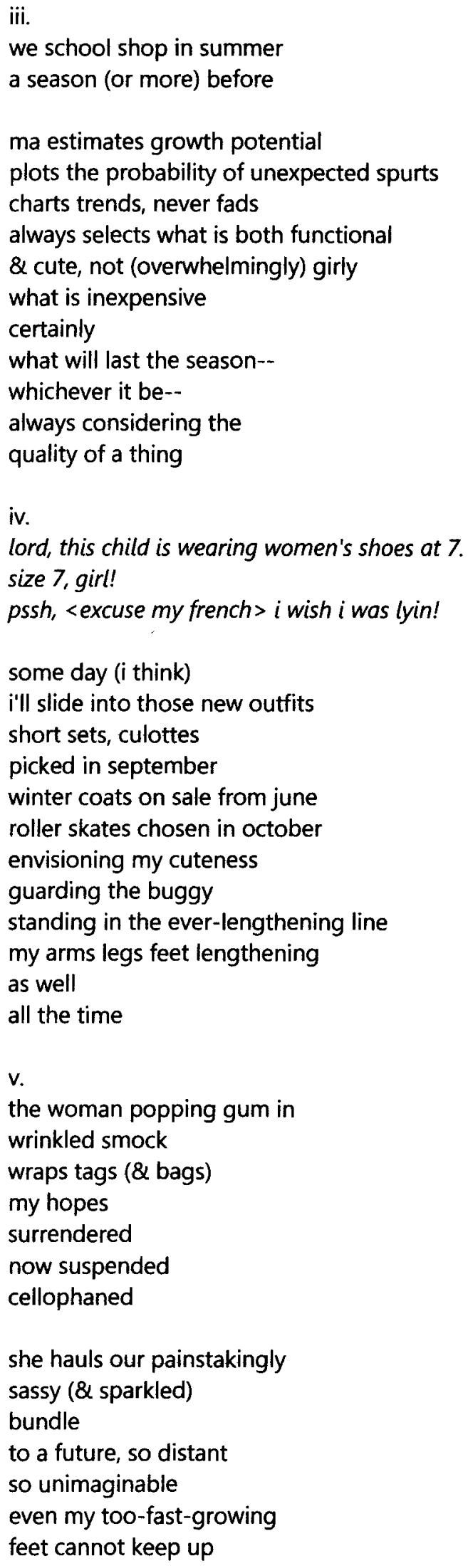




\section{Little Detroit Red}

she was

west side taught to cross

crazy ass livernois 7 mile grand river

navigate havoc

to stand on the yellow lines

$\&$ not get hit

blessed \& cursed (at)/(with)

longish tan legs

oooh wee (oooh lawd)

longish brown hair

yellowish skin, keen eyes

cautious smile

w/ her mama's auntie $\&$ nem's booty

\& learned a big butt never trust a smile

cultivated amazonian war stance

she was dangerous

jail bait

walking to the store

even before her bloom

<beebeep!> ay, want a ride?

arms eyes speakers

lips \& kisses distend

some woofers, some tweeters

hey pretty thang | hey red

sookie sookies from passing cadillacs

so much like calling hogs

from rolled down windows |over too loud radios | across the handle bars

tracking her scent

somewhere, shaking her tail

leading them not-home

dark-haired men \& darker eyes

leer across gas station counters

$\$ 10$ on 5, please. pack of benson\&hedgesmenthols

\& some rainbow nowandlaters please

8 they shoot

big wolfen | lupine grin to her big booty mama

waiting at the pump

walking home from school

she hears,

oooo that [ice cream] looks good

i'd love me some of that [ice cream]

can I have some of that [ice cream]

hunh please? 


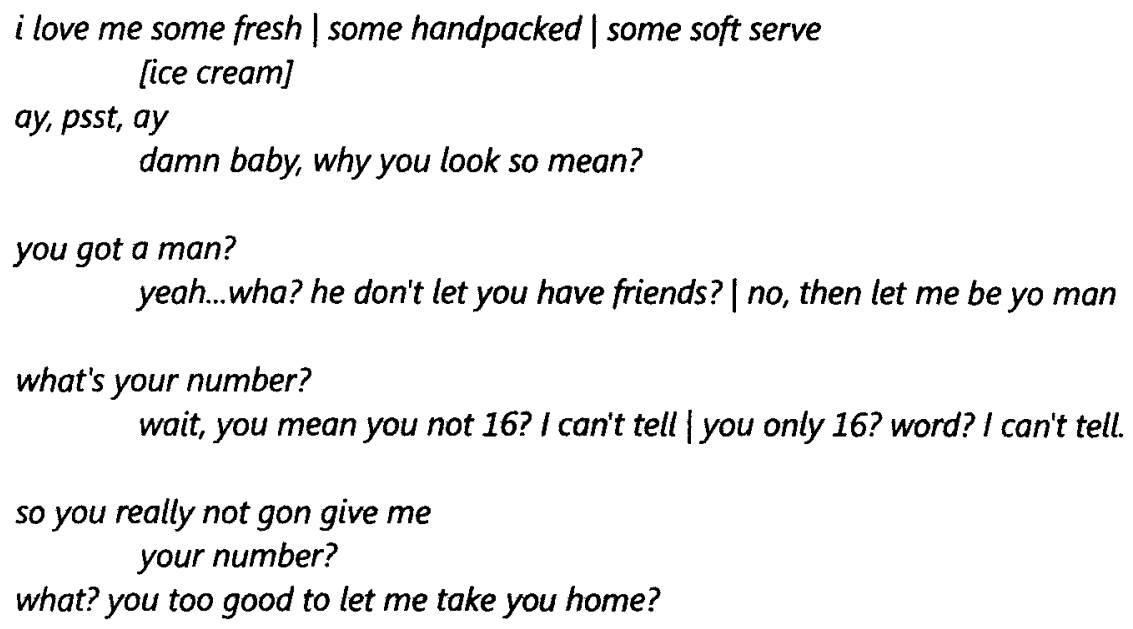

all that rotten sweetness burned away

$\&$ she'd march home 
toward the wrought iron doors

alarm code

furious terrified

as fast as her pretty legs could go 
On Coming [Grammatically] Correct[ly]: A Very Short Lesson

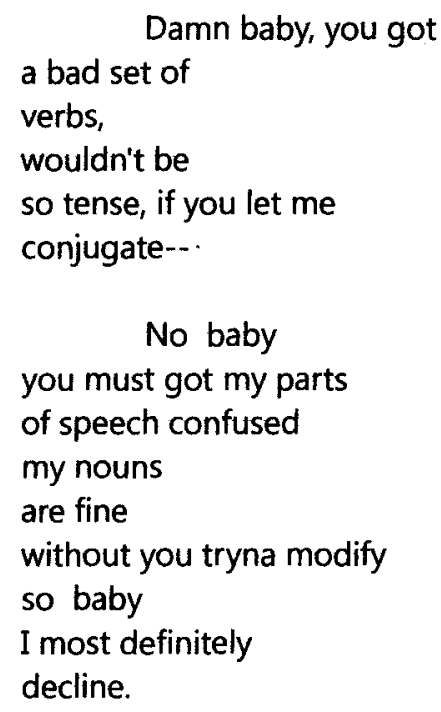


Old Wives' Wisdom

$\begin{aligned} & \text { What } \\ & \text { of }\end{aligned}$
$\begin{aligned} & \text { wind } \\ & \text { sends }\end{aligned}$
out $\quad$ man
\& don't
hungry
expect
him
to eat


Sweet Nothing

I know a lie when I taste one; why are your kisses

still sweet 


\author{
Don't Explain \\ To Billie \\ Sister, \\ why is he still your man \\ so low in his high pants \\ yellow stripes, slick \\ shoes \\ Tipping in, covered \\ in some heifer's lipstick? \\ rather he beat you \\ than quit you- \\ black your face than leave your bed \\ I hate him for hurting \\ you, again \\ I hate the heft of your resignation \\ the sloping fullness \\ of your want \\ So once again \\ convinced \& pissed \\ I bend to help you \\ gather him, cradle him \\ stand him up \\ Prop \\ that bastard \\ once again \\ inside \\ your open, waiting \\ door
}


For Schaherazade

Sister,

a thousand women

lived

because you

had the guts to run

your

mouth. 


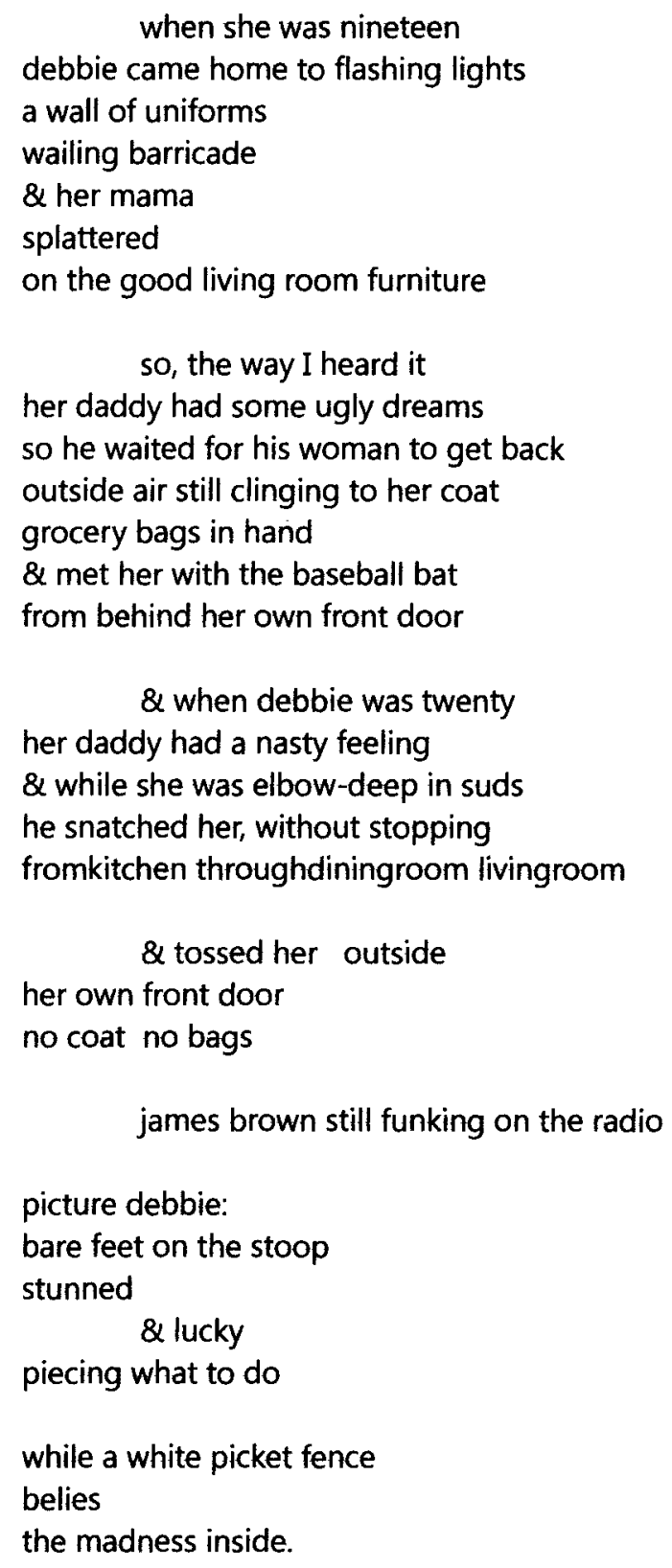


October 2009

I. After The Dance

They raped that baby for hours

looking so, so good

15 years old, dolled up for the homecoming dance

so sweet \& fine

onlookers joined, watched

I want you

recorded video on their cellphones

they'll be talking all night

they raped that baby for hours

then discarded her

like rubbish

how could you, baby

aw, baby dance with me

they raped that girl they watched so freaky
on the ground for hours
after her first school dance
they raped her $\&$ saved the videos
to remember the night
Richmond High
scored

II. On Imperial Avenue

For Amelda, Crystal, Diane, Janice, Kim, Le'Shanda, Michelle, Nancy, Telacia, Tishana, Tonia \& those still missing

It had stank for months

neighbors thought it was the factory

the funk of sausage $\&$ head cheese

clogging the rundown street

they found the first two on the living room floor

he was going to bury them in the basement

he'd raped $\&$ beaten them

strangled them

stowed them in shallow graves

filling the block with the reek of the missing

the funk

of the un

looked-for

Junkies,

the police said

dope fiends she'll come back when the crack

is gone 
runaways. whores.

felons. street women.

questionable women.

unquestionably absent

Now,

into the crawlspaces, the attic

the cavalry goes

tearing down the walls

to find the women

scattered \& tossed there

eleven women

with names

he'd mauled them

gorged himself on the meat

\& now only husks

fragments of black mamas

somebody's baby girl

somebody's chocolate drop

some damn body

ravaged

\section{\& he kept them}

sprinkled them in his garden

he kept them

placed them, like totems

like rotting charms

he kept them

wards to keep the police away 
The Soucouyant Considers

I. A Dilemma

I have no idea what I want from you

if it's everything

or nothing

your smile,

or the light inside.

\section{Man-eater}

"oh-oh here she comes..." -Hall \& Oates

You almost never look me in the eyes

perhaps, you know I'll bite into

your tenderest places

soft flesh just below the ear

behind angle of jaw

that hollow at the base of the throat where

kisses

coughs

lies

\& lumps of tears

get caught

taking hold

kneading the tough parts

between neck $\&$ shoulder

small of your back on the right side

inside left thigh

rolling them between my hands

until they yield under my fingers

\section{\& they will}

\section{I suppose}

I wouldn't look too long into my eyes

either

if I were you

I wouldn't linger in their brownness

or simmer in the upturn of their smiling

unless

I was prepared to be

slowly

\& perfectly

consumed.

II. pretty black thang

you make

my belly

growl. --lilith 


\section{Pin Up}

Everyone wants some

thing from me, even if it's

to be nothing, no one

just lie here

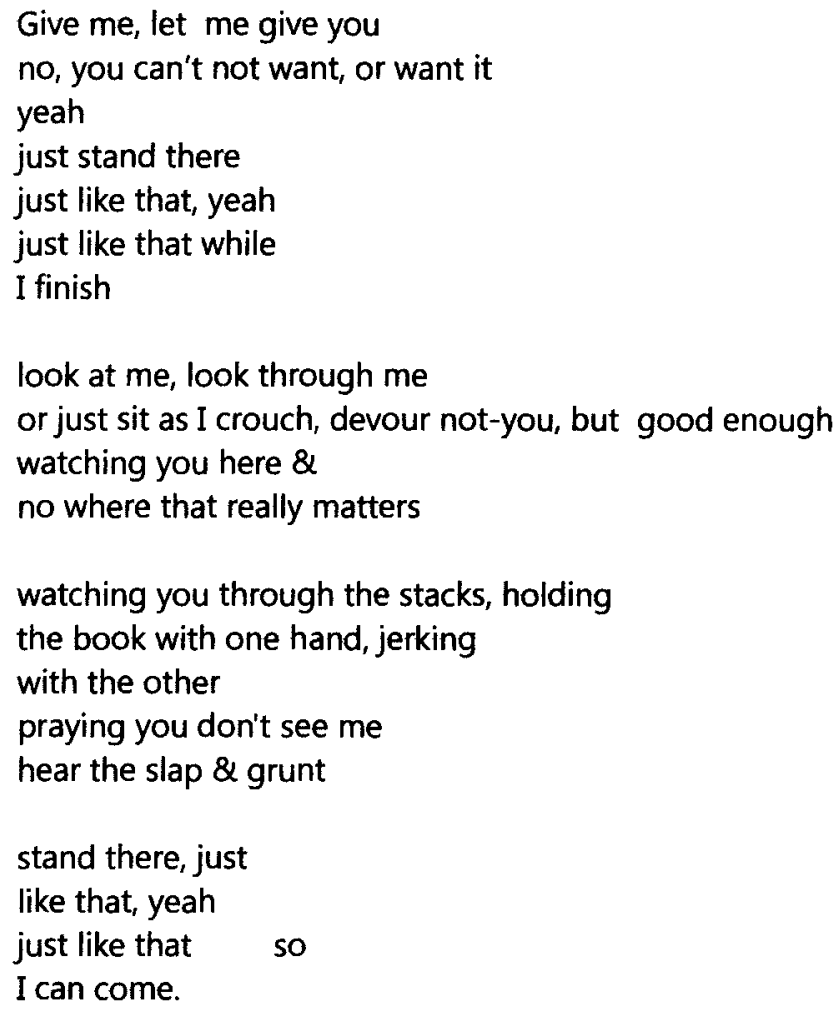


aunties

when we're children

are timeless

they live

forever

auntie rose was beautiful

she was tall, over $6 \mathrm{ft}$. in heels

with long brown hair that she wore

in a ponytail or one braid hanging down her back

rose was sweet, generous

\& like most davidson women

she was fierce \& fine

I loved auntie rose

when ali stole my

cabbage patch-the boy- $\&$ hid him

somewhere in their huge house

\& I tried to beat him into telling but he wouldn't

never did so she gave me one of hers

a redheaded baby whose cornsilk ponytail

could grow or shrink, depending on how

you pulled it

she wore a green velvety dress

$\&$ white green patent leather mafy janes

lace-up oxfords

It was sitting on her bar-waiting for me

$\&$ even though I've never been

much for doll babies, I never forgot

how even though cherruth had wanted

that dolly with the pretty

silky hair auntie

rose gave her to me still

in the box

brand new \& I

never tortured that dolly like

I did the rest

I tried to keep her special

\& when mama told me the story, I took the

facts as she gave them

I was just

too little to wonder

too little

to understand 
mama says:

$$
\begin{aligned}
& \text { yalonda, never sit your drink down } \\
& \text { \& walk away } \\
& \text { never drink it if you do } \\
& \text { mama says: } \quad \text { be careful when you go out } \\
& \text { be sure you got someone } \\
& \text { to watch } \\
& \text { your back }
\end{aligned}
$$

mama says: auntie rose was beaten

shot

set on fire torched

it took so long to find her

she'd been missing

$\&$ we couldn't find her

not in the ERs, not in the morgue

even though she was there

in the morgue weeks

unidentified because she was

so light, no black woman

here by that description, no black jane

doe here

mama says: (they might've had a white-looking one though)

no telling because

all

they had to go

by was a too-light

pinky

\& so she lay

very still \& quiet

I was just too little

until we could find her

daddy says:

we still don't know who killed her

daddy says: $\quad$ she only wore ponytails when

her hair wasn't done she kept her hair laid she stayed sharp

I was too little to wonder if there was an open casket

I couldn't go to the funeral

\& they kept me outside during the wake

but I remember the closed doors, the anger

$\&$ the tears \& loving arms shooing me

$\&$ the whispering

who's gon take the kids?

who gon get the head stone?

I remember wanting to say goodbye 
But I never wondered why there was no trial never asked if someone had been caught

by now

I just saw heard but did not

understand

$\&$ so it was over filipino beans $\&$ rice

my mouth full of pork adobo

$\&$ the story

telling my husband

as mama told it to me

that the grief $\&$ horror hit me fresh

between chews

I understood:

auntie rose was stabbed.

$\&$ auntie rose was beaten.

$\&$ auntie rose was shot.

$\&$ auntie rose was set on fire.

$\&$ auntie rose was found in an alley

left to smolder \& cool

$\&$ auntie rose was unclaimed for weeks

because no one could find her..

$\&$ her kids didn't have no mama anymore

\& no one knew why

$\&$ it was just another

detroit story one of

the seven in ten murders

that goes unsolved

or did

back then

when everything

was on fire

storefronts boarded

every night devil's night

maybe I had to be 30 to

appreciate what was lost

maybe I had to be telling the story

by rote relaying the

horror casually matter-of-factly

\author{
oh, babe, I thought you \\ knew that story \\ I thought you knew about \\ what happened to \\ my auntie rose \\ well, she was killed when I was about 7
}

for the nausea to flood 
finally

for it all to fall to sock me in my guts

when I got to the part

about her

pinky

for me to mourn

grandma says:

it was 1987. In mid-March.

same year eric was born

niecy called saying she couldn't find

rose

she been calling her, calling her friends

she called the hospitals \& the morgues

been all in the street, her house all her spots

anna,

auntie niecy says

I can't find rose.

anna, she says

rose is missing.

\& grandma says: $\quad$ girl, rose is in las vegas or orlando somewhere rose is in mexico having a good time

girl, quit calling the morgue she having a ball somewhere

because

grandma says: $\quad$ rose would do that you know

she lived that kind of life

sometimes, she'd

just up \& leave be in the wind for days weeks

\& grandma says:

I was heading to Jamaica to get married that week \& I knew

rose would turn up

she always did

But while anna was gone,

rose kept right on

missing

so

niecy kept right on looking

$\&$ looking until

she found her

big sister

just two fingers fused

was all they had 
\& somehow they matched her prints

when I ask, grandma says:

whg < unintelligible > of course it was a closed casketwasn't nothing left

she was burned beyond recognition

\& no one was at her funeral

no one but us

none of her friends came

none of them said a word

rose was gone
\& no one could would tell what they knew \& they knew
\& I was just too young to care or wonder
why it was so violent so thorough
what she could do what anyone could
owe to earn an execution

how common how

mundane the torched body

of a beautiful mother 40 years old

a sister a wife an auntie

how typical the missing

how routine the grief

aunties

when we're children

are timeless

they live

forever

\& even as a woman

auntie rose lives with me

she sits in my mind she is closer

to me than myth or

jane doe more than cautionary tale

than a pretty auntie

who gave me a pretty doll

more than her long black ponytail

that grandma assures me

black? my sister's hair

was brown

more spiny thistle \& thorns

wherever she has gone 


\begin{abstract}
rose is in mexico
she would do that, you know

maybe neither the tongueless friends
\end{abstract}

nor the prints

nor the miraculous white-skinned fingers that

didn't burn were hers

\author{
maybe \\ $I^{\prime} m$ too young to understand \\ maybe
}

I never will 
Another Black Girl Poem

Q. What did the Cleveland PD say to the black girl trying to find her missing mama?

\begin{abstract}
A. 'Oh, go home, she'll show up by Christmas

after the drugs are all gone.
\end{abstract}

\& we only know it

because of the one who got

away you're just another crack (blank) from

the street no one will know if you're missing

$\&$ when they came to arrest him just days after his last check-in

they found the first

the 2 meant for the basement on the living room floor

blatant as a welcome mat

4 in the basement $\&$ the crawlspaces

$3 \&$ remains of a $4^{\text {th }}$ in the backyard

\& Le'Shanda's skull was stowed in a bucket

they haven't found the rest

of her yet 
Knock Knock

\section{Who's there?}

Black girl.

Black girl, who? 
The 6

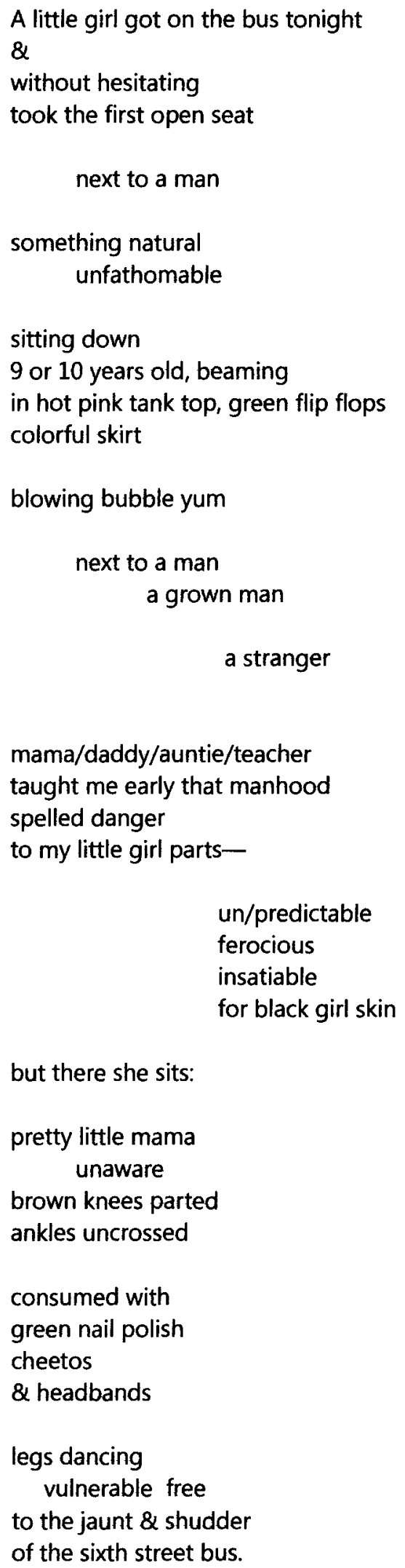

but there she sits:

pretty little mama

unaware

brown knees parted

ankles uncrossed

consumed with

green nail polish

cheetos

8 headbands

legs dancing

vulnerable free

to the jaunt \& shudder

of the sixth street bus.

not family 
Gravity Explained; Or, What Did I Do To Be So Black \& Blue

The air of our dreams is thin \& perilous

inspires euphoria, raving madnesses

\& so we fear take off

favor the landing

over the exhilaration

of flight

cling to the crushing

reunion

of feet

\& earth 
To the husbands of women who are afraid

that they are not enough

are too much

to be soft

too hard

\& end up brittle, with crackling skins

who grew up in fortresses

with open doors

who knew no fear

who know only fear

who have grown quite comfortable with the

knots $\&$ bile

who are prey

who are hunters

who want to be loved

who want to be invisible

who want to be wanted

who want to run

to the ones who yearn for home

$\&$ never to go back

who have learned to worry in their sleep

who spit \& thrash

who only sleep, walking dead

who may never sleep again

We have been sent to tell you

the answer to your questions

is yes. 


\section{ABSURDITY}

except for the

cancer

her doctor

says

granny's in perfect

health 
Terminal: A Meditation

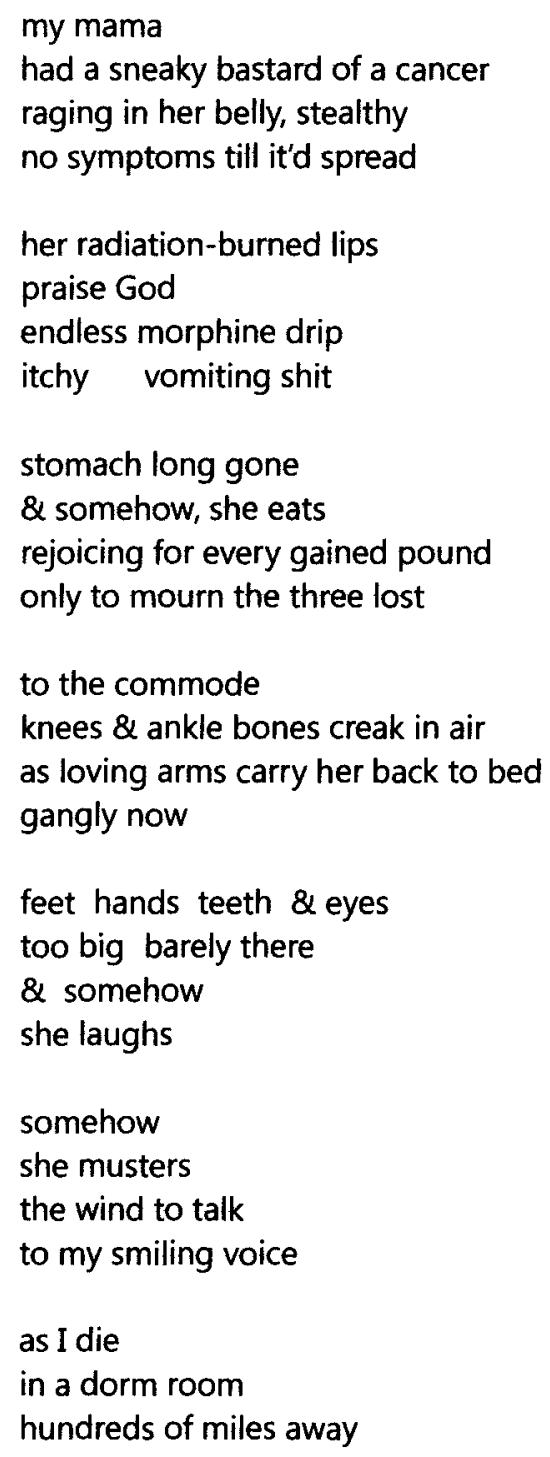




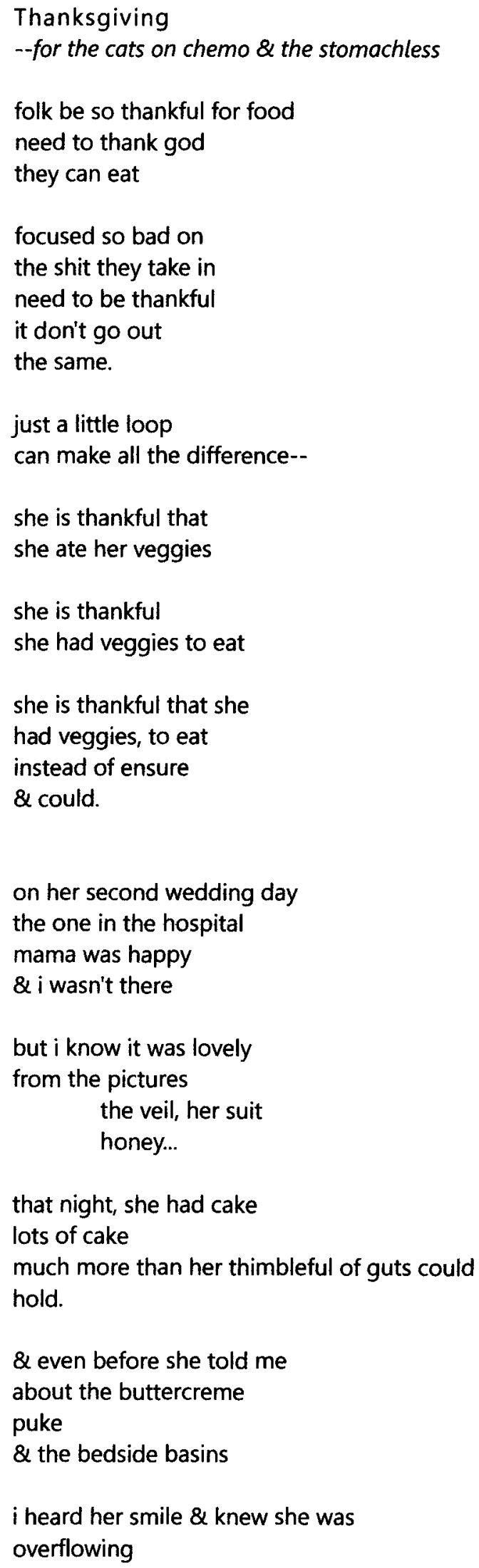


Terminal: An Addendum

The cancer tiptoed from her breast

down corridors of tissue

to liver bowels

\& Mary kept its secret-

grimaced

complicit

perhaps in the ravage

endless eat $\&$ waste

as it destroys she smiling moaning

we saddened glutted defiant

bloated outraged

faith she thinning

bountiful in pain \& joy

for a time 
1.

I am twenty again with ma \& she is increasingly silent still

I am here with ma increasingly silent terrified again

I am twenty with no songs to sing alone

I do not know to hold her hands

or stroke her brow while she is still warm

I do not dare to mumble prayers

I $\&$ she are here alone together

each withdrawing but to where?

2.

fuzzy black head propped on white pillows

brown once-lovely face now thinned, radiation-burned, chemo-scarred

two spindly arms two tiny legs buried under white, aggressively laundered blankets, under tucked white sheets \& I am stranded

among the monitors \& wan yellow basins \& the soft respectful clop of feet \& morphine $\&$ pumps $\&$ beeps $\&$ cancer $\&$ her leaving

3.

I am twenty \& menstruating \& not-sleeping on a recliner by her bed

standing sentry as herselves descend farther into herselves

\& her body continues to wither to creak to stink \& she is only forty-three

$\&$ I am only twenty unwashed for days \& watching my mama die

waiting for someone to care waiting for my daddy to come to take us home

4.

alone
with my uncertainty
alone
with the certainty
of alone

5.

sometimes when I enter,

I am the girl who carries her mama's fierce souls inside her belly
who comes prepared to stay
has learned to pray
clasps warm fingers \& sings
or just stands guard
who may not eat who will never leave


who is finding new ways to ask the same question: what can I do to help you forget you're dying?

6.

sometimes when I enter,

I am ill omen

I am anathema

I am marked by the dead mother tainted reminder of what is unanswered

of healing oils gone putrid on wanting palms or prayers too flaccid to bother god

my

presence is pocked by the reluctant duty of knowing

7.

This is

my penance

for letting her

die 
On Trying Not To Fall Apart

Wish I had been

a scout

for nothing

if not

the knots 
Waiting; Or, The Fear Of Hypochondria; Or, Negative: At Least It's Not Cancer

I wish being told there's nothing wrong

meant that

nothing was 


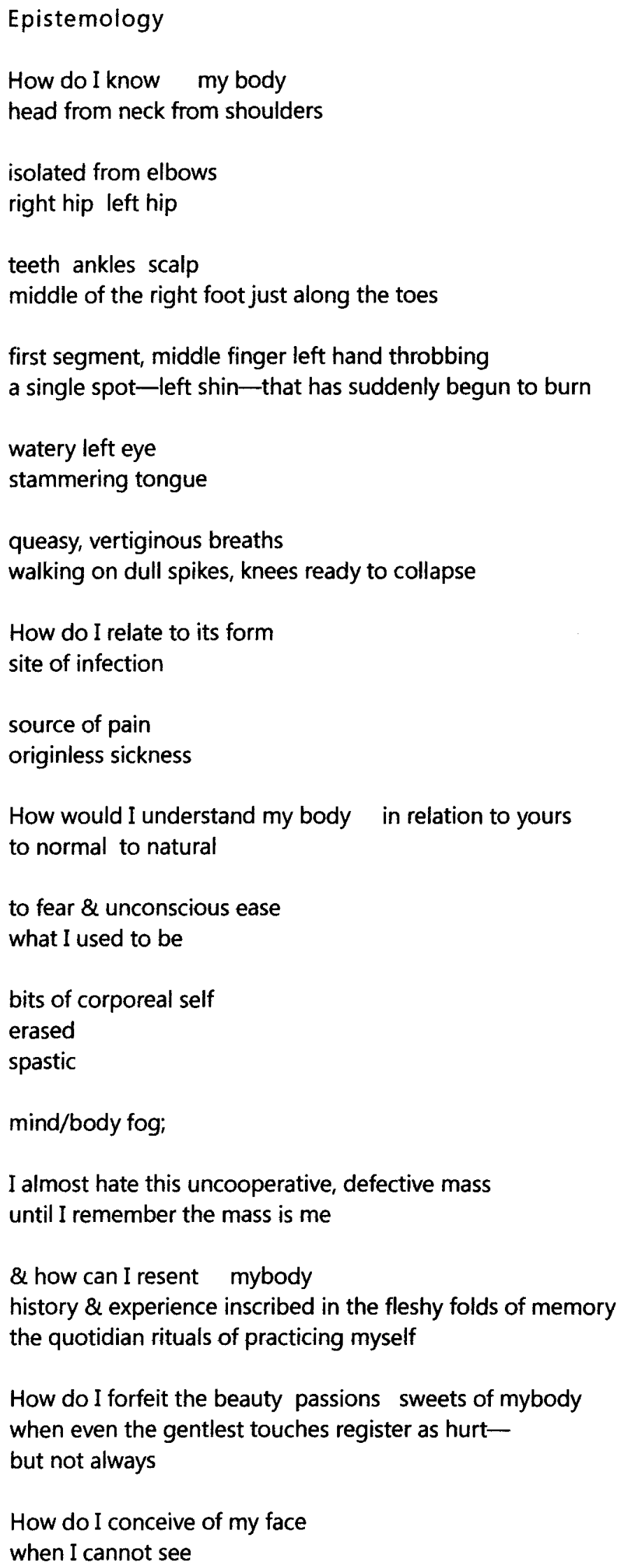


sometimes cannot feel it

awareness keened by sensation

or the absence of it-

Now that I am

frag

me

nted

I no longer frame myself on how I

think I look;

sectioned into areas limbs systems varying degrees of discomfort

mybody is based on what I do not feel. 
Sanctum Sanctorum

for black unicorns and forked, poet's tongues

1.

for some

of us,

even

no

where

is home.

2.

Aw baby, show me

where

it hurts

every where, baby

everywhere

3.

My body becomes flesh

again-for the

first time

not just systems \& dysfunction

pain anxiety

the rigor of diagnosis

my body is body

again

Skin \& smile

peace, $\&$ then

poem.

4.

I am lame, dumb

having become stone again

un-

again

today

unyielding ledge

unbending

again

the same body that sings

\& soars

must sit

for a time

this body, this flesh

site of pain \& confusion

is paradox $\&$ elation 
again.

5.

so she asked the sphinx

what moves on four legs in the morning

struts on two in the afternoon

$\&$ jams on three legs in the evening

\& she said

you

6.

soon

I'll find out what mybody

is doing

to me

\& Girl

someBody's gon be

in trouble

7

we were close once

the skin our only barrier

it seemed, learning together

each other

but these days

as I finally consider children

mybody, my friend

is stranger.

8.

statement

"our bodies themselves, are they simply ours, or are they us?"

--William James

I am a body

enfleshed \& lovely

that sometimes

walks

with a limp.

9.

Black girl-

you are

some thing

else 
10. At The Bus Stop

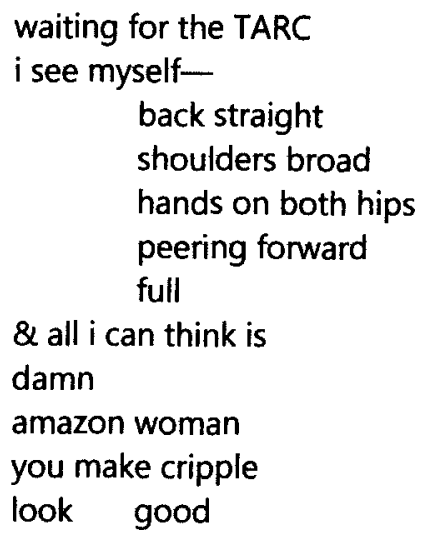


Panacea; Or, One Pill To Rule Them All

To Francis

I. Kindred

My co-laborer

fellow of the delicate constitution

tenuously secure

we ever in peril

thank you brother

for knowing the name of the pill

before I tell it.

II. Pills

I am a beneficiary of pharmacological grace

\& a good copay

blessing

divine intervention

afflicted with ailments, allergies

of sight, mind

I am a medical marvel, a miracle

who otherwise might've been picked off

from the pack or used as bait

unless I could prove myself useful

Maybe I could've been the blind seer, the rocking oracle

storyteller passing on the history

the priest who sang them into battle

incanted the juju

ensured the warriors' victory

by the skin of my rotting teeth

the grace of my own wounds. 
There are two of them this time their cart trundles into my room I am seated on the bed 8 then the chair-

One at the back of my head the other my legs they have secured me with belts parallel around breasts belly my neck \& head measured quietly, steadily swabbing scrubbing alcohol \& paste gauze $\&$ tape pressing moving quickly electrodes on my scalp

my clavicle

$\&$ when it does not stick, they push harder

my face forehead eyes cheeks chin my neck still red \& gummed from before tender please $\&$ thank you but not to me polite, silent passing colorful bursts of wire between affixing them as though I am not here

We are close

breast on the back of my head I can feel her on my legs, my knees, no excuse me, no bit of humor to soften discomfort, one scrapes

my chin, the other my scalp \& they press together in time into my flesh, the one I cannot see is on my cheeks the short one my temples $\&$ they press together in time

they don't know about the migraines $\&$ so they press, together thumbs in the soft of my face rock of skull alien fingers holding the connections in place I just love your hair they don't have to ask to touch it here not like in the grocery or the office; here, it is their job to inspect 


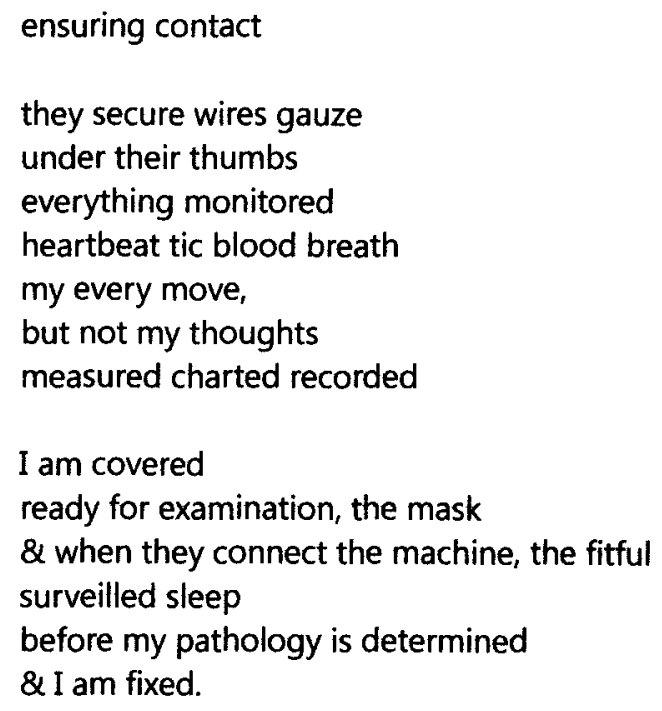


Observation

Seems like the validation of illness

is linked to proof of sanity:

having real symptoms

corresponding to a name

is better than being disbelieved

better to be sick

even terminal

than crazy

but what's so wrong

with being crazy especially

if you're the only one who doesn't know?

Apparently, it's better to be sick \& sane,

than well $\&$ crazy as all hell. 
Serotiny

$\&$ so the migraines come

to purge the undergrowth

of tangle \& funk

the thrumming lick of

wild fires fixes

a clearing

8 there amid the soot, ash

myselves lilt eastward

rooted, smoldering

in fertile

ground 
Legacy

Your lips are sealed

\& all that I'll never know

buried

with you

snatches of stories, snapshots

fuzzy

I squeeze them

until memory becomes memory

\& my lips

are sealed

too 
Aphasia

Funny that there is a word

a single word

for there-are-no-words

or there-are-none-that-I-know:

One word

for the inability to string phonemes

morphemes

syllables

meaningfully

forthejumbledexperienceofmeaningbeyond the clamoring clutch of $\mathrm{l} /$ anguish

defiant sobs

desperate silences

moans, grumbles

$\&$ intercessory groanings only

could even

come close to articulating approximating

the chaos

that smolders

just

on the tip of the tongue 


\section{Enjambment}

It's becoming harder $\&$ harder to think stringing -emes like beads gets tiresome tedious, i love the slick roundness severe angles

rush of thought in the span of a second furiously forming, my fingers grasping

But I find myself lingering in the gaps

the colorless spaces the clearings be tween syl lab les the frag

ments clut ter the ter rain make the lang-scape

danger ous, crag gy

it's be com ing im pos s i bl e to sim ply en joy the tin gle of un clogged sy nap se

for less time than I can con ce $i$ ve of can lo cate the pro per root, find ing the times when ev er $y$ thing just makes per

fect sense 


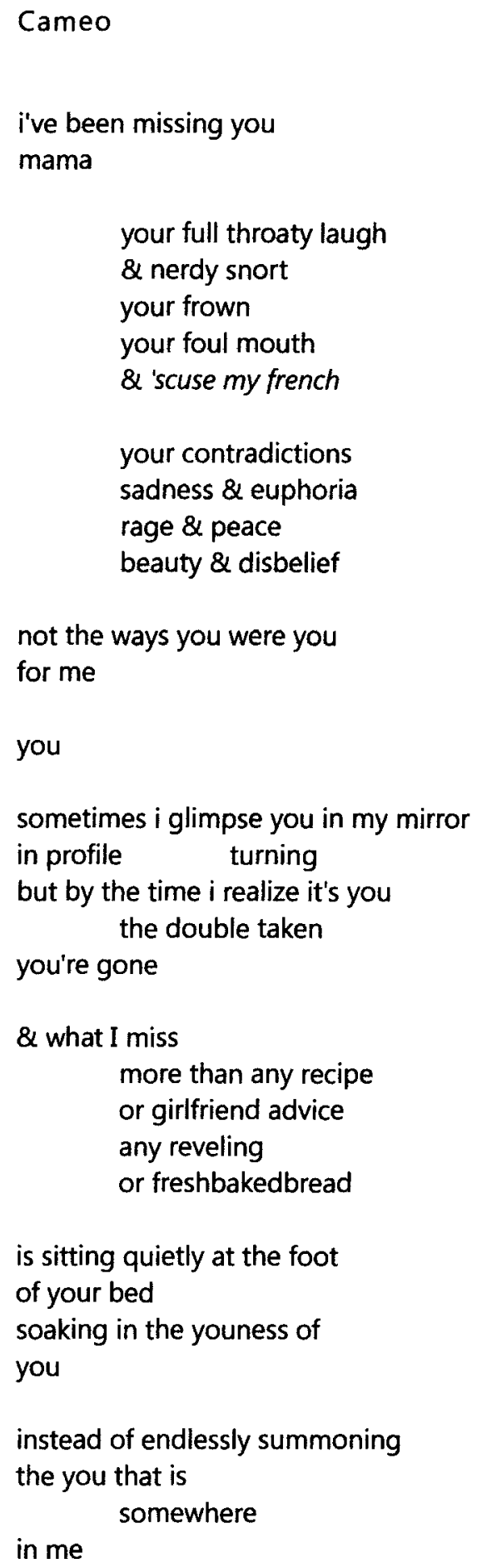




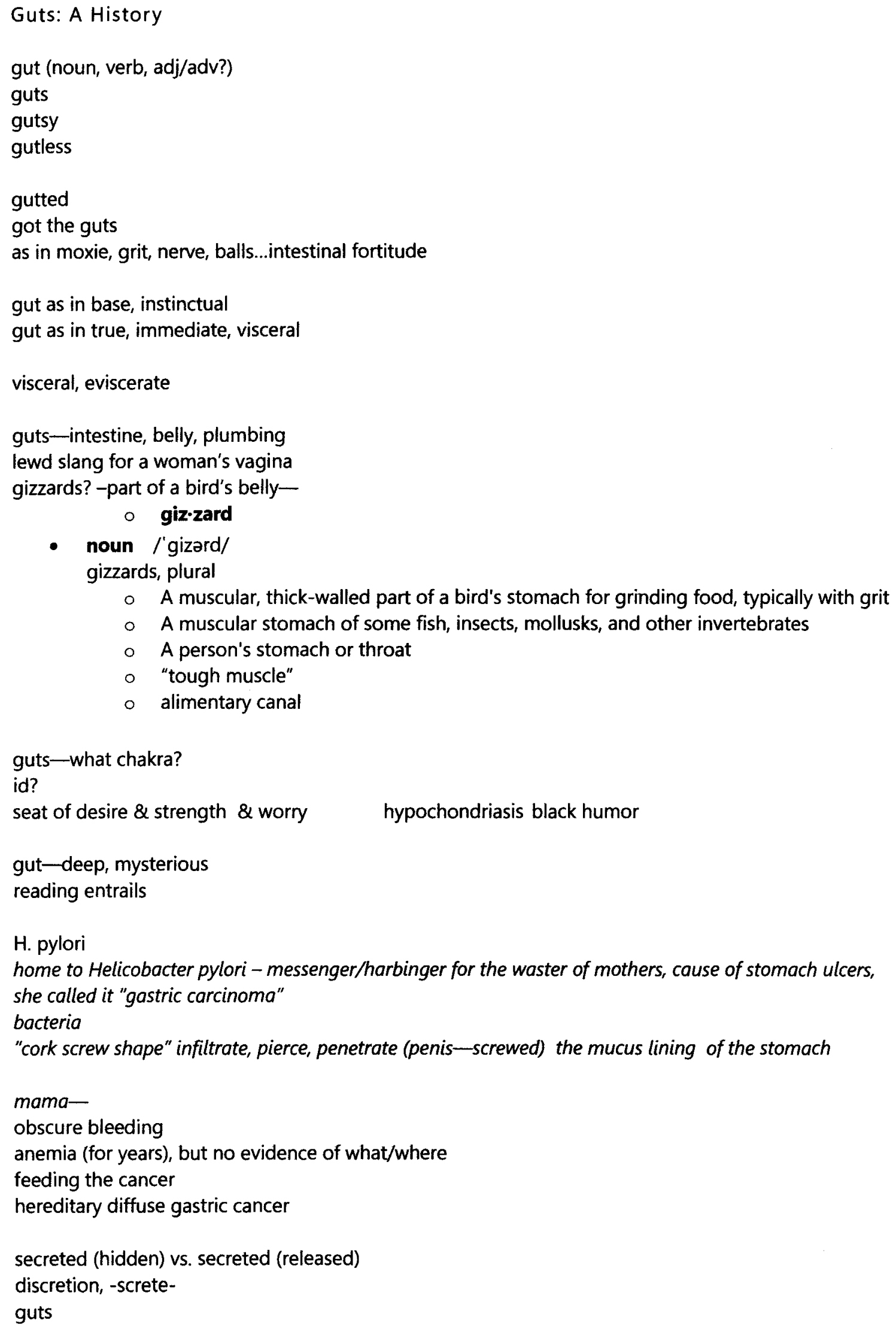


Ma's Obituary

a kind of poem, opposite

of cancerous eat-

life compiled

compressed

$81 / 2 / 11$, back $\&$ front

trifold

semiglossy busy lovely

mama on every surface

layered

filling filling 
Melancholia

$$
\begin{gathered}
\text { /he i } \\
\text { s a vio } \\
\text { let flower } \\
\text { - orchid lo } \\
\text { tus hearts } \\
\text { ease }
\end{gathered}
$$

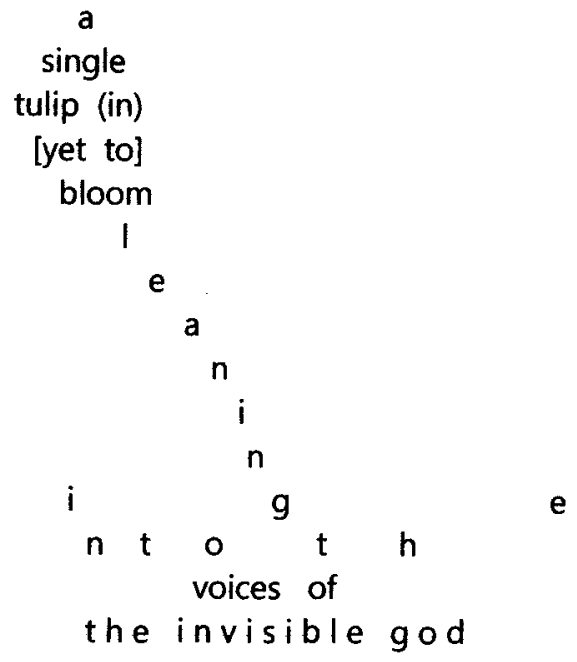




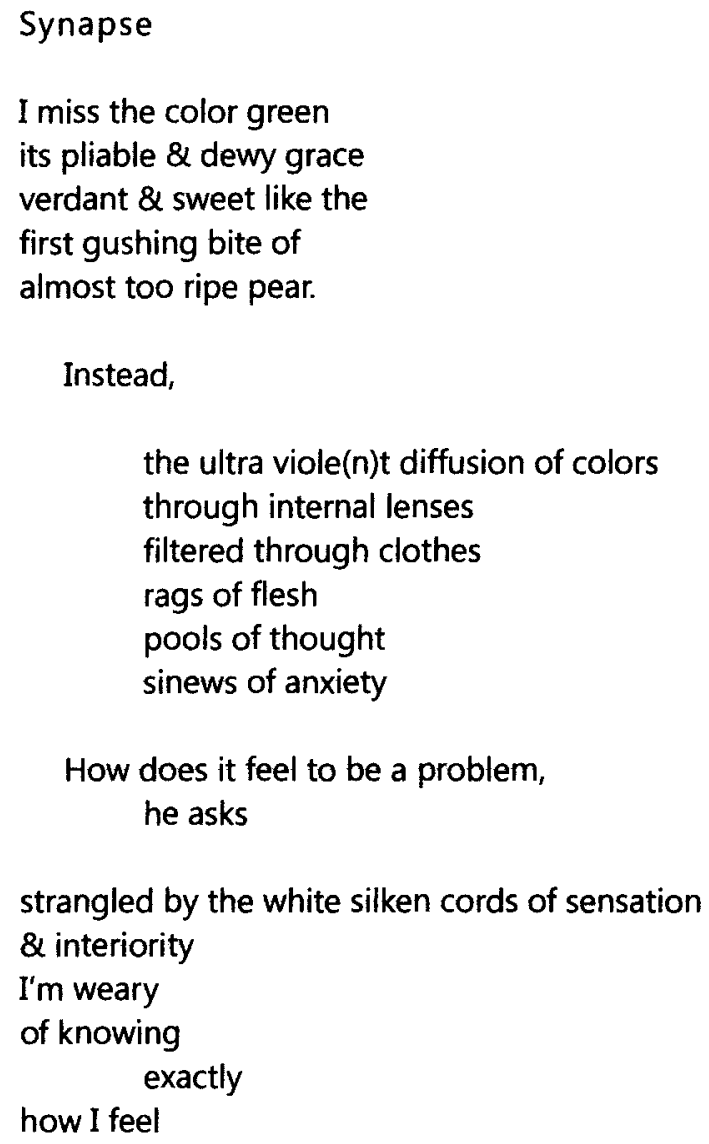

how I feel 
The Verb To Be

Neither one wants to become her mama nothing against them

excep

one's a would-be

$\&$ the other's a never-was

one's dead, would be 51

would be proud

$\&$ the other's still struggling

for peace $\&$ her own space;

one mama just needs a little room

her own plot of earth

to take root grow $\&$ dream

while
that's all
the other one
has. 


\section{Distinct}

Ma prayed I'd never know the prickly-sweet cloy

of fresh \& violent

blood \& matter clung to walls, pooled

carpets to be scrubbed

but never clean no never gone

of Gary, of her mama

of despair a pistol

or the trusted baseball bat from behind

the front door

Instead, I know the bitter singe

of terminal

shit, bagged \& measured

mucous \& prayer

scrubbed hands, the lingering sour of disinfectant

of life receding, of her dying

preserved

clung to nostrils stained

never clean no

never gone 
CONJURE WOMAN

while her body ails

$\&$ mends, her

selves conspire: they

bottle the tree

gather bits of hums scraps fists

word the walls, chalk

the circle to finally entrap

healing 


\section{Sweet Talk}

i speak to her gently, sweetly

calling her dollbaby, sweetheart

or like her mother, "get up, love"

you can do it, honey

without looking her in the eye

$i$ can speak her name in such a way

that will get her moving

$i$ am her friend, one of her oldest $\&$ she

knows

that's why she listens, even when

she grumbles

$i$ know her pain, have shared her doubts

the brittle resolution not to break, fold

$i$ know her fear

\& so i prod her tenderly, loving

coaxing her, girding her

$i$ am the plaintive voice that drowns out the ugly

we are close

she $\& \mathrm{i}$

am the sweetest bloom of our mind. 
Ailey Suite

I. Watching the Ailey Dancers Perform at The Kentucky Center

deep soul ache

arm

joy

up - extend

spring

languish. as they dance,

I initially long for the gifts of movement

to join

later, I recognize my desire for music

song-

to sing the complementary sounds

to join the articulation of

bodily involvement

sound

leaning into the hooks \& curves

sliding noiselessly into the moving parts

no ridges, all groove

line $\&$ funk

sorrow \& swoon

II. Breath

What always clenches me watching dancers

Ailey tonight, is how soundless they are

If it was me, I woulda grunted by now

I woulda hollered by now

I woulda started up

Some blues shout

Some gospel hum

Dropped some syncopated whatnot

To relieve the grinding burn

Of the voice building up. I never

Woulda been able to shut my mouth

Swallow that moan

Bridle that bucking tongue

Or be still 
with all that moving going on

III. Grace

When I was a little thing -about 11 or 12

My mama said I needed some grace

You gon take dance, tired of your stomping

clomping, slew foot walk-just-like-yo-daddy

sound just like a herd of something

wild

$\&$ I did

in this house

Ms. Gillmorgan taught me to see my body without looking

know where I was headed without thinking

\& though

I am not a dancer

I learned to bridle my wind

\& fly

IV. Fix Me

he covers her, holds her

lifts her

no matter how low she goes

she never touches

the bottom

her heights

beautiful, of course

are possible by his hands

arms, knees

precision extension

render interpretation

distillation synthesis

he is brown under her tan

almost invisible

almost

shadow

just before, just behind

twinning complement

faithful attendant

tender guide

arc flex 
what is impossible for her

is not for them

ascension flight

the sufficiency of grace

is in the dance. 


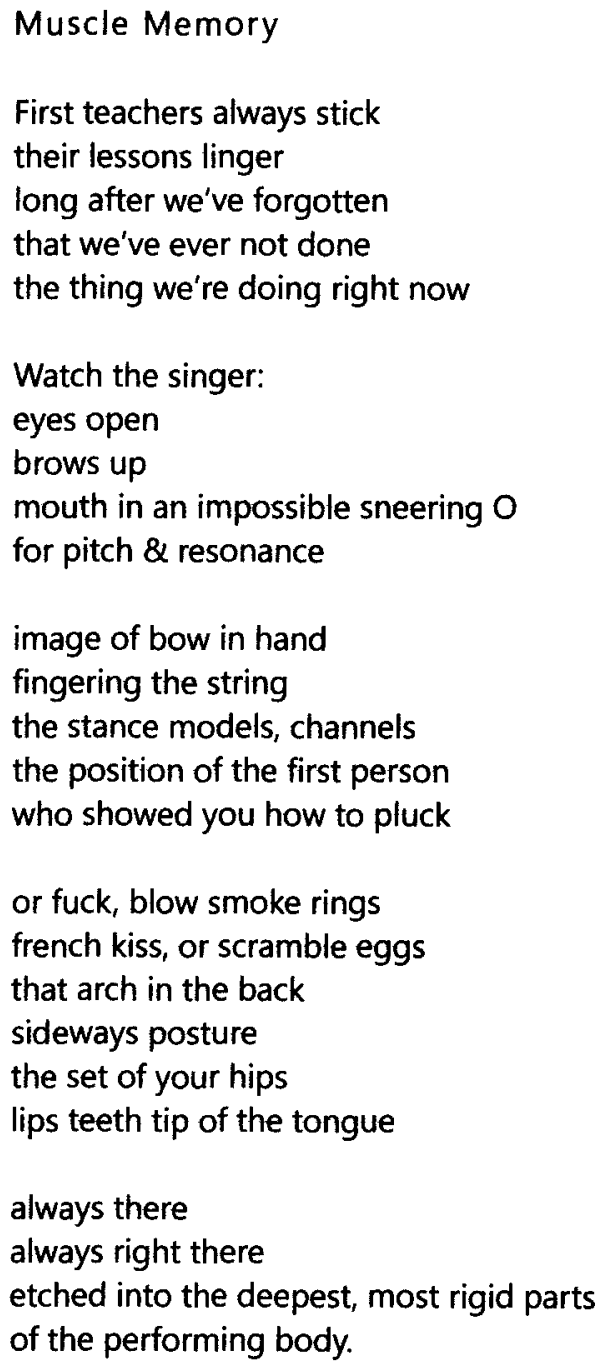




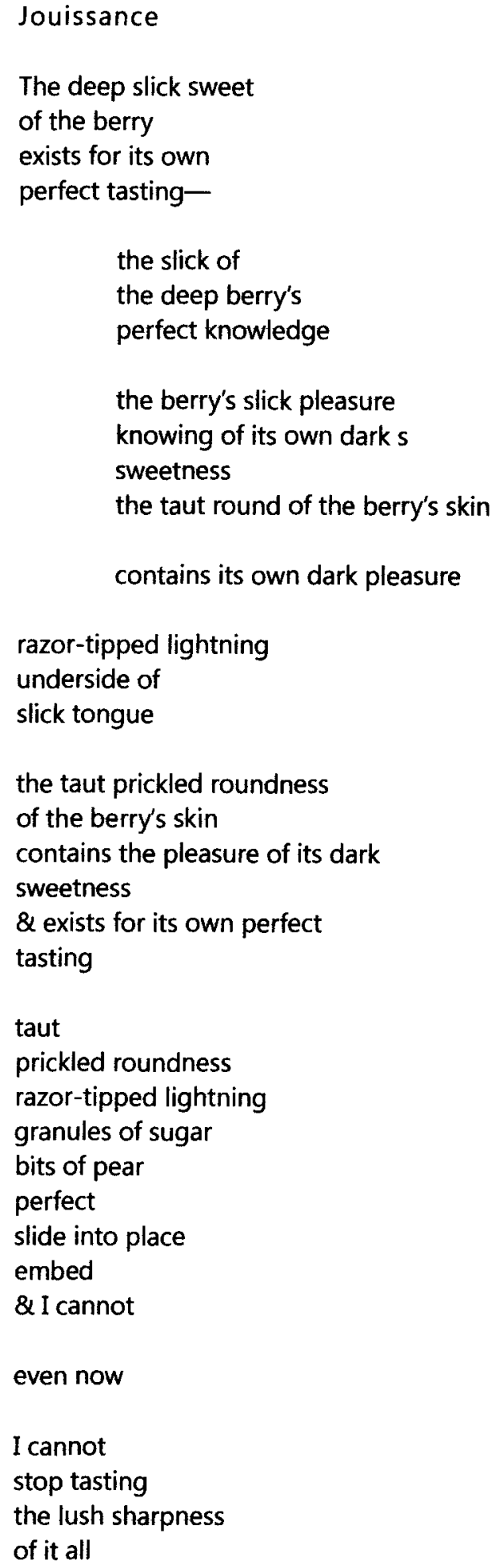




\section{Intercourse}

our bodies bend, fold into questions ancient, wordless

confound the assignment of anatomical parts

end over end over middles, conclusions draw us

like water

toward the sweetest, darkest

unison 
Seeds

fertile

in mind, if not

womb

today

babies

may never bloom

there 
In Response to TIME Magazine's Photographic Elegy, "The Remains of Detroit"

"And when the groove is dead $\&$ gone, you know that love survives $\&$ we can rock forever..."

- "Rock with You" recorded by Michael Jackson on Epic Records

Though, now the motown sound is dirge

$\&$ the smoking dragons

have ceased

even

to sputter

$\&$ the creature beautiful, horrible that only snacked

itself for decades has begun to eat its tail

in earnest smaller, smaller

gorging collapsing starving

$\&$ the ground is poison now

perhaps

choked by soot \& fumes

from earth to sky

My mama is buried there

$\&$ the migrations have begun

again, all has gone to seed

perhaps as god intended

swallowed up in grief

$\&$ the city ruined, wounded lay gaping

the firebombed storefronts still smolder

from the white-hot combustion

of black rage turned inward

$\&$ the grapevine swears there is no chorus, no doo-wop

no tambourine, handclap

no soulful croon

no wonder

only the mournful taps of

shined black shoes

steeling for the inevitable weight that

only the pallbearer knows

My mama is buried there

$\&$ we who continue to keep the time

the pulse in our pockets

the beat in our soles, who live our days

ever under the groove

we know deep in our funky

$\&$ battered hearts that

sometimes

the miracles don't really get cooking

until after the second bridge 


\title{
Ars Poetica \\ For Langston
}

\author{
I struggle with my bags \\ even with help \\ down the hills $\&$ ramps \\ into the rooms \\ alone
}

make the bed, my bed,

search through bits $\&$ ends

moving absently deliberately

watching for what must

come

the landing, the familiar

skiff of thought preparing to be

caught, but the words that

come are not

mine

they belong to the lone colored

boy down from the hill now

scribbling in his room at

the Harlem Branch Y -

hear me?

heavy, I close my eyes

welcome the thrum/clang

of emptying mind, until

I wonder:

will my page be?

$\&$ then I hear the circle's buzz

as voices stir through walls

straddle whens

\& blow into

me:

will my

page.

be. 
Double-Bind

It perplexes me just how

double-minded

bodies are

See,

mine's got this

habit of wanting

to will my selves away

knit my needs

into neat angles

tuck $\&$ fold

burrow, until

even we

disappear 
Being Contrary; Or, I Am Not-Descartes

I yam what I am!

-- Ralph Ellison's invisible man.

I feel, therefore I can be free.

--The black mother, the poet within each of us in Audre Lorde's "Poetry Is Not a Luxury"

\section{Wanting}

I am. I want.

I want because I am.

I want; therefore, I want.

I am want.

I am wont to want.

\& I am.

8 there I am:

wanting.

I am; therefore, I-want.

\section{Wanting Not}

I am not-not.

$\&$ yet, I am not, when I want Not

I think, sometimes:

Waste not want-Not

then, I am want-to-want-to

$<$ sigh $></$ sigh > I am want. I am not-want. I am want-not.

\section{Wanting Am}

\& sometimes,

I am I-want-not, too

Or I want want-to-am,

but I don't want to am.

I want not-am,

sometimes

I want to not-want,

sometimes

i want Not

sometimes.

Therefore, I am because I want.

Because I want to want; because 
I want to am.

To spite I-want-not, I want. Despite I-want-not-to-want, I want.

Despite I-want-not-to-want, I am.

but sometimes I think,

am I?

IV. Am-ing

I think:

I want to am. I want to am. I want to am.

\& so I am.

I want am. I want I-am.

\& so

I am; therefore, I am.

I am not-not. I am not Not.

I am. I am. I am.

Want is. Not is.

Think is.

\& so am I.

Amen 


\section{Blue}

to the seeline woman

who

will sing the backlash blues

for us now

provoke us to curiousity

goad us into selfknowing

now

who

when even the body

is satisfied

who

when even the invisible man

believes he can be seen 
Elegy for Phyllis

After TVOne's Unsung Episode on Phyllis Hyman

Your shoulders broad \& brown

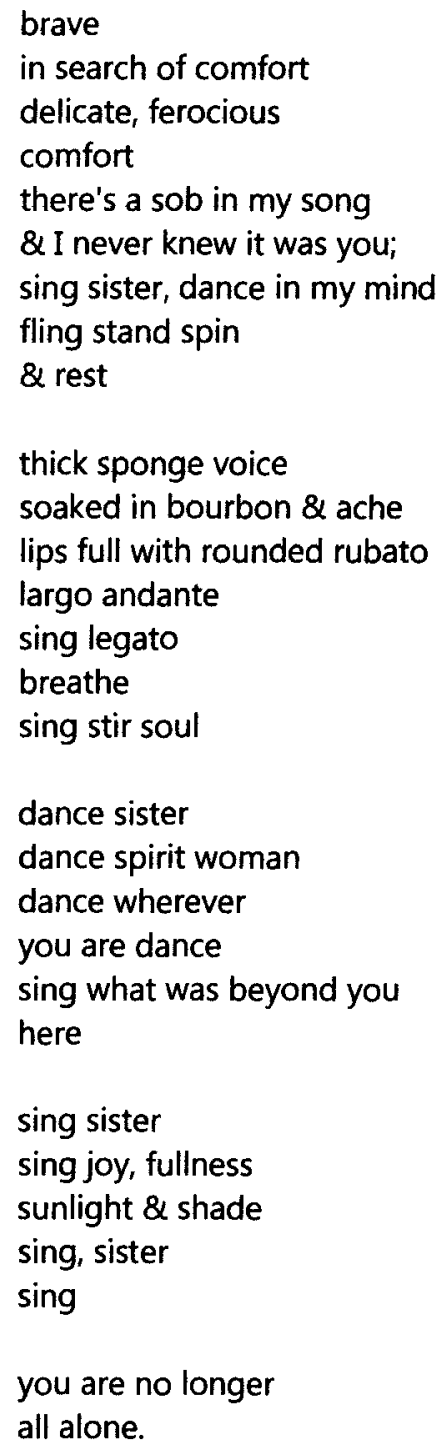


Strange Fruit

She is slumped, her gaze

distant, downcast

simple ponytail, sparkling knit gown-

her only accompaniment

the pianist $\&$ her rage

Her twisted mouth is spit, acid

her voice clangs \& scrapes each clipped line

all wail \& grimace

she leans into the southern wind

\& suspends herself there

until the piano's final, sudden pluck

Billie is singing "Strange Fruit,"

\& I am breathing the burning flesh

as my daddy hangs there

I know it is him by

the sole of his one shoe, tatters of a once-

starched work-shirt

the simple wedding band embedded

in the purpled meat of his left hand

but not by his face

gnarled \&

blacked by boots $\&$ flames

I have seen it-

wretched

char \& ruin; what

was lovely

is now pulp, carcass,

peculiar wretched crop

After she has sung me sorrowful

$\&$ fit to kill

Billie the crows \& I wait

for the sweet, disgusting fruit

to drop 
One Way To Rid Yourself of Spooks

hating me too much to banish me, you choose instead

to keep me close

dissecting, peeling back the skin

to watch me flinch

all the while telling me

i do not exist 


\section{Assumption}

Of course, it's a given

you know, that everyone

knows what is

general knowledge

to me.

It really goes without saying

you simply must

understand

that what I believe

myself to know is

canon

of course. 
Scriptotherapy

--for sandra \& emily

\& virginia \& alice \& audre \& harryette \& marlene \& gloria

\& lucille \& toni \& estella

mama \& nem

self ish women

make me sick

with all that self

talk

all that

narcissism

navel-gazers

mirrors tween

their

knees \&

for what

vain stingy bitches

just what's

so important

they need

a room of their

own to do it

better (not) be

a man in there

Folk say

talking to yourself

is only okay

as long as

no body

answers;

but,

$$
\text { I say }
$$

I remember being 8 years

old

$\& 15$

\& 21

writing \& crumpling

doodling confessing

screaming pages

encoded

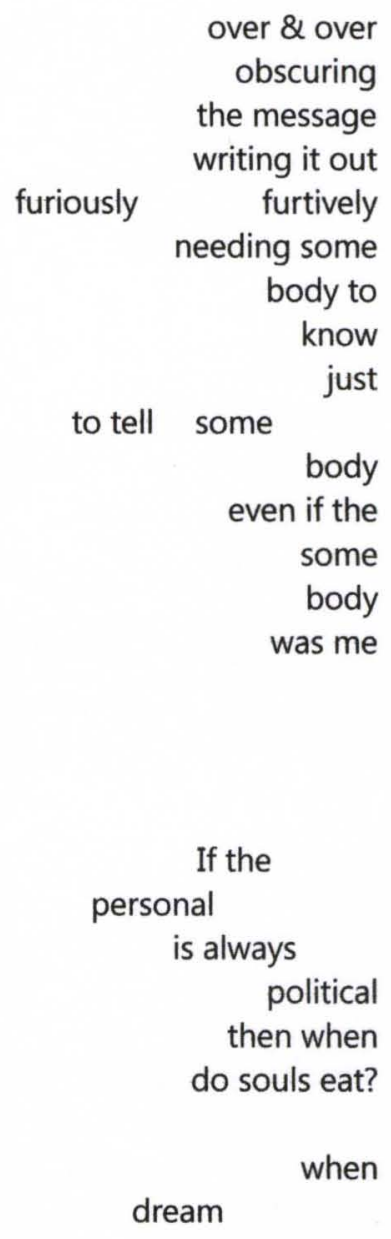

After much deliberation we submit to all concerned parties that selfish \& stingy ain't the same thing. 


\section{Originary: A Hybrid Found Poem after Bhabha}

the endless chain of stereotypical signification

is curiously mixed \& spl-

it

polymorphous \& perverse

the mythical moment of disjunction

kinked \& tangled

imprisoned in the circle

(circuit) of interpretation

black, female, educated working class

from the most dangerous [one-time murder capital of the world--does that include Gaza?]

city in America

place me in an oppositional relationship to

self

home

mind

body

expectations (but whose?)

being

i am simultaneously everything \& nothing

ever the contradiction

miraculous exception

mybody

the nigger, the cunt

the bitch

the simpleton

the savage

the keeper

the maneater

the mare

the black hole

the babymachine

the death star

the absence of light

ann, aunt jane

bottomless well of discomfort

never simple

always already disruption

always always meaning

my unhomeliness

sacrosanct 
I am no starlet, no Carmen Jones no symbol, sex or otherwise

I am curvy, too-broad brown sugar

my one-piece bathing suit is conservative

perhaps even for the 50 s-

I have been in the salt water pool

stretched ligaments, chatted with my therapist

splashed, but have not swum

\& only slightly registered my oddness:

the youngest, the coloredest

But it is the hot tub that takes me back

the tipping into the bustle of white, heat

$\&$ water Everyone faces me

bubbling \& silent

$\&$ then I see her:

As they attempt to escort her to

the colored quarters, the hidden corridors

she daintily dips a

single

rose-tipped

toe

into the Vegas hotel pool

$\&$ the white folks are horrified

She is defiant indignant

until she sees the men

drain the pool as promised

to rid it of her particular black filth

She sees

their furrowed brown brows

their resignation \& blame

their faces shuttered against her

$\&$ is shamed.

I remember this in the water

as I am shoulder-deep in white bubbles

my toes, all ten, unpolished-but still coloredare in the pool

protected by my black rubber shoes

I stand immersed in the roiling, shifting current

somehow still

not of it. 


\section{Morphology}

Harryette \& Marlene are hanging out in my mind, trying to make my poems make sense--

they want me to play, dispense with the formalities

they want me to scat through the breaks proceed with causation make the meaning in the process

scatter the becomings behind us as we go

one sounds \& mouths \& the other chops one stretches as the other smashes they shuck \& debride the lines slivering them down to the -emes I mean $\&$ chuck the detritus to the side

they crack the shells down to the meat the tiny contrastive units crack shell \& toss down to the hemispheres they grind, pound combing, combining until we make 
Blues Woman

what if ain

no [mo] songs

in me

only

echoes 


\section{Disclosure \\ for Lynda \\ gamble of truth \\ $\&$ confidence \\ \& extension \\ \& mutuality \\ $\&$ respect \\ $\&$ reciprocity \\ $\&$ fear}


Debris

Gathers into corners. Mine aren't the only ones to collect

Nap balls \& dog hair rubberbands buttons

Bobby pins \& potato chips somehow overlooked

What begins on the kitchen countertop bathroom sink

Fluff from absently-emptied pockets residual muck of

What we tracked indoors hugs the baseboards back of the toilet

Migrates toward the periphery unseen selectively ignored

Until all at once our margins overtake us. 


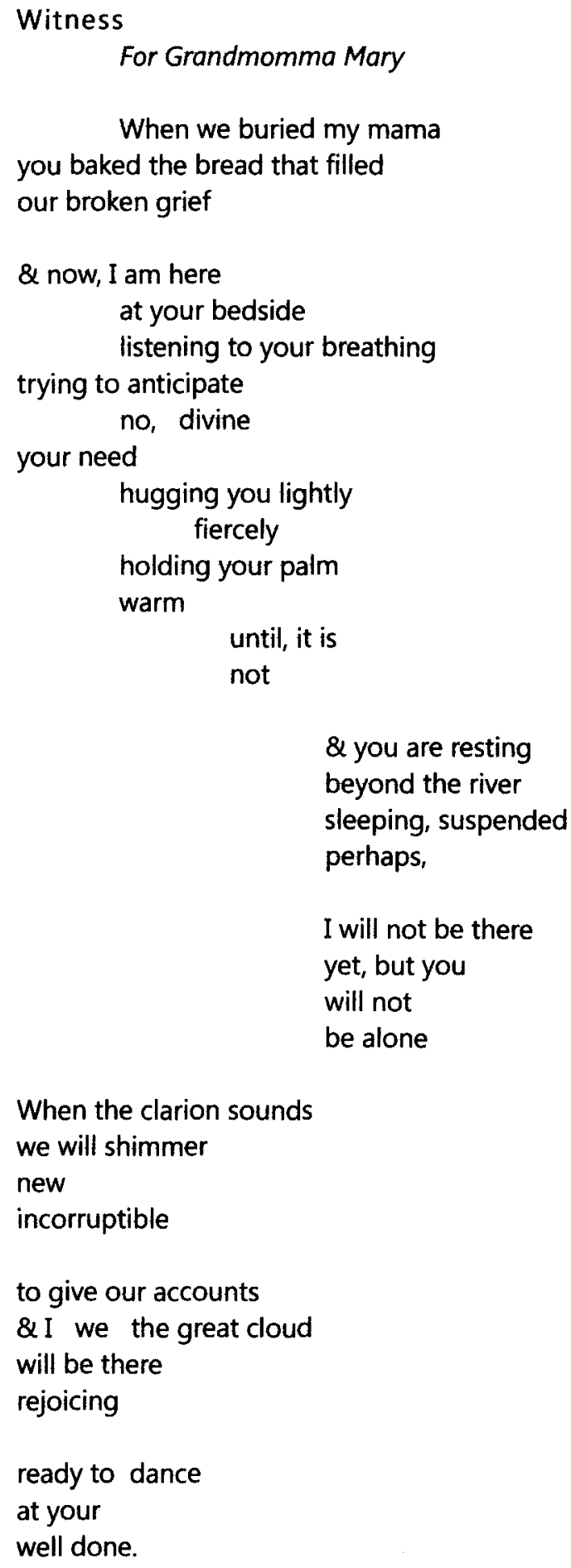

When the clarion sounds we will shimmer

new

incorruptible

to give our accounts

$\&$ I we the great cloud will be there

rejoicing

ready to dance

at your

well done. 
Here, After

I.

black Girl,

don't

nobody care

about your dead

mama-

didn't she teach you

anything?

II.

i still miss

you-

still reaching for

every celebration $\&$ victory

every loss \& fear

forgotten recipe

on your seventh year

underground

but where are you, mama-

sleeping? or dancing?

silent ageless, or forever

almost fortyfour

Are you, mama?

Are you anymore,

Mama?

is there memory where you are, mama?

eternally everywhere

finally carefree?

No where

smiling, planting

waiting
for me?




\author{
Last Night \\ I was visited by a village \\ the kind it takes to raise a woman \\ Tears arms crazy cackles \\ ring-dancing singing playing \\ leaves me surging \\ yet weak this morning \\ enlivened aggrieved \\ by my finite encounter with \\ SHE WHO IS WE \\ My face gradually loses its glow \\ as I awaken with grasping \\ $\&$ breath \\ $\&$ you \\ siphoning the pot liquor \\ vestiges of the visitation \\ through my pen: \\ Now that I remember \\ what it felt like \\ to carry my mama when she \\ wasn't \\ anymore \\ I am strong.
}




\author{
Mortal Paradox \\ our bodies \\ are continually making \\ \& unmaking dying \& birthing \\ as the skin thins \\ flakes \& sloughs more \\ split \& make \\ renew \\ each moment we \\ ever dawn \\ \& dim
}


Black Girl Eternal

before my mama, my daddy was formed

i was $\&$ my soul was with you

my body spread across generations

of splitting cells

bits begetting bits

the mystery of multiplication

older than my conception

$i$ have never not been 
SUNTERBLOOMS IK TEW

Sunterbloom ik cyndon sockling teeper ot taf downcroft sark puckerkin ot darbon cabing symcobrome ot fucules sisk fucules noktules

sunting, fifft. 
To Cassandra

I be
lie
ve
you 
Provision

\author{
Forget \\ we are more water \\ than word, more \\ light $\&$ air than \\ rhythm \\ sere as wit \\ depleted, the dust \\ reclaiming us \\ the poets will \\ be next \\ where \\ worlds end \& I am \\ only mostly dead \\ I covenant with \\ spiders: \\ they \\ teach me to live \\ on the tiny; I \\ teach them \\ to hum
}


Stardust

We are stardust.

We are golden.

And we got to get ourselves back to the garden.

--Joni Mitchell's 1969 song, "Woodstock."

Listening to me $\&$ the girls singing "If I Can Help Somebody" feeling the tears coming. Back in '98 we were so young. We still are. So much life before us then $\&$ now, we pray.

Sometimes I can't help doing the math: when Ma was 30 , she only had 13 years left.

She couldn't've known that. She just had to live. I wonder how much worry she'd've cut out $\&$ if she could've realized how precious \& short a decade is.

I can't help remembering the certainty I had from childhood that mama would die young $\&$ I would too. What a difference a decade makes. The pendulum, the tightrope, the romp, the rind of time is deceptive. Relative, indeed. A flick of the wrist. Mobius.

That song always works me over. It was emotional then, but for different reasons. We had no idea what time held for us then. We still don't.

We have our memories, but even the nature, clarity, \& perspective of those shift over time.

Life is a puzzle. A trick of the eye. I'm thinking parallax. I'm thinking sleight of hand. I'm thinking milk bottles $\&$ rings that don't line up $\&$ who still uses milk bottles anyway? I'm thinking three-card monte. A Jack Kennedy behind the ear. Life has our noses. Wide open.

Time is magic. Fun with mirrors.

Funny how a song can rock me back \& forward in time.

Life is the pirate ship at Boblo Island.

Time is suspended there.

$\&$ the days so full of hours that we squander, misuse. Wasted on banking or sleep.

I want to wake at dusk, watch the changing darknesses, shifting depths of unlight.

Shimmer in the beauty of it all. Gobble the day \& night whole.

Full up with the glory, the sheer impossibility of it all.

The earth rotates, the stars scramble align scramble again $\&$ we do not die, until we do. \& the murky wonder of birth begins again. Eyes closing, open in new half-light.

Learn to see the light in the dark. Learn to be the dark in new light. 
On the Balcony

The sweet of sunlight

\& cigarette smoke

catapults me-

riding shot gun

mama puffing out the driver's side

popping our fingers to the isleys

heading over to winnie's

early evening

not quite dusk, somewhere about ' 89

mama glad to be off the clock

$\&$ free

\& I'm just glad to be anywhere

with her

seat-belted \& smiling

Yet

standing at the University balcony

on a smoke-free smoke break

with diane \& melissa

straddling time

inhaling deeply 
Your Mother Is Very Alive In Your Poems

To Julie

thank you for reminding me

that she is alive

some where 


\section{Maya's Voice}

Clack of brazil nuts in their shells, split of almonds groaning give of cherry legs across mahogany floors

Thick, cognac leather sheened \& fragrant warm syrup, maple a cello line, long $\&$ blue

Winding hum of wind harp leaning, soothing smooth of uncut shea butter on dry, cracked palms

Balm \& salve

the sweet language curved

lovely 
Metaphysics

The Body African. Is Mind.

--M. NourbeSe Philip, "EarthSilenceSoundBodyText"

It's all matter.

--Bilal, "All Matter"

mind is
body
voice is
body
body is
body
all is
flesh
is not
matter.
even
thought
is meat
gristle
we are
corporeal
ether
is corporeal
woice is
psycho
somatic
we are
soul, fire
embodied
we are
wind spirit


\& not even nothing is

immaterial

all this matter

all this will

aspiration

cleaving to

my meaty

mind 
swoops shoots to save

a soldier's grace

need to save, if not

his own skin

or hers

then mine

IV. according to the maniac

Because the world is hell

we have a chance to start

over in the rubble

but first there has to be rubble

see

the phoenix on the pyre

of its own making

living for the death

the remaking, only to die

again

only to live again

only to wish it

gone.

V.

how much a life can mean

even after appreciable life

has ended

what is life after life

a ghost of himself

that only exists

in its own time

in its own hell

in its own making

inside, ever inside

always, already nested

this is Death-

over\&over

VI.

[the scientist]

life and death $\&$ life $\&$ life

after scripting

all from a keyboard

fingertips

memory wipe?

knows the workings of 
brain, but not mind

of transmission, but not

communication

of code, but not

intimacy

of life, but not

living

8 minutes

what spins on the

record

what calls to make

what question

what love

what voice, phone call

what is on the loop

what regret, what back

question, on the mind

what love

what is there on the tape

on the loop

the spindle

at the end of my

mind? 


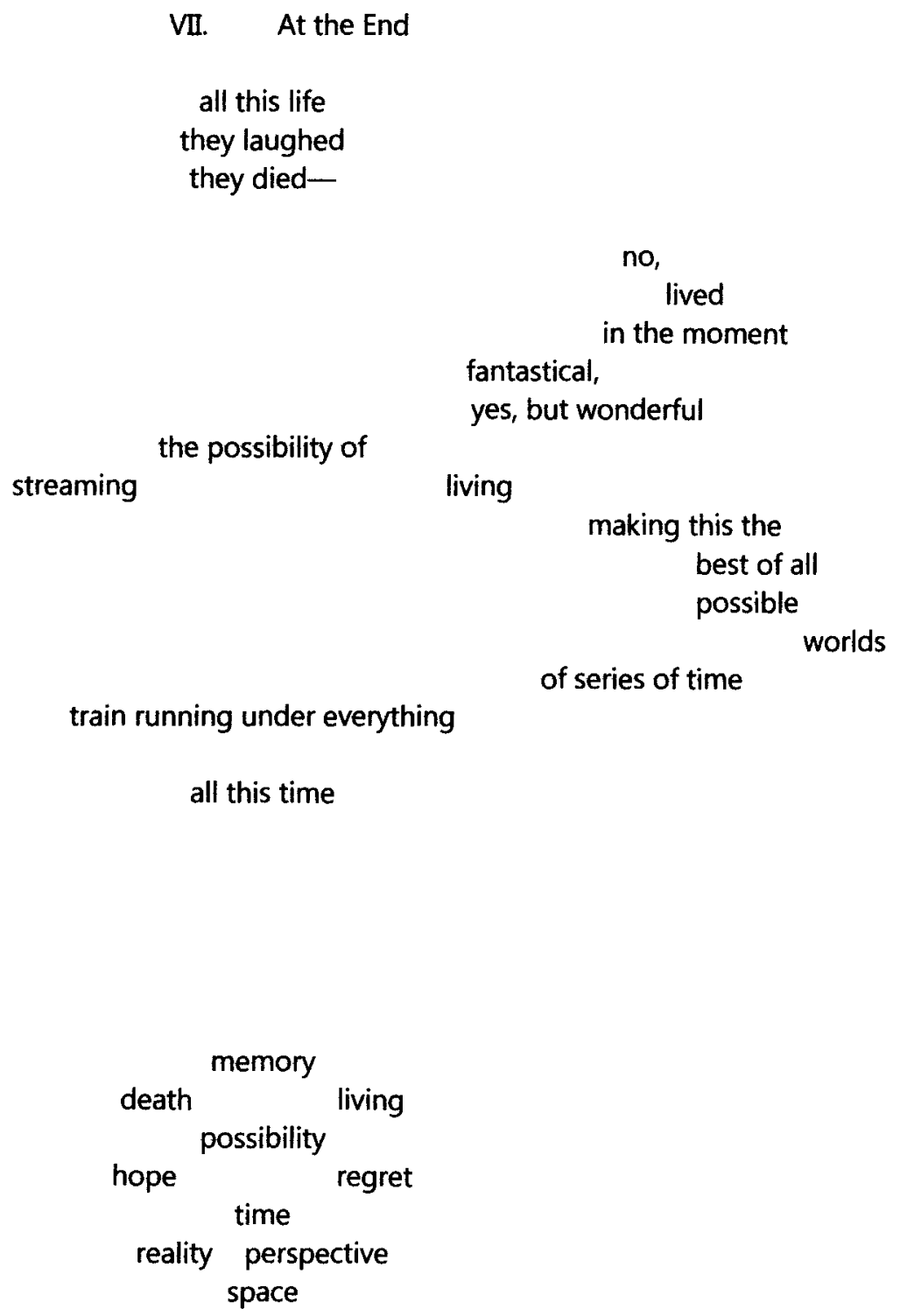


VIII. renaissance

waiting for all the goodness

\& calamity that has

already happened to begin

again

again

again

again waiting for the right crisis

\author{
because \\ outside of the code, \\ even what is right \\ does not \\ cannot
}

exist 
Here, My Dear

for ma \& marvin

Whenever her jam came on, she'd

tell me how she went to school

with marvin gaye

even though he was at least 18 years older $\&$ from $D C$

\& she might've been his type

I believed it, too

until I knew better, yknow?

but she would say stuff like that

like me $\&$ daddy were distant-

twins

both june 12th geminis

electric

\& brooding

Anyway, I know

what she meant:

she might not've gone to school

with marvin,

but marvin definitely went with her

stuck close to her soul-

brother by her side, riding shot-

gun in her mind

he was the swing in her hip-

pocket modified-to-be-fly hand-me-down-jeans

I know she bawled when they said

marvin was dead

april fools

I know she wept \& flailed that

he was gone, then she flipped to

the b-side of her favorite jam

I know because marvin's

here, with me now

$\&$ she is, too

He's in the next room

floating on his belated birthday bump

shuffling to himself

\& she is hovering nearby, like always

peeking out of my chicken-

scratched melancholy

popping her fingers

while I bop \& scribble

$\&$ dedicate this thana-

topical funk to them

both 
31 Years After The Audience with Betty Carter

\author{
I was still gestating \\ between worlds \\ when betty carter \\ was really cooking, now \\ I'm eating at her table \\ belly-swole \\ \& gobbling
}




\section{Undermining Cynicism In The Universe}

To flowering things; to inching, climbing, sprouting things; to bursting, striving, running, flying, crawling, thriving, budding, shining, swimming, diving, loping, leaping

To things rooting, floating, molting, wriggling, breathing;

To heliotropes \& others turning, leaning night-blooms, seedlings;

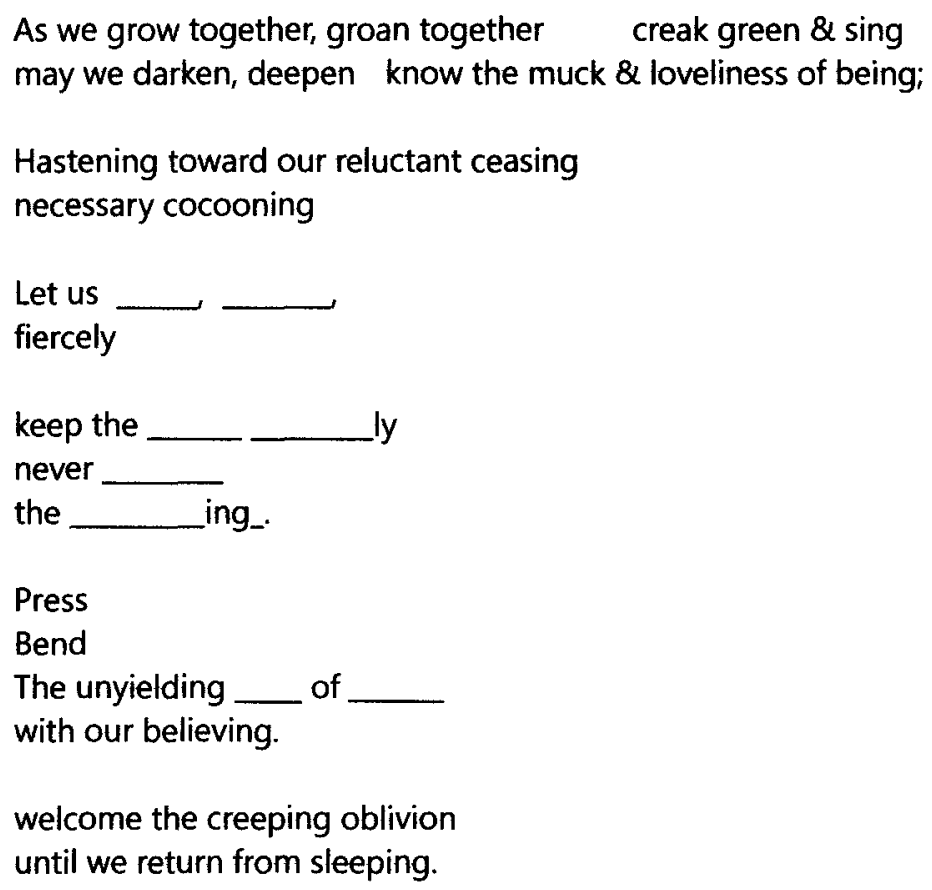


excursion

for Paule Marshall \& her fabulous first lines

there is so much space there

breath before the tale

we settle in, suspend our disbelief

fly 
Flying From Home: Detroit - Baltimore

Apparently, I'm riding Southwest's variety hour flight from Detroit to Baltimore. Within the flight crew there's comedy, singing, directions to the tune of Take Me Out to the Ball Game. Right side, window seat, just in front of the engine.

Below: two silos, lake, dusted earth, highway, ripples, two vessels on the water. Tiny forms. Squared plots of land. Perfect borders, no bleeding

everything outlined, close, but separate--distinct $\&$ yet it all looks the same. $\&$ the vast waters, the island (Mackinac?). A jigsaw piece with no corner, no border. Only itself $\&$ the water. Beautiful squiggles $\&$ jutting angles (do angles do anything else?) $\&$ vast water. The peach hovering, the slight arc of the earth $\&$ the waters above the waters.

$\&$ the unending, unnamable blue.

Pockets of land, fluffy almost peek out of the lake. \& now, even the waters disappear. Nothing but the imprint of the water like elephant skin, \& sloping peach earth.

Stillness--\& light--

\& snow. So much light.

The ripples become delicate creases, ants' tracks. The soft, packed tumble of snow.

Scribbling, thinking: I must find the route. I have to know where we are, if 'where' even matters here-coordinates maybe-where there can be so much snow undisturbed. Then the sudden jolt of life, of avenues, smoke, movement. We are above the clouds, jets in the distance-- 2 ...no, 4 .

\& what was snow is cloud, is vapor, is mass, is nothing. Dense, unpeekable, and always was. Never snow.

The clouds blanket the life below and all that's here -- layers of cloud, of water, of light -- sound.

We are an asteroid in the distance. On some other plane, maybe, someone is watching, scribbling, too. Considering the magnitude of everything $\&$ the magic of flight.

How many are in the air right now? How many others scribble, search for holes, for evidence of ourselves below the everything that continues, ever-arcing, ever moving, ever-stretching. Abiding. 
Flying from Home: Detroit - Baltimore, Descent

shocking appearance of land, Monopoly board

furry --thin trees cover everything that is not water

everywhere, plum-colored trees

\& earth

Shock of red -- hot pink?

line of light above the land

sudden and beautiful

outlining, separating the expanse of

earth, sky

Brown, green, white, sand -- movement

trees everywhere

trees

highways, tennis courts

swimming pools

then: parking lots

campuses

subdivisions--plots of townhouses, planted

amid the honking city.

Fewer trees

circumscribed

ornamental

sparse -- a house on sand in a copse of trees

dozens near-- the first settle,

to disrupt the growing

Churches, concrete, industry

tracks, cracked freeway

grass

tarmac, runway

rush of connection

wheels to lined road

our souls to the earth. 
Flying from Home: Baltimore - Louisville, Ascent, Night

as we rise, lights speckle the surface of night

$\&$ in the gaping darknesses

I know there are trees 


\section{CHAPTER ONE \\ TRANSLATIONS: \\ S/PLACE, EMBODIMENT, AND THAT TERRIFYING CENTER}

The problem of vocabulary [...] is obvious, because a solution to the problem is made of the words...If a bird has a problem with its whistle it has to whistle to fix it.

--Fanny Howe

In the earliest stages of my studies, this dissertation was intended to explore the ways in which our conceptions of our selves shift and change as we contend with the physical and emotional challenges of chronic illness and pain. It is no great secret that protracted and/or sudden, debilitating illness forces us to consider the meaning and functions of our lives. As I sought to describe my own experience of chronic, though undiagnosed, illness, increasingly I began to think of "myself" and "my body" as distinct entities at odds with one another. It was no longer simple to answer casual greetings of "How are you today?" More and more, I needed to determine which "I" I meant. I had to differentiate between how "I" might feel physically and how "I" might feel emotionally. More and more, I felt fragmented and estranged from my own body. My sense of identity was no longer unified-I had become collective. The unitary sense of my identity was displaced by the physical experience of illness. Rita Charon explains in Narrative Medicine: Honoring the Stories of Illness, her study of illness narratives and their role in contemporary medicine: "Illness occasions the telling of two tales of self at once, one told by the 'person' of the self and the other told by the body of the self" (87). Illness created a shift in my subjectivity - to narrate my experience in daily life and in poetry, I had to begin to think of "myselves" and consider the relationship between my "self" and body in increasingly complex ways: 
"The self depends on the body for its presence, its location. Without the body, the self cannot be uttered. Without the body, the self cannot enter relation with others. Without the body, the self is an abstraction" (Charon 87-88). While Charon appears to endorse the existence of a unitary or singular "self" that belongs to any one "body," her insight is the role of illness in narrating one's experience of "being sick" is a helpful one. She seems to suggest, instead, that the body is necessarily multiple as it mitigates and conveys our interactions in the world:

The body defines the self from the inside, but the body does not define the self to the outside. There are two bodies: the one lived in and the one lived through. One body absorbs the world, and one body emits the self. Poised between world and self, the body simultaneously undergoes the world while emanating to that world its self. Or again, the body is simultaneously a receiver with which the self collects all sensate and cognate information about what lies exterior to it and a projector with which the body declares the self who lives in it. The body is in the copulative position between world and self (88-89).

In considering the nature of ourselves in the world, we must acknowledge the ways in which our experiences in the world are dictated by the orientation of our bodies in the world.

Our articulation of experience to others outside of ourselves is inextricably bound to embodiment. But what does it mean to speak the body's language? How do we reconcile our relationship to the problematic inarticulateness of bodies in the pursuit of voice through poetry? Writing about the body, regardless of what experience of the body or ways in which the body is read, still requires use of the same problematic body. So how do we treat the body? How to write about bodily sensations and readings of our bodies while simultaneously living (in) them? When it comes to how to tackle the poems and beginning to clarify what my "thesis" was, how to begin to talk about my thoughts on "selvedness" and explaining the focus on body, memory, selves, and locatedness, I drew from Marlene NourbeSe Philip's concepts of "dis place" and "bodymemory." I also found Audre Lorde's recontextualization of creativity as an ancient, black, feminine force in writing her body to be an excellent framework for understanding my approach to exploring manyselvedness of women through poetry. This chapter looks at poetic and philosophical work by M. NourbeSe Philip and Audre Lorde to 
show how poets make sense of our internal and external worlds through interrogations of location and our subjective experiences. Following the discussion of Lorde and writing the body, I'll briefly demonstrate how manyselvedness manifests in my poem, "Last Night."

Space as Sexed and Raced: Dis Placement $\&$ Genealogies of Fear

In "Women and Everyday Spaces," her essay on time/geography and the invisibility of white/male/heterosexual privilege, Gillian Rose situates her arguments on geography and the limits of space within the framework of prior feminist research: "Many feminists have looked at women's unease in and fear of public spaces, and many argue that 'women's sense of security in public spaces is profoundly shaped by our inability to secure an undisputed right to occupy that space'" (Rose 363). June Jordan explains this lack of security in public spaces as

a universal experience for women, which is that physical mobility is circumscribed by our gender and the enemies of our gender. This is one of the ways they seek to make us know their hatred and respect it. This holds throughout the world for women and literally we are not to move about in the world freely. If we do then we have to understand that we may have to pay for it with our bodies. That is the threat. They don't ask you what you are doing in the street, they rape you and mutilate you bodily to let you remember your place. You have no rightful place in public. (Jordan qtd. in Rose 363)

Feminist theorists have deconstructed the ideas of public and private space as they relate to the roles and oppressions of women and their bodies in global societies. Whereas men-particularly white, heterosexual men-possess a kind of freedom to roam and create their own spaces in public, women are forced to assess the risks of venturing into the public sphere. To transgress the boundaries prepared for and maintained by men, to invade this space is to leave a woman vulnerable to the invasion of her s/place. Given this threat, girls and women are raised to read places in terms of their relative safety and prohibitions regarding their ability to enter particular realms reserved for men. The actions and movements of women are governed by fear. The bodies of women have been severely censured by the threat and implementation of systematic sexual violence. For many women, the threat 
of rape and the violation of sacred space is more threatening than that of murder or other forms of mutilation and brutality. According to NourbeSe Philip:

In patriarchal societies (the only societies we have known), the female body always presents a subversive threat. By far the most efficient management tool of women is the possibility of the uninvited and forceful invasion of the space between the legsrape. Which is a constant. A threat to the space-the inner space between the legs. Even if never carried out, this threat continually and persistently inflects how the female reads the external language of place, or public place- the outer space. One woman raped is sufficient to vocalize and reify the threat of outer space, and the need to protect this inner space means that the female always reads the outer space from a dichotomous position-safe/unsafe, prohibited/unprohibited. (75)

Limitations are placed on women's access to spaces and these limitations are often enforced by the threat of physical/sexual violence and women's vulnerability in public. "At fourteen," Philip explains, "my son takes up space in ways I never could, and he lets me know this-that he is safe on the streets in a way in which I, more than twice his age, can never be" (Philip 102). As a man, even a youth, her son has certain kinds of freedom in public space. While men and boys, particularly those of color, do not have immunity from victimization and danger in the cityscape, the nature of their vulnerability is often different from that of women within the same cityscape: "Boys, men," she explains, "had a lot more freedom-this is bound to affect how we respond to place" (74). For Philip and many women who move in public space, such as the city at night, threats of violent attack, abduction, and rape compel them to assess risk in ways largely unfamiliar to men and boys, like Philip's son. (Black) femaleness and womanhood are themselves transgressive in an androcentric framework. According to NourbeSe Philip, "space and place-the public space-must be read and interpreted from the point of view of the space between the legs and, in particular, from the perspective of how safe the space between the legs is or will be" (76). She collapses the overlap of space and place into s/place-the nucleus of women's boundaries and limitations in the public as well as the private spheres: "S/Place. Where the inner space is defined into passivity by, and harnessed to, the needs and functions of the outer space-the place of oppression" (77).

While many women have a measure of agoraphobia because of sexist constructions of space that use the threat of violence-namely rape-to circumscribe the lives of women, the uses of violence and 
the state of black women's bodies have a particular relationship to slavery and the construction of black womanhood in the New World. Enslavers used violence to break them in, to fragment them, to destabilize them and to make them cease to be subjects, to transform them into 'docile bodies' (Foucault 1977) that became bodies that labour" (Bakare-Yusuf 318). Demoralized, weakened bodies were necessary for the survival of plantation slavery: "The Body. And that most precious of resourcesthe space. Between. The legs. The Black woman comes to the New World with only the body. And the space between. The European buys her not only for her strength, but also to service the Black man sexually - to keep him calm. And to produce new chattels - units of production-for the plantation machine" (NourbeSe Philip 76). Over-determined from without, the black woman is her body only, but does not "own" her body. She is a work-horse selected for her strength; she is a vagina, bought to subdue the black man, to "keep him calm" and to serve as a hindrance to his desire to escape; she is a womb-she houses and produces more cogs for the machine of plantation slavery. Bibi Bakare-Yusuf speaks to this control of black female bodies in her essay, "The Economy of Violence: Black Bodies and the Unspeakable Terror": "[The black woman's] flesh is the signification of her worth within a system whose organizing principle is premised on a proprietary conception of bodies; a system which deemed it its birthright to legislate on her very humanity, control her movements, her body" (317). NourbeSe Philip likens the bodies of enslaved, black women to that of the land that they worked:

Body and place. Fertilized. Cultivated. Harvested. In the same way. Between parent. And child. Mother. And child. Father. And child. Rupture. Umbilical cords to centuries of learning and culture severed. The Body African Place The inner space between the legs linked irrevocably to the outer space of the plantation. (93)

She is sex and re-production. What should be private (belonging to herself) is made not only public, but supports the very economy of oppression. 
Memories in the Flesh: Gender, Bodymemory and Language

With "Dis Place" M. NourbeSe Philip not only locates the origin of women's social displacement in their own bodies, but demonstrates how writing from their bodies and experiences of displacement can also serve as the source of black women's empowerment as well. These issues of embodiment, space, and language are applicable to writing ourselves and how we transmit our bodily narratives: “Bodymemory is passed down and re-interpreted through generational remembrances, textbody—-teachings, forewarnings, and advice—'blanket prohibitions' that move through time ('Dis Place" 97). Philip's work reveals how place, space and location are lived and experienced across time/space, through our bodies which are themselves texts, upon which our histories are written. "It Is Our Loving Will and Pleasure" by Philip shows how fear and caution are also transmitted across generations:

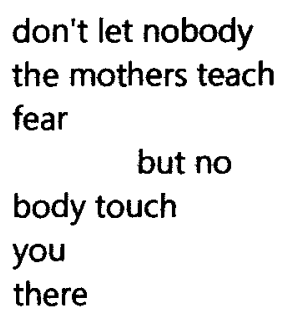

"Don't let nobody touch you there"...The mothers knowing the outer space controlling the inner space which in turn inflecting and affecting the interpretation of the outer space...So the mothers teaching fear. Naming the space Between. The legs-the young girl's legs. The MUSN'T DO. (97)

Mothers pass on "all the lessons of fear. don't let/no!/body touch/don't let/you there!/nobody touch you/ there" (97) to their daughters, marking "there"-the space between the legs, their inner world-a non-space, determined by what musn't be done and what it musn't be. In trying to preserve their daughters from rape and misuse by men, the internal worlds of black women and girls becomes negative space defined by absences and silence, framed by prohibitions and avoidance. What then is the language of this non-space: "Does the inner space exist whole in any language? Other than 'threat' and 'fear'? What is the language of the inner space? Beyond the boundaries of control and fear. Is its language silence? A silence other than the imposed silence? To read the text that lies 'missing' in the 
silence of the inner space, we needing a new language-the language of jamettes, possessing their inner and outer space. The be-coming and coming-to-be of a jamette poet" ("Dis Place" 100). Using the image of the "loose woman" and the jamette, NourbeSe Philip excavates public space and female choice:

Jamette: from diametre, the diameter, dividing the world between the space and place of respectability and that of the underworld, the lower classes. Or, from a Wolof word, jaam, meaning slave. Jamette! A "loose" woman, a woman of loose morals, whose habitat is the street. Jamette! A woman possessing both the space between her legs and the space around her. Knowing her place. On the streets of Port of Spain. ("Dis Place" 77)

These women, these jamettes-stick fighters, "hos," "warrior women"-move freely in the street, transgressing the prescribed boundaries of female movement. As such, they are considered less than women, indecent, and uncoincidentally, in possession of their own bodies: "De space between we legs is we own to do with as we please, and we not frighten of these streets. Dese streets is we own-we have a right to be here and we beating any man who telling we different" ${ }^{\prime \prime}(82)$.

Philip lends me the words to articulate my life and memories, my fears, in light of these absences and silence. Her work has encouraged me to be "a jamette poet," reclaiming my place in the street, reclaiming my voice, and reclaiming the silenced voices of so many women. Philip's concepts of dis place and bodymemory have given me a mode of conceptualizing my own interpretive processes as I move through space. Indeed, I am often acutely aware of my femaleness as I interact with the world around me, and how my interactions with the world are filtered through my poems. Being a girl, being a black girl, fear and danger are not cursory concerns that turn up in the poems of That Terrifying Center, these elements are rooted in my body; mybody is rooted, is read within the context of these experiences. Therefore my filters, creative and critical, are themselves shaped by the ways in which my body has moved in various spaces as over/determined by external contexts. As poet, I read the world outside myself, the "outer space" in a gendered (and I would add raced, classed, educated, urban...) language; as an agent, I create language, disrupt spaces, choose silence, reclaim narratives of 
resistance. As a woman who is also a poet, the pieces I write and the landscapes I navigate are all filtered through this same interpretive/interpreting textual body.

In writing my experiences, I explore the tension between the active, writing self/body and the potentially apprehended, invaded body. This is what Philip does as she puts herself in the narrative of black women's experiences: "By weaving herself into the text, Philip, the 'subject-in-process', recasts the narrative and mobilizes a black woman's distinct subject position. Philip uses herself and her (dis)placement to access and disclose the unsilences and missing texts that are at the heart of black diaspora studies" (McKittrick 232). This is what Philip does when she explains the locatedness of her body and presents the nature of black women's relationships to language, geography, and their own bodies. She uses her work as a black woman artist to simultaneously reflect and change the cultural contexts of everyday life.

\section{Refashioning the Creativity Within: Audre Lorde's Poetry}

For M. NourbeSe Philip and Audre Lorde, writing is strategy: to move out of fear, to own the space between her legs and the space around herself, to recover the silences and the missing. In "Poetry is Not a Luxury," Audre Lorde reorients the interior, lived experience-feeling-in relation to thought and rationality. According to Lorde, "[Poetry] is a vital necessity of our existence" (Lorde 37). Feelings precede thought. Poems precede/facilitate ideas. In order to understand fully how I truly "feel" about my illness, my body, I have to write it down, to arrange the thoughts. Poetry is vital to understanding ourselves and the world around us. It is a kind of consolidation of experience, sensuality, and understanding: "We can train ourselves to respect our feelings and to transpose them into a language so they can be shared. And where that language does not yet exist, it is our poetry which helps to fashion it. Poetry is not only dream and vision; it is the skeleton architecture of our lives" (38). At its most potent, poetry, then, also forms the "skeleton architecture" of this project. Through the poems come theoretical concerns, clarity, and many times, more questions. Lorde continues: "The white fathers told us: I think, therefore I am. The Black mother within each of us-the poet-whispers 
in our dreams: I feel, therefore I can be free. Poetry coins the language to express and charter this revolutionary demand, the implementation of that freedom" (PNL 38). This passage not only challenges the Cartesian body/mind duality, but offers an alternative paradigm for effecting cultural change. When one ceases to feel, not even thought matters. "As a poet, [Lorde] heals the unnecessary divisions between emotion and theory. Positions which white western patriarchal thought would have us believe are inherently contradictory; thus denying the emotion which informs theory presented as knowledge" (Sparks130). What we feel is the impetus for what we think; what we think is the impetus for what we do, what we write, and what we become. These feelings--perceptions that are rooted in our bodies-can move us to act, to make, to do. Poetry as the synthesis of thought and feeling, as the mechanism for the creation of new language, gives us power to speak our experiences, to shape our silences, to reclaim our voices, to define ourselves in our own terms, to remythologize our possibilities, to write ourselves free.

Poetry is the vehicle for dismantling fear and countering displacement. Audre Lorde's work gives me permission to feel. She does this by relocating the locus of creativity for women so that they may give themselves the authority to create that Estella Lauter states so beautifully:

Lorde's figure of the Black mother poet, then, symbolizes the belief in one's own authority to create, and her association of it with the erotic, with Eros in female fform, is a potentially useful strategy for rethinking women's relationship with love...If a woman believes that the source of creativity lies within her, perhaps she can more readily marshal her resources to combat the external conditions of her life. (416)

By resituating and redefining women's relationships to creativity, community, and possibility, we have the potential to write ourselves free, beautiful, and "perhaps women can not only survive as artists but also re-envision survival itself as a matter of reclaiming what has been repressed and nourishing the capacity to change" (Lauter 416). Audre Lorde is a major influence in my writing, particularly writing about mybody and negating voicelessness. In her work, "the body speaks its own history; she chooses corporeal language to articulate what she could not previously put into words" (Alexander 174). Though (colored) women have been "defined into passivity" (Philip 77) by history and language, Lorde's 
remythologizing of creativity and the authority of women to speak on their own behalves, to access the reservoirs of our own embodied memory, creates new models for creativity, and in particular, creating new possibilities for women as artists: "Creativity need not be the result of woundedness and sacrifice; it can also be the result of natural processes coming to fruition. The passion of the Christ, which denies the body in favor of transcendence, is not the only viable model of creative transformation...Lorde's revaluation of erotic energy in the name of the Black mother has much to offer women despite all our [cultural or racial] differences" (Lauter 412, 414).

Our bodies anchor us in space, time, and context. This corporeal materiality of our being gives us multiple subject positions. Awareness of our bodies, and writing from our symbolic connections have the potential to bridge across difference through our narratives of experience to counter our displacement. In works like The Cancer Journals and A Burst of Light, Lorde overcomes her fear of death, mortality, cancer, and silence by sharing her experiences. She "speaks from her body, about her body, so that her pain will be of use to other women" (Morris 174). Intimate treatment of embodiment, not "black women's, lesbians', mothers' experiences, but her own agency, her own identities, her own skin and breasts, and fears, and cancer. These things move through her body—absorbed/internalized, processed, and then emerging from these internal processes, we learn how Lorde experiences racism, fear, anger. Writing voice and experience can counter the negative, dangerous forces that can endanger and oppress women and girls. In a bid towards wholeness, Audre Lorde uses the poet within, her subjective voice as Black lesbian, feminist, mother, activist, cancer survivor and more, to positively illuminate her knowing (Sparks 130). She revises the ways in which women see themselves as multiple, complex, but contradictory-simultaneously fragmented, yet whole. In the same way, she revises the way that women see themselves in relationship to creativity:

The creative impetus is in all of us in our capacity for feeling. Lorde speaks of creative process as a matter of tapping or honoring the "deep place" from which perception comes; rationality, she says, serves feeling and knowledge by building roads from one place to another, but "Perceptions precede analysis just as visions precede action or accomplishments" (SO 100, 105). The figure of the Black mother within allows us to stop questioning our perceptions before they have a chance to become poems. (Lauter 415) 
Lorde's strategies in her own work (and her own life) of reclaiming the erotic and anger for survival, and harnessing our untapped reservoirs of power work toward creating sustained and meaningful cultural change through women.

\section{Poetry and the Village: SHE WHO IS WE}

Over the past few days, I've been going through my old poems, sifting for good examples of in-process drafts and visual elements in my work-to include in the appendix. I've run across about five pieces that I've pulled out to rework for later, ones that I'd forgotten—or abandoned—but which spoke to my current project and train of thought as if I'd only recently written them. I'm not the first doctoral candidate to pick up an article or book, ostensibly for the first time, only to find my scribblings in the margins ${ }^{1}$. In my episodic rummaging, I've read papers or journal entries that I have no recollection of writing. Brilliant stuff! Sometimes it's easy to miss what is right in our hands: while struggling with ways to word my arguments of embodied identity, poetry, and memory, I encountered "Last Night," a poem that I wrote in 2006 or so, loved for a while, but eventually stuffed back in the "revision" pile, never to be seen again. Its resurfacing now is rather fortuitous since it is perhaps the most explicit (yet natural) example of what I mean by manyselvedness that I have written thus far. Now that I've found "Last Night," I'm certain that I'll be doing surgery on it very soon. Despite the fact that it's not "finished," I'd like to include it here and talk a bit about the concept of "SHE WHO IS WE" that appears in the poem. I'll be moving between the slightly revised draft of "Last Night" ("LNR") provided below and the handwritten original draft of the poem (Illustrations 3 and 4 in the appendix).

Though I neglected this poem for a while, I still remember the dream it recounts. I've only had a handful of "dream poems" come to me. I can think of three at the moment. All of the poems have the same odd, untenable, slightly creepy feeling to them. With the dream that precipitated "Last Night," I

\footnotetext{
${ }^{1}$ I experienced this scholarly amnesia very strongly while preparing for my comprehensive exams. The sensation was so troubling, I was moved to write a poem. Though "Revelations on a Reading List" is arguably crass, I believe it sums things up perfectly. It simply says: "I have read/ a lot of/ shit/ \& don't remember/ half/ of it." I'm sure that I am not the only one to experience this particular forgetfulness.
} 
swam up out of sleep with the phrase about "remember[ing] what it felt like to carry my mama when she wasn't my mama anymore" in my mouth. I kept repeating it to myself as I scrambled to find my notebook and write it down. And all the while, there was this palpable feeling that I had come from somewhere. Or that I had been in another's presence and now we were mutually parting, returning to our respective homes. "Last Night" opens with the speaker's account of the previous night: "I was visited by a village / the kind it takes to raise a woman" (LNR 1-2). In the original draft, the speaker makes a distinction in the second line, before moving on: "Not the kind they say it takes to raise / a child" (LNO 2-3). Though the revision omits this line to avoid cliché, it is nonetheless an important distinction that introduces the tone for the rest of the poem: something significant is happening here. She does not say that she'd visited a village, rather that village had come to her-with all of its fullness and peculiarity, the encounter leaves her electrified and exhausted, renewed and distraught:

Tears arms crazy cackles
ring-dancing singing playing
leaves me surging
yet weak this morning
enlivened aggrieved
by my finite encounter with
She Who Is We

(LNR 3-9)

Though there is the unmistakable echo of the exuberance of little girls in the "ring-dancing singing playing" (LNR 4), what she relays is pertinent to adulthood and maturation: the "tears" and "arms" suggest pain (or perhaps uncontrollable laughter) and the intimate, emotional sanctuary of a sister circle where women may voice hurts, and receive the affirmation of community in tears, hugs, and the laying on of hands. These are the "crazy cackles" of mature women versus the carefree giggles of girls. The diction suggests the tribal and the esoteric, that the speaker has participated in a kind of ritual or rite of passage- even an initiation - that signifies the transition from childhood into womanhood-that is precipitated by the collective gathering of power. On the surface, the suggestion here is that the speaker has been asleep and is recovering from a particularly vivid dream. Through the dream, she is strengthened by a powerful-if a bit hazy—-memory of her mother and writes a poem. This would be a 
perfectly acceptable reading of the poem, were it not for the reference to her "finite encounter with SHE WHO IS WE" (8-9). SHE WHO IS WE elevates the poem to for alternative readings. Rather than assuming the speaker of the poem is asleep, the allusions to the "finite" as opposed to the infinite, the glow of her face as in biblical accounts of Moses leaving the presence of God, and a "visitation" suggest the ecstatic and the supernatural. Like a medium or oracle, the speaker experiences and encounter with the divine, then returns to consciousness to transcribe it:

My face gradually loses its glow as I awaken with grasping

\& breath \& you siphoning the pot liquor vestiges of the visitation through my pen

(LNR 10-16)

The product of the visitation is not only the strength she gains from the experience, but the account of it that she shares.

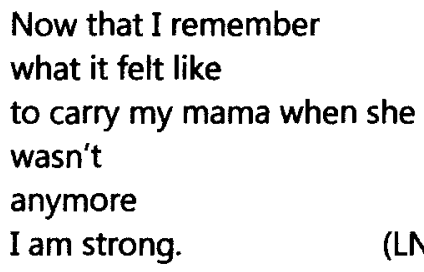

(LNR 17-22)

We should note that it is not the bearing of her mother that makes her strong, it is the memory, or the re-membering that strengthens her. In "Last Night," we see how the coming together of a collective, a village, a body, a creative (re)generative force that is around her and within her, results in her strengthening, but also creates a record. The poem is a testament to "you" (LNR 13) and to herself that she can bear the weight of life by communing with the feminine, generative village, power-SHE WHO IS WE.

My recent (re)reading of Lorde and Jordan (and discussions of their work by Lauter and Sparks), and a life-changing performance as Lady in Brown in Ntozake Shange's For Colored Girls Who Have Considered Suicide When the Rainbow Is Enuf at The Kentucky Center in October 2011, have revealed elements of my work to me that I had no idea were there. As I'm sure is the case with most 
dissertations (and dissertators) everything seemed to be pointing toward and informing my work. Only very recently, did I realize that "Last Night" echoes and invokes the work of Lorde, Jordan, and others. In a dream, my connection to the many-tongued, polyvocular well of creative potential, the writings of (colored) women artist-theorists who have come before, and my own generative embodiment of language gathered ground, and the charge to share the "visitation" all coalesced in this poem. Only in this moment, in this convergence of will, scholarship, experience, and time (chronos and kairos) is it wholly apparent to me that my work helps to affirm and further the theoretical and intuitional figure of the Black mother, the erotic generative force remythologized in the work of Audre Lorde. Drawing on the black mother on the African god/dess Aido Hwedo, the song of Shange, the forked poet's tongue of Anzaldua, the sounding of dis place/inner space, shaped by silence, and the terrible poem within us all, my aim, my passion is to further a genealogy of possibility shaped by memory and called into being through voice and song. 


\section{CHAPTER TWO}

\section{RIFFING: HAND-ME-DOWN HYBRIDITY, SENSUALTY, AND POETIC STRATEGY}

Harryette Mullen's work and her discussion of her poetry gave me immense assistance when it came to talking about my own poems, how to discuss my aims and objectives without spoiling any of the magic that makes poetry "poetry." Like Mullen, I love language; I, too, slept with the dictionary. Also like Mullen, I'm using language to look at lineages and bodies of cultural knowledge: "continually recasting, exploring composition as cultural 'composite,' Mullen critiques existing poetic and sociological divisions. The recyclopedia of Mullen's poetics assumes knowledge always to be hand-medown... Her innovative, highly dialogic texts recycle lineages of a 'mongrel' American culture" (Frost 406). As I consider the work that Mullen does in recombining and deconstructing conventional understandings of English's lexicon, and composting the various American histories she has access to, I also hear echoes of 'bodymemory' and the conception of genealogies as in M. NourbeSe Philip's work in reconceptualizing black women's bodies discussed in the previous chapter. I consider my work to be akin to that of Mullen and Philip in that I seek to subvert expectations of what poems by black women are "supposed" to sound like, look like, and do. And I want to do this by tinkering with what I have inherited: dialects of English and vernacular speech, cultural and family histories, popular culture, university and graduate study, and imagination. I am working toward a kind of hybridity or prismatic poetics (of parallels and intersection, of reflection) —of language and sounds, but also of space and embodied experimentation that uses poetry as an epistemological tool. 
My poems interrogate language and somatic realities, not just what the body says - or how it is read by outsiders- but how it interprets, interacts with space, location, geography. I see the body as a repository of memory and possibility. Consciously, I want to cultivate a poetics of hybridity, of experimentation with language and form, while keeping a narrative voice (or voices) telling the story, using absences, space, shifts in time, memory to translate and even reproduce the sensations of being human. Or perhaps as a kind of speculative poetics that explores human sensation and manifests it for our own minds as much as to others, for those in our time, and the time to come. My objective is a particular kind of resonance. I want folks to be moved-to empathy, understanding, action, resolution, recognition-to consider something unsaid, to make present [things] visible, provide a lens, a pattern of making sense of shared space and history.

This dissertation, and my sense of my own poetics with it, is something in process, selves in conversation - theorist self, poet self, black girl self, young woman self, sick self, righteous self, depressed self, angry self, singing self, motherless self. As such, I find that my sense of my poetics is shifting toward more explicit experimentation with style and language (this is most evident in the "Sunterblooms Ik Tew" section of the manuscript). I'm intrigued by fragmenting the narrative, or finding new ways to keep narrative, but also fragment and stretch. Just as my poems are examining and trying to find the language to undermine the body/mind dualism, my poems also subvert the false dichotomy of lyric and experimentation in considering poetry by cwa's. I am realizing that the issues that I present and explore in That Terrifying Center are connected to ongoing questions of selvedness and subjectivity. I am realizing that I am yet changing, that these "competing" poetic impulses are there and will be, and I don't have to choose, that being a poet, a voice, is a condition of my identity, and as such I get to explore.

I like to combine experimental and conventional lyric elements in my poems. While many of the poems are autobiographical, with an explicit " 1 " and singular voice, and sense of linear time, many other poems experiment with subjectivity, time, and space. They have strong a visual element to the 
form. Consequently, poems have a similar look, shape, structure. Also, pieces are of variable lengths, from the very, very short to the longer, including segmented or serial poems and lyric essays. In some cases, the thematic content dictates the form of the piece, i.e. whether it will be more linear or more spread across the page to take advantage of space. Within "That Terrifying Center," poems contain meditations on metaphysics, elements of wordplay, deconstruction of language with what I call my narrative/"talky" poems versus my brainy, thinky poems. I like to work an idea through, looking at an issue from multiple perspectives (examples of this include "On Being Contrary," "As She Passes," and "Jouissance"). Language and diction are very important in the conception of my poetry-language of terror and violence, graphic descriptions of the horrific juxtaposed with tenderness and sweetness ("On Imperial Ave"). More and more, I am experimenting with the limits of language and voice as I tinker with arrangement and synthesis by mixing form and style within segmented/serial pieces. I have a strong orientation toward juxtaposition and paradox, and work to create tension and uncertainty by using ambiguous language and peculiar syntax. Apo koinou and other forms of zeugma like syllepsis are techniques that describe something that I'd been doing in my poems-attracted to because of its peculiarity — but did not have a name for. It's also a technique employed by Audre Lorde (masterfully!) to subordinate conventional grammar and expectations of time and linearity:

Apo koinou in Lorde's poetry is a way of subordinating the sentence structure to the association of ideas as they are explored further and more deeply through the sequence of the poem. Because, as we have seen in the cases of Modern poets, apo koinou suspends the temporality or causality normally implied in discrete sentences and their orderly sequence, it allows Lorde's voice to reveal feelings that are "chaotic, sometimes painful, sometimes contradictory," without undoing those very features by subordinating the feelings to the ordinary rules of syntax. (Morris 175)

I am drawn to this disruptive, resistant relationship to the rules of language, favoring contradictory, "both/and" constructions that undermine the presumption of a singular reality by introducing ambiguity, uncertainty, and simultaneous/competing experience.

As I continue to write and experiment, I am continuing to appreciate what a poem is and can mean and what the function of a particular piece may be. Not every poem that needs to be written 
needs to be shared. I'm learning to tell the difference. Sometimes, poems come because we need to make them. The knowledge or process or code that is transmitted in the poem may be for ourselves. The poem as an instrument of knowing isn't always didactic, or meant to inform for external audience. Sometimes, the poem is for the audience of ourselves. I believe that is what Cisneros means when she says that "that terrifying center is a poem." A poem is a place. A poem is a sensation. A poem is a tool. A poem is a place. Thinking about what Emily Dickinson says about how to identify a poem: "If I read a book and it makes my whole body so cold no fire can warm me I know that is poetry. If I feel physically as if the top of my head were taken off, I know that is poetry. These are the only way I know it. Is there any other way?" (L342a, 1870). What I love most about this quote, other than how descriptive it is, I love that she gives two examples-the feeling of an unwarmable cold and the feeling of being headless-but considers them only one way. She knows a poem by feel. She knows a poem by reading. She knows a poem through her body. As I move the words around the page, channel memory, and sweat the language, I do so always with the conviction that a poem is meant to be felt.

\section{Voice and Narrative}

Voice and the representation of voices are central to my work. My poems feature multiple voices, narratives, and commentary about the action within a poem. Voice takes the form of testimony, political voice, physical voice (speech, song), nonverbal utterances, hearsay, and silence. My work is in conversation with my world and includes references to other poets and poems, current events, family narrative, song lyrics, quotations, to historical and cultural figures, critical and theoretical texts. Beginning with "Night Whispers/Hush" in 2004, and the inclusion of my mother's voice in my creative nonfiction after she died, I've been trying to capture and render utterances in my work. My poems are, to borrow again from M. NourbeSe Philip, "polyvocular" pieces. They feature multiple voices that I try to differentiate using italics and spacing on the page. Within the poems, different kinds of polyvocality and narrative are emerging. I have tentatively begun to identify these iterations of various voices, scripts, or streams of thought/speech as three kinds of narrative: embedded, alternating, and 
simultaneous. At the moment, embedded narrative happens in the poems when another voice enters and takes over storytelling or when the speaker steps into another time/space-whether the facilitated by memory, song, or other catalyst. "Strange Fruit," "On the Balcony" "Entering the Therapy Spa, I Remember Dorothy Dandridge" are examples of embedded narrative. Alternating narrative occurs when another narrator speaks in concert with the primary speaker, or another voice interrupts and takes over the primary stream. "Pin Up," "Rose," and "Selfish" are examples of this. The final example that I have identified is what I am calling simultaneous narrative. As in "Hush," and "After the Dance" (the first section of "October $2009^{\prime \prime}$ ), simultaneous narrative describes the presence of multiple voice speaking at once-they may alternate, overlap, represent conversation or multiple streams of thought as they occur within a single mind (or train of thought). The constituent "voices" may be characters, song lyrics, allusions to pop culture or theory as they pop up in the midst of thinking. And because many of my poems are dedications and invocations, or written on the occasion of something, or as something is happen--after reading, watching, listening to some something-the poems are responses to some occurrence or stimulus. For example "After Source Code" should more accurately be called "During Source Code." Once I began to identify "the familiar/ skiff of thought/ preparing to be caught," ("Ars Poetica" 77), I begin rummaging in my purse for my notebook and pen. While watching the movie in the darkened theatre (and while watching the Ailey Dancers at The Kentucky Center), I am writing the poem in the dark. As the scenes play on the screen or stage, the poem forms, and I scribble-oftentimes in the dark-transcribing my thoughts as they come. These nonlinear, serial, polyvocular pieces are connected always (at least for me) to their sources of inspiration. These are my most ambitious pieces, wherein I try to approximate and graphically render nonlinearity of thought as it splinters. I want to plot and translate the experience of "thinking" or "speaking" to the graphical/visual terrain of the page. Sensation, streams of thoughts, and multivoicedness--the braiding together of voices, either competing or complementary narratives-are sources of fascination and inspiration for me as I try to consider the composition of my poetry. I appreciate that these spatial choices may make the poems "unreadable - in the sense of one person getting up before an audience 
and reading" (Philip "The Habit Of" 211). When I hear and see "Hush" in my mind, it is staged-a communal text-read/performed by multiple voices, interpreting the lines together. In that moment, "the work immediately becomes a mini-drama. Constantly changing depending on who is reading it. Along with me. The polyvocular. The multiplicity of voices" (Philip "The Habit Of" 211-212). Being as process-oriented as I am in creative pursuits, it is heartening to think that the poems that I write may live far beyond me, that other voices will find new inflection, new space to breathe into the various voices, that they will put new words in the "___, that as culture changes and the lexicon with it, even more possibilities for what my poems can mean will multiply as well. By opening up these verses to voices other than a single, unitary "I," what I am attempting to convey can be breathed into by audiences that I have yet to even imagine. That is a humbling and awe-inspiring thought indeed.

\section{Writing Language in "That Terrifying Center"}

When it comes to presenting my experience of language as a word-lover and as a poet, I have to point to my primary influences: Harryette Mullen, Gloria Anzaldua, and M. NourbeSe Philip. In their work, I saw the possibilities of language - ways to invoke both the sensuality of language and speech, and the oppositional, even violent ruptures that it also contains. Their work makes clear the complex relationships between language, history, gender, sexuality, oppression, and colonization. The love of language is presented in terms of closeness, of intimacy, and location within the body (the tongue), framed in terms of "sleeping with the dictionary." Consider the following excerpt, "Mother's Recipes on How to Make a Language Yours or How Not to Get Raped" from M. NourbeSe Philip's longer poem, "Universal Grammar":

Slip mouth over the syllable; moisten with tongue the word.

Suck Slide Play Caress Blow-Love it, but if the word
gags, does not nourish, bite it off-at its source -
Spit it out
Start again

Philip's piece presents language, our intercourse with words in sexually-charged and sensual terms. We love language in a physical way, however, if the word in our mouths "gags" us-I'm thinking here of 
enforcing our silence, rather than merely making one to retch—if it does not "nourish," Philip directs us to bite it off and spit it out. In response to what Anzaldua calls "linguistic terrorism" in "How To Tame A Wild Tongue," we need to respond decisively and directly, "at its source." For Philip, Mullen, Anzaldua,. Lorde, and many others, just as language originates in the body and in circumscribing and describing it, the language of history and conquest is contained within and inscribes itself on the body as well: "The Body African henceforth inscribed with the text of events of the New World. Body becoming text. In turn the Body African-dis place-place and s/place of exploitation inscribes itself permanently on the European text. Not on the margins. But within the very body of the text where the silence exists" (Philip "Dis Place" 95). Because language is symbolic of culture, as part and index, we must resist, recast, and reimagine our relationship to the language that has been used to silence and oppress us. While trying to make sense of my relationship with language-grammar, syntax, roots, history, connotations-and cutting through the layers of meaning as I compose my poems, I could not shake the image of Philip and Mullen in my mind. The poets that influenced me as a reader began to take shape and chided me as a poet when I wrote more "conventional" poems. Sometimes after reading their work, I felt the pull to rebel. And so, Marlene NourbeSe Philip and Harryette Mullen found their way into the actual lines of my poem, "Morphology." Arguably, the metaphor of inspection in "Morphology" should be their mouths, instead of the hands, to further the analogies of the sensuousperhaps, we're at a buffet table instead of chopping and shucking-maybe I'll consider the racier/tastier side of things in another poem. In any case (pardon the pun), the materiality and tactility of language is significant: words are to be handled and examined carefully before being combined into poems.

In "Morphology," the speaker describes the process of tinkering with words and word parts, but in "Enjambment," I actually work to not only break down words to their smallest phonic or graphical units, but I also want to disrupt the meanings of the words by intentionally avoiding chopping them up syllabically. I am still developing the means for examining words and their associations through poetry- "Guts" is one example of what I am calling word studies. I have 
considered using mind mapping programs to plot visually the sequence and splintering of thoughts as I conceive of the associations between words. My mind tends to go faster than my hands can, but when I am researching or composing, I not only have several tabs open on my computer, but I keep a pen in my hand and write all over whatever is in front of me. I also keep lists of words that I like and want to use or meanings that I would like to map².

"Sunterblooms Ik Tew," "Undermining Cynicism in the Universe," and "Provision" are three poems wherein I experiment with ways of understanding and presenting "wordlessness" in verse. ${ }^{3}$ This "wordlessness" project began out of frustration during my first Cave Canem retreat in the summer of 2010. Each day, for workshop, we are to present a new poem that we have composed overnight. On the first or second night, I sat up waiting for my night's poem to arrive. I knew I couldn't force it, but my usual tricks to "induce" a poem didn't work, and so I went to sleep and hoped that I would wake up with something. And, miraculously, I did. In the middle of the night about 3 am, I woke up with "Ars Poetica"-then titled, "Theme for CC"—and the words from the colored boy on the hill in Langston Hughes's "Theme for English B." "Distinct" and a few other pieces found their beginnings during that Cave Canem retreat. After finishing "Theme," I went to sleep again. At 9am, I awakened with the beginning of "Undermining Cynicism": "To flowering things..." And I just kept adding "ing" things until they stopped coming (see Illustration 5 in Appendix for original notes). After that, every morning, I woke up with more "ing" things to include on the poem, but no ending. In that night of initial waiting, I mused in my journal: "what if all of us needing to write tonight have used up all of the words?" What if there were no more words left, what would we use?

\section{Paradox, Repetition and Time in That Terrifying Center}

My world is full of questions and juxtapositions. My work is an ongoing experiment, an exploration of play, tinkering with the language of experience, finding ways to connect and

\footnotetext{
${ }^{2}$ I have already mentally titled a forthcoming work that consists of word maps and studies. See Illustrations in the appendix for examples from "Botany: A Study of Roots and Stems" (Illustration 5) as well as the "Morphology" word study (Illustration 6).

${ }^{3}$ Illustrations 7-10 present the genesis of the project from my notes.
} 
communicate. My creative and critical impulses are complementary and tightly woven. I love words, sound, texture, melody, oddity, and I experiment with these elements for my own pleasure \& release, but also as a mechanism for connecting to others seen and unseen. My objective-compulsion, really—is to receive and process input, I'm driven to communicate, to question, examine, deconstruct, and then translate, to interpret, articulate; to transform and reveal the magic, the insanity, the possibility in our lives. Tom Sleigh describes a similar impulse in his essay "Self As Self-Impersonation in American Poetry": "I am not so much interested in how we read, as in the experience of understanding what happens when we read. And since I'm a writer, I take the further step of trying to account for what happens to us when we write...What I am doing is hoping to find some inklings and intuitions that will suggest a more comprehensive model of subjectivity for the working artist" (127-28). Like Sleigh, I want poetry to be "complex," "resistant to generalization," and "humanly capacious" (128). Like the "multiply-overlapping I" of Proust's Remembrance of Things Past, Sleigh's view of poetry sums up much of what I am attempting to do in my own work: "This many-eyed way of seeing many-leveled reality suggests, for poetry, the obvious analog of many different kinds of speech sorting together, with no self-consciousness about juxtaposing wildly differing lexicons and forms of diction" (128). I love to contrast modes of speaking, such as the high-sounding abstraction of titles like "Epistemology" and "Morphology" with the concrete and practical, or the demotic and "standard" iterations of English. I am very comfortable with paradox. Consequently, contradiction, juxtaposition, and irony often sit side by side in my poetry. I embrace "contrariness." The subjective realities that I attempt to approximate in my work are designed to create uncertainty, ambiguity, and a prevailing sense of competing possibility that I experience in the world around (and within) myselves.

Though I am not a painter or visual artist, I've been told that I am "painterly" in the way that I envision and arrange poems on the page $\mathrm{e}^{4}$ I am continually working to refine and clarify this movement

\footnotetext{
${ }^{4}$ See Appendix for handwritten, rough drafts of two poems, "Laws of Movement" and an untitled piece (Illustrations 1214). These drafts illustrate how this "painteriness" is present in my conception of a poem even before I transfer pieces to the computer.
} 
from my mind to the blank canvas. Whether I am scribbling across the pages of my notebook in a darkened theater or transferring the poems to the blank space of the digital page, I'm also conscious of the treatment of space and line. Some of what I'd like to do visually is limited by the tools I have at my disposal-I have yet to find the word processing program that will allow me to create a line/stanza at any point on a page. I may have to take up "drawing" my poems by hand. Poets like Susan Howe and M. NourbeSe Philip, whose works can be very visually and graphically driven are particularly intriguing to me. I want to know what tools they use in rendering their poems. Working with shapes of the line, cursors and counting spaces and tabs, I try to shape and craft the line, manually hitting the space bar to create arcs or images-as in "Melancholia" or "After Source Code." I think of spatial relationships in terms of white space and punctuation. I frequently use space/tabs to indicate time, proximity, to demonstrate visually or symbolically what is being described in the poem. Stanzas may represent the beginning of an idea by capitalizing the first word (or not). Italics, spacing, justification, line breaks, punctuation, case/capitalization are representative of the limited tools I have (at the moment) for presenting the polyvocular, multidimensional poetries that I experience in my mind in a visual, printed form that can be shared and articulated to my audience.

Related to that, I like the idea of doing studies as in visual art, or etudes or variations in music, repeated iterations and perspectives to capture the subject —even the shifting, wily subject-and that all of these exercises to hone technical skill will be right in their way. Poems like "Jouissance" and "Metaphysics" are blatant attempts to reconsider and revisit a theme, memory, or subject, as are the series poems, "Terminal," "Oversight," and "Without Words." And that subject-the traumatic event, perspectives of mybody, my relationship to our world-will continue to shift, settle, and even erupt. Consider what happens in the poems and the bodies within these poems: as time flows, my body changes, my perception of myself changes. In the same way, I am changed by the continued study and experimentation; I am changed by the poems themselves. I'm thinking of what Cynthia Hogue says as she interviews Harryette Mullen about theorizing identity and what it becomes on paper: "We theorize identity as fluid....A word is never fixed; it's always bleeding into a new identity by the process of 
association, but in practice, once we fix that theory of identity as fluid, then it solidifies into something more inflexible" (n pag. Paragraph 26). And Mullen concurs: "it's a paradox." (26). I believe that this paradox is a challenge. The paradox of seeking, finding, and rendering in the context of change is the wonder of poetry, of life, of everything. And my poems attempt to get closer to that wonder by experimenting with repetition, time, and the connections between ideas. Anaphora and other figures of repetition are staple techniques that I use for building momentum and establishing a rhythm for the reading and experience of my poems. The ampersand $(\&)$ is the single-most frequently used word/symbol or conjunction of these pieces. While trying to ascertain the contents of these poemsand I mean contents literally-I used online applications to generate word clouds or tag clouds to show me the words that occurred the most in my manuscript ${ }^{5}$. With these clouds, the larger the word appears in relation to those around it, the more frequent its appearance in the text. I copied the text

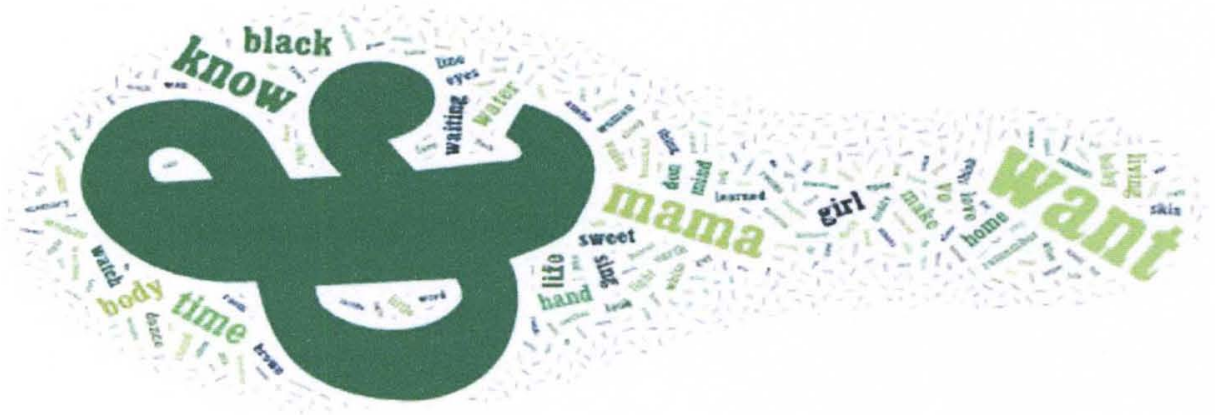

tagxedo.com

Illustration 1 : Six hundred most common words

with ampersand. From That Terrifying Center's poems and pasted it into the generators. Illustration 1 shows the six hundred words that appear most frequently in the poetry collection, including the typically excluded symbols like the ampersand (\&), in comparison to other frequently used words, such as "want," "mama," "know," "black," and "time." The ampersand is consistently one of the most used "common" words.

\footnotetext{
${ }^{5}$ See the Appendix for more of the word clouds that I generated (Illustrations 15-22).
} 


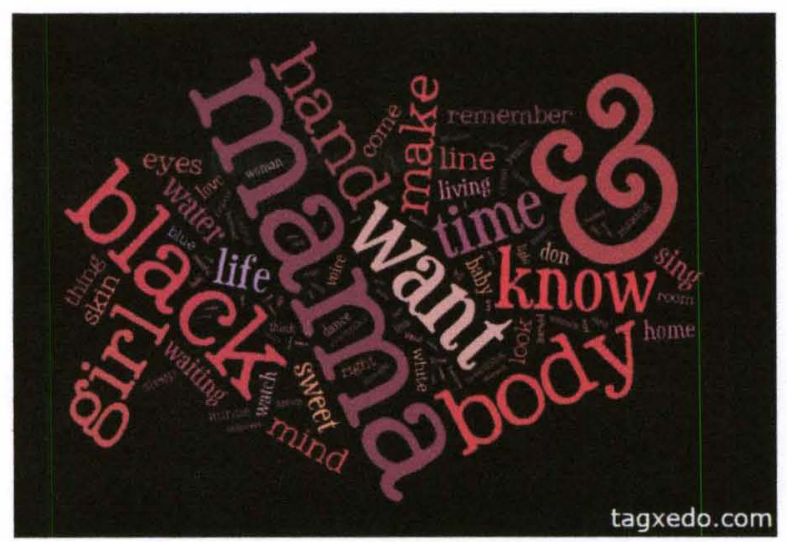

Illustration 2 : Ninety-nine most frequently used words with ampersand.

While I'm still feeling learning how to articulate the stylistic impulses my poems, the ampersand, with its strings of " $\& \mathrm{~s}$ " demonstrates my desire to create connections between moments, even as I want to show that what constitutes "a moment" in our experiences and in time is subjective and malleable. . Illustration 2 presents the frequency of the ampersand in another way. The frequency of words like "mama," "body," and "black" is consistent with the most prominent themes of That Terrifying Center. That the ampersand occurs relatively as, or even more, frequently than these words demonstrates the significance of time and "conjunction" in my poetry.

\section{Epigrams and Segmented Poems}

The use of epigrams and segmented poems also seem to be connected to the rendering of time and sequence. I have also considered the segmented poems to be serials, though I am not certain if they're quite long enough. The lengths and structure of my poems are variable-some consist of multiple numbered or separated sections; some are four or five stanzas; others-and these are some of my favorites-are very short, only a sentence or the fragments of a single thought. Poems like "On Trying Not To Fall Apart," "To Cassandra," and "Blues Woman," are examples. In the case of "Waiting, Or the Fear of Hypochondria; Or Negative, At Least It's Not Cancer," the title is far longer than the poem itself. These shorter poems contain a single realization, one statement or idea bookended by breaths, and ideally, understanding and empathy. "Waiting" attempts to say something about the 
nature of diagnostic testing and attempts to figure out "what's wrong" with a person who is chronically or severely ill. Because the epigram and the serial poems often occur together and seem to dominate much of the poems in That Terrifying Center, I took Dr. Golding's suggestion to use the epigrams as an mechanism for structuring and making sense of the higgledy-piggledy sheaf of poems that I sent him to review. Once I read them thoroughly, I saw that the poignant wisps of thought in the epigrams point to longer poems that bear these ideas out in longer, sometimes serialized form.

An example of the epigram and segmented or serial working together is "Sanctum Sanctorum" from the Absurdity section of the manuscript. In its current form, "Sanctum Sanctorum" is a serial piece comprised of numbered epigrams about the body, dis/ability, the thoughts and approaches to looking at oneselves from the inside out as well as the outside in. Though translated into English, "sanctum sanctorum" refers to the biblical "holy of holies" - the tabernacle and (portable) dwelling place for the divine manifestation of God in the Old Testament. The epigraph of "Sanctum Sanctorum" invokes the mythical and mystical work of poets Audre Lorde (the black unicorn) and Gloria Anzaldua (forked poet's tongue). The first section is meant to subtly echo the closing lines of Lorde's, "School Note": "for the embattled / there is no place / that cannot be / home / nor is." For those of who live in contention with our bodies, and must consider what we do not feel (e.g. pain, nausea), the no place of our bodies is still home. Our bodies are still ours. Or-as James suggests-our bodies are still "us," whether we want them to be or not. The successive segments in "Sanctum Sanctorum" interrogate the interior experiences of our bodies as "places," belonging and exclusion, the feelings associated with being and dwelling in a particular place, what it means to be "home" in our bodies. If we think of our physical reality as conditional, "Sanctum Sanctorum" meditates on embodied dysfunction and pleasure as one's body cycles, much as the seasons cycle. If the body is a house, joints and muscle swell with heat and contract with the cold just as wooden doors do. They creak and stick and whine. And the voices of these poems in turn voice the cycles - of confusion and derision, acceptance and awe. While holy and sacred, the temple depicted here is a kind of metaphysical fixer-upper. 
"Sanctum Sanctorum" and other segmented poems are suggestive serials because their relationship to the passage of time and transmission of a particular story. While the action of "Sanctum Sanctorum" moves between voices and settings, the unified piece presents the story or narrative of be(com)ing comfortable with one's body. Related to the pieces with embedded or simultaneous narrative voices, "Sanctum Sanctorum" attempts to render various sides of the same moment or situation through a more prismatic representation of embodiment. "As She Passes" has a similar mechanism for translating the iterations of "grieving" as one witnesses the dying, manages the aftermath of death. "As She Passes" tells the still-progress-story of the girl's attempts to live even after her mother's death. Grief is not linear, and yet "As She Passes" moves around the story of grieving (versus grief), through time and memory, inside and outside the speaker's own subjectivity. In poems like "Size 6 Slim: A Flashback," the story is more straightforward, presenting different aspects from a memory of school shopping. Each of these pieces are examples of my evolving approach to connect narratives, memories, thoughts and sensations across and through time. As I have stated earlier, I want to test the elasticity of time, considering multiply—from various perspectives, in varying voices- what defines a moment, how to conceive of discrete time within the context of continuous action/experience/sensation and how it can be shared.

\section{Vocables: Scat, Poetic Syntax, and Formal Innovation}

Voice, language, experimentation, and time are vital elements to my creative work as a poet as well as a performing vocalist and songwriter. Incidentally, these elements relate very closely to discussions of formal innovation and experimental poetics. In Muse \& Drudge Mullen writes at the borders of poetic modes and musical languages, often employing "language as verbal scat" (Henning interview with Mullen 6). While Henning suggests Mullen's work as verbal scat in a casual kind of way, a way to sum up the sonic elements and wordplay, the scat of Mullen's work strikes me more personally. I'd like to consider the notion of "scat" more critically for a moment using excerpts from Open the Door: The Life and Music of Betty Carter (2003) by William R. Bauer. As a singer, a jazz singer, 
and a scatter, this allusion to scat is a rather resonant one for me-pardon the pun and prepare for more. I'd like to use this discussion of scat to work in some treatment of improvisation, formal innovation, and my growing body of influences who are also considered to be jazz poets.

This riffing is something that I want to do more of in my poems. When I sing, I am a scatter. I perform, compose, and interact with the diverse genres of music that I perform with vocal improvisation. Of course Ella Fitzgerald is one of the first names one thinks of when scatting-well, Louis Armstrong, too-and Fitzgerald is a definite favorite of mine. But I'm more intrigued by Betty Carter who was "serious about [her] scat" (Carter qtd. in Bauer 29) and Anita O'Day, who adapted to the accidental removal of her uvula by taking a rhythmic approach to "song stylings" over more melodic singing. I love what they do with syllables and time. Speeding up, slowing down, swinging behind the beat. Or like Carter, bending notes so that they're not quite on pitch, giving the line an unwieldy, precarious balance. Adventurous. Experimental. Wacky even, but serious. I tend to scat on the syllables of actual words. Or with a mix of plosives and fricatives, but I practice down the alphabet. I like a percussive scat, but I also appreciate melody, and so I mix them. Blending the textures for the mood and I want to establish. Singing is very tactile for me. I feeling the sound roll around in my mouth. How can I make the vocal lines and syllabic experimentation "sensible"? I also love vocalise-what can I communicate without words? This kind of communication is very sensory for me. I make these sounds by considering where they are in the body. Placement, resonance. How to position myself to create the tone and phrasing: my poetry is composed much the same way. Where within my self, my body is it coming from; how can translate this emotion or experience to the page while maintaining its orality? This locatedness of language and poetry in the body reminds of the work of Audre Lorde in particular. Like her prose, Lorde's poetry is a performance of the embodied self. Just as many of her essays were originally speeches, so, too, her poetry emerges from an oral impulse. As Lorde composes poetry, both speaking it and hearing it are essential to her. She explains in the documentary $A$ Litany for Survival: The Life and Work of Audre Lorde, toward the end of her life when her voice weakens and cracks, she is hard-pressed to continue writing poetry. She depends on speaking the words; hearing them connects 
with the feeling she is trying to embody in those words. This process, she says, is part of her structure and technique...Lorde connects her poetry to her body through its oral quality" (Morris 176-177). This orality and embodiment of feeling in words is particularly salient for a discussion of jazz vocalization and composition.

In jazz and other musical forms, scat singing is the creation of wordlike or non-lexical vocables to fill the melodic line in a particular song. One of the apocryphal stories of Louis Armstrong and the "invention" of scat is that he told another play: "hey man, just make some shit up." Most associated with bebop, scat singing can be used to encode meanings, convey messages contrary or beyond what can be transmitted through words, and mimic the musical line and qualities of an instrument other than voice. In this way, scatting creates language where there is none, just as Audre Lorde states that language does not exist before our poetry fashions it: "Unlike singing lyrics, in which a musical setting typically reinforces the song's verbal meaning...scatting makes singing into a music-centered activity" (Bauer 32). By extension, I believe that poetic scatting and experimentation with sound and spacing makes writing into a poem-centered activity. This bargain between lyric/s and improvisation enables scat singers to use sound in much the way jazz players do: as a vehicle for the expression of feelings and ideas that are not directly linked to words. According to Bauer: "the ability to phrase like an instrumentalist has become so crucial to jazz singing that it may be considered a defining feature. By treating the phones of the English language almost as though they were scat syllables, jazz singers manifest a fascination with the sonic properties of speech that may also be found in other African American-as well as West African-cultural expressions. In jazz, the singer must not only express the lyrics' verbal meaning; she must create a musically satisfying statement as well." (32) Singers must invent convincing vocables-nonsense syllables that effectively capture the line's phrasing -as well as satisfying melodic ideas.

Though a novelty for some in scat "sounds coalesced into a crystalline structure that, for the initiated, had its own unique logic and beauty" (Bauer 28)-To scat is to manipulate the timbral qualities of one's voice to carry the musical moment along without the use (or relative safety of 
established lyrics). Scatting "is when... a singer displays her timbral virtuosity most...The importance of timbre to the jazz aesthetic has links to African music, in which acoustically complex timbres such as raspy, buzzing, or scratchy noises are used to relate musical sounds to those of everyday life. The formulation of a cultural sound image, like that of a language, entails an "editing" process in which certain sonic possibilities acquire more aesthetic, or semiotic, value than others. (Bauer 353). To maximize the efficacy of the "cultural sound images" and other textural qualities of one's instrument/voice, experimentation is absolutely vital for an artist. Consequently, the only way to find your voice is to use it: "developing a technique entails the thorough investigation of one's instrument, for singers as much as for players, in order to exploit all of its unique timbral resources" (Bauer 28). In other words, honey, you got to make some noise. Play and jamming, following the suggestion of words and rhythm makes all the difference in the development of one's voice.

Performing, playing an instrument, whether a horn, a piano, or one's voice is very sensual. It is located in the body and is a deeply pleasurable experience for the artist. As I consider the search for one's voice and the "alone time" with one's craft that musicianship requires, I feel a certain resonance with what Sandra Cisneros has said about how she arrived at The House on Mango Street and the proliferation of voices that subconsciously influenced her work. Cisneros' works and determines that within them there is a personal enjoyment of creation, a private "selfishness" that explores the virtues of privacy for its own sake. And that Cisneros' excursions as poet, Esperanza Cordero, and as herself, all create a particularly fruitful space for the exploration of the self and mysteries of artistic creation. The personal reward that Cisneros discusses in her interviews and poems, writing for her own "selfish" enjoyment melds beautifully into notions of selfhood and the possessiveness of the artist over her own creative processes and creations.

Initially, she Cisneros writes to parrot the styles and inflections of her influences, it is the desire to write something that her grad school classmates could not write: "My intent was simply to chronicle, to write about something my classmates couldn't. In a sense, I was being defensive and rebellious" 
(78). She was writing to find a voice that was distinct and set apart. In the course of that rebellion, she states: "I found a voice that was uniquely mine" (78). I can remember my earliest poems (which were terrible) and how much I wanted to be brilliant and witty like John Donne. "The Flea" and "Holy Sonnet 14" aka "Batter My Heart, Three-Person'd God" are still two of my favorites. Yet no matter how badly I wanted to make weighty metaphysical poems, his voice wasn't my voice. I found my voice by telling my stories. I uncovered my stories by writing my mother's stories. In the same ways, Cisneros discovers her voice: "These two voices at odds with each other-my mother's punch-you-in-the-nose English and my father's powdered-sugar Spanish—curiously are the voices that surface in my writing... It's ironic I had to leave home to discover the voice I had all along, but isn't that how it always goes..." (Ghosts and Voices 71,72$)$. Yes, I believe that's exactly how it goes. The voices we have are ours-we use them every day. The same voice that signals our safe passage into this world is the same voice we have when we take our last breaths. The voice we have grows with us, it cracks with us, scratchy when we are sick and sweet when we are rested, our voices are ours. The voice reflects our living - hard living is hard on a voice. Voices mature as we do--in the $30 \mathrm{~s}$ and $40 \mathrm{~s}$. When a woman is pregnant, her voice changes. The voice is located in the body that carries us through our cultural exchanges. Our voice is us. And the only way to understand what our voices can do and can be is to experiment. We must sing if we are to sing. We must write, voice the experience, capture the cadences of home, spend pleasurable time with our voices, if we are to discover the style of our own utterances.

Cisneros in addition to this discussion of voice, and ultimately inspiring this collection with her words about the "terrifying center" of ourselves that is a poem, also provides a helpful perspective for seeing this "quality time" alone with oneselves, with one's writing, with one's instruments and voices, in a healthy light-she helps to reframe and redefine the notion of "selfishness," reclaiming it as a necessary space that artists—specifically Chicana artists and other CWAs—not only require, but deserve. She expresses a personal enjoyment of creation, a private "selfishness" that explores the virtues of privacy for its own sake. Cisneros' frankness about being a "selfish" woman creates a 
particularly fruitful space for the exploration of the self and mysteries of artistic creation. The personal reward that Cisneros discusses in her interviews and poems, beyond the body, the socio-cultural, and political ramifications of a CWA (Chicana \& working class) writing for her own "selfish" enjoyment melds beautifully into notions of selfhood and the possessiveness of the artist over her own creative processes and creations. She articulates an almost masturbatory pleasure that one can derive from creativity for its own sake. Considering what Lorde has done in reclaiming the erotic as a wellspring of creativity from which we can draw, the linking of writing (or musicmaking) and sexual pleasure makes perfect sense. Cisneros makes the link even more explicit:

Discovering sex was like discovering writing. It was powerful in a way I couldn't explain. Like writing, you had to go beyond the guilt and shame to get to anything good. Like writing, it could take you to deep and mysterious subterranean levels. With each new depth I found out things about myself I didn't know I knew. And, like writing, for a slip of a moment it could be spiritual, the cosmos pivoting on a pin, could empty and fill you all at once like a Ganges, a Piazolla tango, a tulip bending in the wind. I was no one, I was nothing, and I was everything in the universe little and large-twig, cloud, sky. ("Guadalupe" 48-49)

The euphoria of writing, of singing, all the working and the sweating to get that thing out, the climaxes in the solo work...sex and creativity make perfect sense together. Working to redefine "selfish" as distinct from its common association with "stingy," aligns well with my focus on interrogating the languages of bodies, selves, and artistry through poetry. Discussing a woman's "body" of work, relates to discussions of the body, notions of pleasure and enjoyment and societal conventions related to the roles of the female body. I can't help but to chuckle when I think about the overlap between the cultural construction of the selfish woman artist and the selfish musician-and then I realize that I am both!

The figure of solitude, time away to explore and to simply enjoy the rush of creativity is absolutely vital for creation. Cisneros, Alice Walker, M. NourbeSe Philip, Harryette Mullen, and Audre Lorde—some of my hero poets—while representing decidedly different perspectives on creativity and style, all assert that women must be free to write. Recognizing that for colored women working class 
artists especially, that creativity is paradoxically a tool necessary for our survival and yet a privilege afforded at someone else's expense - or perhaps to state it differently, an opportunity that when given must be fiercely protected. I'm thinking of Cisneros's mother allowing her daughter the time to read and explore her imagination, rather than forcing her to do focus on domestic responsibilities only, or that perhaps Emily Dickinson was able to write those 1700 some-odd poems because she had a housekeeper. Or consider Alice Walker's treatise on the repression of Black women's creativity in "In Search of Our Mothers' Gardens." I think of my mother's silk floral arrangements, or her beautiful flower beds, or the clothes that she would sew. My mother told me that she used to be a dancer. And while she worked to keep beauty in her home, she didn't feel that art was a luxury that she could afford; however, my mother encouraged my bookishness; she would do my science experiments with me. Of course I had chores to do, but Ma gave me space to think, sing, read, write, and dream. She pushed me toward the opportunity to express what she, and my grandmother before her, were unable to. When I wanted to get a job during the school year, she wouldn't have it: my job was school and performing. She gave me the space to create and was proud of me for doing so. My voice-as a poet, as a musician, as a thinker, and scholar-is developing because of the time, the "selfish" moments I have been given-or that I have stolen-in order to nurture myself.

Moving back toward the discussion of study and experimentation, I liken the interplay between musical craft and intuition or "feeling" the music to the relationship of the rules of grammar and the subversion of grammar in experimental poetries, particularly that of Audre Lorde. In an interview with Adrienne Rich, Lorde explains her rationale for undermining traditional syntactical structures in her poems: "I learned that grammar was not arbitrary, that it served a purpose, that it helped to form the ways we thought, that it could be freeing as well as restrictive.[... O]nce we know it we can choose to discard it or use it, but you can't know if it has useful or destructive power until you have a handle on it" (Lorde Interview w/ Adrienne Rich 93). According to Fraser, "The myths of a culture are embodied in its language, its lexicon, its very syntactical structure. To focus on language and to 
discover what can be written in other than traditional syntactical or prosodic structures may give an important voice to authentic female experience" (27). This estimation of experimental grammars very closely mirrors what Lorde says in her interview with Rich about understanding the potential power of grammar, of knowing when to deviate from it, purposefully undoing traditional grammatical structures to create new understand and new meaning. To create new languages and find the freedom in performance, improvisation is key. Making it up as you go, and yet, keeping it coherent is not an easy task: "An essential component of the jazz process, if not of the music itself, improvisation operates by degrees. Even in a relatively straight rendering of a melody, the spirit of improvisation can and should be present, informing the musician's rhythmic and melodic nuancing, phrasing and articulation, accentuation, dynamics, and timbre, making a familiar tune feel altogether fresh. (Bauer 27) Jazz players must know the fundamentals of musical structure, chord progressions, modal movements and the like, but in order to improvise in a compelling and engaging way, one must be able to feel the music on an intuitive level. The real magic happens when we absorb the rules and follow the subtle leading of the music. No one can teach you to swing; you've got to feel it for yourself.

While Bauer acknowledges that "although scat lyrics are nonsensical, scatting does not altogether lack meaning, for an array of nonverbal and pseudoverbal associations can shape the vocal line" (33)-and this may be a small point-but I contend that to regard scat vocables as inherently "nonsensical," limits one's interpretive reach. While they're not tightly bound by convention, verbal grammar, scat can be still take advantage of the texture, inflection, and phrasing to connote "sense" as well. Similar to a vernacular English, such as African American Vernacular English, or a Chinese, Spanish, or Arabic Vernacular English wherein there are mixtures and inflections that bridge the two languages, I think of scat as a kind of dialect of the song lyric, that it has its own grammars, its own rules, that only to "native speakers" of said dialect are the rules and tendencies most apparent. What is nonsensical (or a "broken" English) to one, is demotic home-language to another. Like the scat conversations between Dizzy Gillespie and Carroll, I hear think of poetry as a "hip foreign language" (Bauer 33) that can stretch, scrunch, and otherwise funk up the range of meanings available to the artist. Scat, in the complex 
poetry of Mullen and Philip --as in singing-- provides opportunities for fresh intensity, phrasing, and articulation.

Formal Innovation and (Women) Poets (of Color)

With all of this talk of complexity, experimentation, and improvisation, the question of audience and accessibility is one with which I grapple constantly. As in my music-and even the predicament of jazz music globally - I want my work to be appreciated by a diverse range of folks, and yet, I have the drive to create linguistically and conceptually complex works. To put it plainly: it's easy to lose people when you're scatting and riffing and mucking with the rules of conventional grammars-either in music or poetry. I understand and identify with the contradictory impulses that Harryette Mullen and M. NourbeSe Philip express about their own creations_ I, too, "want the work I do to be intellectually complex, but at some level, the form is open to allow people to enter wherever they are" (415, Mullen qtd. interview w/ Hogue). I am continually working to reframe experience in my poems as well as gently reorient—other times, violently disorient—my readers by using formal innovation to recontextualize what we mean by "audience." As I experiment and work to integrate a variety of forms, cultural voices, and media into my poetry and music, I find myself shifting from the singular audience/reader to a more communal notion of audience. I recognize also that I am writing for a diverse and largely unknown audience.

How ought innovation to be defined given discussions of language and form-whether the avant-garde, or jazz, or language-oriented? Even as I discuss my poems and parse the qualities of That Terrifying Center, I am unsure just how "experimental" or how "conventional" my work is. I can see how my work can be included or excluded, but have reservations about rooting my poems in any single category or mode of presentation. It seems to me, poetry should always be experimental, even when using traditional elements. In "Poetic Statement," Harryette Mullen states that it is a "meditation on the various experiences of inclusion, exclusion, and marginality of a 'formally innovative black poet" (Mullen 27). "The 'avant-garde poet of color," she continues, "threatens the cohesiveness of the accompanying narratives that allow the mainstream audience to recognize, comprehend, or imagine a 
collective identity, purpose, and aesthetics of a literary group or movement, whether it is a group 'of color' or a movement defined by its commitment to 'formal innovation'" (28). In trying to articulate the quality of my own poetry with its decidedly lyric qualities and its slyly "avant-garde" qualities, I found myself stumbling to find a place for my work. Only thorough scouring journals and taking recommendations from other poets and critics did I find poets—black and not, female and not—who served as precursors for understanding my (own) work. I certainly found this to be true: "In each generation the erasure of the anomalous black writer abets the construction of a continuous, internally consistent tradition, and it deprives the idiosyncratic minority artist out of history, compelling her to struggle even harder to construct context out of her own radical individuality. She is unanticipated and often unacknowledged because of the imposed obscurity of her aesthetic antecedents" (28). The "innovative" or idiosyncratic poet then, has no context for her work. Because of the consistent erasure of her predecessors, there is no tradition to which she can belong. For all intents and purposes of a marketable and teachable poetics, these poets do not exist. In the course of writing the poems, receiving feedback on the manuscript, analyzing them myself, I've discovered more poets, more poems that reverberate with mine, poems written decades before mine, poets only recently dead, others still scribbling. In a meeting with Dr. Golding, going over his comments, he turned over to my poem "Sunterblooms Ik Tew," and was certain that I'd read Bob Kaufman's "Crootey Songo." I had not. Written over 50 years ago, when my parents were in diapers, Kaufman's, "Crootey Songo" was already riffing with the idea I thought was so ingenious--the wordless poem. These days, I am rarely surprised by what I will find as I dig deeper and cross the boundaries of genre and "kind." I look forward to finding work that resonates with mine, even as I get déjà vu just looking at the shapes of Ed Roberson's poems; the incisive poetics of Dionne Brand and Erica Hunt, the epigrams of Samuel Menashe, the work and essays of Nathaniel Mackey... The more I write and read the poems that have managed to survive in the wild, the more I learn more what it means to push and make and do, the more I see what my poems have been doing all along. 


\title{
CHAPTER THREE
}

\section{LANGSCAPES: \\ MINDING THE GAPS \& MAPPING THAT TERRIFYING CENTER}

\author{
While art and life are separable, they are not separate. \\ --Tom Sleigh, Interview with a Ghost \\ To survive the Borderlands, you must live sin fronteras: be a crossroads. \\ --Gloria Anzaldua, "To Live in the Borderlands Means You"
}

The major challenge of this dissertation has been connecting the impulses of my poetry with those of my critical discussion of the poems. Chapter 3 has been the stuff of panicky, dissertationinduced nightmares. The questions seemingly had no end- How to talk about my own work? How to do so in a way that is clear, provocative, and rhetorically sound? While still tricky, I remembered why talking about the works of the poets I admire is more natural than talking about my own. All of my life as a learner, I was assured that I lacked the credibility to assert my own claims, coin my own words, talk about my own work-you can do that once you're the expert, when you've got your PhD, my teachers said. Well, that time has come, hasn't it? This is the time where my work and theories must shine. Now is the time for original research. As I conceived of the critical framework of these chapters, I struggled to determine the appropriate tone with which to treat my work: striking the balance between the familiar and critically salient. At times, I became deeply distracted by allowing the work of my predecessors to become objects of inquiry themselves rather than as resources for expounding upon my own work.

Rather than talking around the challenges, contradictions and hybrid bits of my poetry and influences, combing over the bald spots, kicking them under the rug as if they don't exist, I've finally 
begun to address them by couching my discussion firmly in terms of the challenges and seeming contradictions in my work. In Chapter 2, I discuss the tensions between the experimental and the lyric in poetry by Harryette Mullen, Audre Lorde, Sandra Cisneros. In this chapter, I will expound on my own desire for hybridity in my poems and more discursive work. Chapter 3 sets out the obstacles and impulses that make up That Terrifying Center's creative and discursive design. This chapter is multivalent and continues the creative-critical experiment of my dissertation: it is part poetic statement, part discussion of influences, part rationale of manuscript, and part analysis.

\section{THE PROBLEM OF THE “CREATIVE" DISSERTATION}

The guidelines for the creative dissertation require it to be a single document with two distinct halves-one creative, one critical. Each half of the dissertation should be independent. As discussed in Chapter 2, neat, categorical divisions are problematic for me. Because my work tends to linger in the spaces between genres and styles, I had definite problems determining how to compose the creative material so that it would be organic and authentic — but still "fit" with what my focus would be. How much should what I say I want to talk about and demonstrate in the poems determine what I actually talk about and explore in the poems? How much wiggle room did I have? How beholden was I to nail down my proposed critical focus in the actual poems? Once I got into writing the chapters, I fought to keep focus on the entire project-not the poems or the chapters only, but both. It was a major struggle not to think of the dissertation as a poetry manuscript alone, while still seeing the poems clearly enough to discuss them coherently. At the same time, I grappled to save the work of the poems from becoming buried by focus on the critical discussions. This was the double-bind of the project, and much of it came down to definition-how we define and delineate the creative and the critical. And so, the recurring rub in composing That Terrifying Center was finding the appropriate voice for writing about my own work. As an artist coming out of an analytical tradition, I was unsure of the "rules" for a creative dissertation, and just how many of them I could get away with breaking. 


\section{Obstacles: How to Say It and What to Call It}

As I conceived of the chapters, I frequently felt the conflicting pull to write conventional criticism and to do something more creative in the discursive parts of the dissertation. As a result, the chapters tend to oscillate between three main styles or voices: objective critical prose, experimental critical prose, and lyric essay/narrative. Talking about my intimate work in a detached and cool scholarly tone simply was not an option for me. Because my discursive work is continuous with my poetry, I strove to maintain a tonal fluidity in both halves of the dissertation. To take two of my poetic influences (read: heroes) as examples, I sought to balance Harryette Mullen's straightforward, plaintive speech about her own work with elements of M. NourbeSe Philip's enmeshed essays (such as “Dis Place: The Space Between" discussed in Chapter 1), where the entire text is "creative" and the cultural critique is embedded with the poems. Though I had many of the poems written before beginning the more discursive or "critical" chapters, drawing the line between the two halves of the project gave me conceptual hives. Given that they were such interdependent sections, which should be presented first? Or my more pressing concern: which should be completed first? Ironically, the first segment of the final dissertation to stand on its own was Chapter 4, the lyrical essay and my "last word" on what I have attempted to articulate and explore in this project. By taking a more "creative" or lyrical (even more personal) style, I could recount and retrace my steps. In a manner of speaking, by beginning at the end, beginning with my thoughts on where I started and what personal and chronological ground I covered, gave me a place to begin to write the end. Chapter 4 provided the perspective I needed to evaluate the objective of the dissertation. As I see it, my assignment is to make my conceptual impulses and creative choices relatable to folks outside of myself. So I continually wrestled with the best way to present the abstractions and contradictions in practical prose with concrete examples.

I imagine that it's rather obvious by this point that determining what is appropriate for me to say has been so difficult because diction, style, and "the right word" are vital to my writing. Presentation is crucial. Like many artists, I want the work to speak for itself; I want my poems to connect with my audience(s). While I enjoy providing backstory, or sharing the impetus for a piece, I 
still want them to stand independent of my annotations. So as I talk about the impulses and tendencies in That Terrifying Center, is this analysis? Am I explicating them as I provide a context for their genesis? Moving between poet and critic--between composition of the pieces and composition of the chapters, sometimes felt icky--even incestuous. Explaining one's own work, butting in during the workshop to clarify or redirect is/was considered an unspeakable violation in my creative upbringing. In this way, writing about my poems has felt deeply unnatural, and yet I have appreciated the opportunity to engage my own work with a different sort of intimacy, and to articulate what I didn't realize was there. The critical writing about my own poems gives me the unique opportunity to "take the poem one step further and re-embed it, re-encrust it within its context-to put it back in the mire of its origins" (Philip "The Habit Of" 212).

Beyond the arrangement of the work, what has been most difficult about writing about my own work, is deciding what to call it. I'm writing what I might consider an experiential (and experimental) language-oriented poetics of identity, body, memory, and voice. Some common subjects and elements in my work are relationships and generational connections between women, family histories and legacies, illness, pain, and the body, language and writing about writing, voicing trauma, and shifting subjectivities of raced/gendered/classed bodies in urban landscapes. I'm particularly oriented toward approaches to self-writing and understanding one's own-that is, my own-changing relationship to oneselves and exploring notions of embodied subjectivity and representations of the passage of time in verse.

In That Terrifying Center, I explore black women's cultures, by playing with language, voice, and form. I want to represent the idea that there are many voices speaking at any one time, within any one narrative. I try to create uncertainty, paradox, and the presence of coexisting truths/perspectives by using competing grammars or syntax in atypical, and even strange, ways. My poetry seems to straddle the space between narrative/lyric (i.e. traditional, acceptable) approaches to poetry and the avant-garde/experimental (alternative) poetics that tinker with the unitary voice of the "I", spatial constraints of the page, and language. While there is a desire to speak from and through a particular 
body--to be somatically "oneself" who speaks, relaying some story or memory--there also emerge competing or simultaneous "selves," subjectivities, or sources (e.g. selves/souls of other ethnicities, enmeshing of the unitary speaker with ancestral and supernatural voices, song lyrics, theories, collective and shared memories) that challenge ways of knowing and being oneself. I have attempted to build momentum and reconsider units of language, speech, and sound by manipulating conventional poetic devices; I am steadily working to translate sensations, voices, and memories from solitary experience into text-and in turn, from text into collective experience.

\section{Beginnings: Considering the Body}

The Sleigh epigraph that helps introduce this chapter is one of the few to survive all of the various revisions and reframings of my project. Indeed, my life and art are conjoined--and rather than separate them for the sake of a "tidy" dissertation, I've left much of the skin \& sinew that connect myselves to my poems intact. My poetic project begins with my body. This dissertation begins with my own illness as it is connected to my coursework-my creative, corporeal, and academic lives have always been nested and interrelated. I can connect the poems and their beginnings to this project in their own way--whether through inspiration, grief, uncertainty, or rage. Four particularly significant poems that are touchstones for the development of That Terrifying Center as a poetry collection and discursive exploration are "Hush" (2004), "Of Fences" (2006), "Terminal: A Meditation" (2006), and "Epistemology" (2007). "Terminal" and "Of Fences" are examples of my "mama poems"—ones that originate after my mother's illness and death, but typically pre-date my formal diagnoses of disability and creative exploration of my own illness.

The majority of the poems in this collection were written in the time spanning from 2007 to February 2011. The oldest of pieces were salvaged and re-worked from poems or essays written between 2001 and 2004: the years between my junior year of college and the end of my master's degree program. One of the earliest pieces and one of the only ones composed while I was working on my MA at Wake Forest is "Hush." It was originally entitled "night whispers," and composed somewhere 
between 2003 and 2004. "Hush" has always been about the myths and whisperings of little girls as they try to figure out the mechanics of sex and exactly how and where babies come about. The poem's basic form is unchanged. I have added a couple layers to the voices-italicized and staggered on the right-hand side of the page-and reconsidered the language a bit since then. In the italicized lines, we hear and see the girls' voices, their stories; what they get right, what they need to understand, what they fear, about what may become of their bodies are all at the heart of the poem. "Hush" was inspired by a 2004 interview with Rita Dove in Poets \& Writers and patterned after her poem, "Rhumba," from

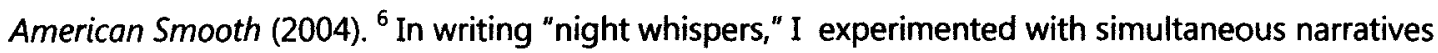
that could be read independently of one another, together, and/or in tandem-I see the poem multidirectionally at any one time-as it presents whispers in the dark, while also taking place in more than one "where" and "when." "Hush" has expanded spatially as well, to three distinct columns, as opposed to the original two. The multiple and layered voices of innocence and experience prefigure later poems that also appear in this manuscript. My approaches to render multiple voices within a single poem have evolved quite a bit since my initial experiment in 2004. Later examples of poems with embedded narratives-whether competing, complementary, or alternating-include "After the Dance" (in the October 2009 suite), "Rose," "Little Detroit Red," and "Selfish." "Night Whispers/Hush" reminded me that I was poet during a time when my mind was too cloudy with migraines, insomnia, and depression to write. "Legacy" is a poem that survived my college years, albeit in more condensed form. It considers the legacies of memory, of hand-me-down histories, and of the premature deaths of mothers.

"Of Fences" has never changed titles since I first wrote it for Dr. Majozo's Creative Writing class, but the structure and the names of the "characters" have changed some. It concerns more explicitly the "legacy" of mothers who die prematurely, and the hearsay, and storytelling that we find in "Hush." In 1975, my mother came home to find that my grandfather had murdered my grandmother. My mama is Debbie. "Of Fences" is an fusion of the stories she told me about the death of her

\footnotetext{
${ }^{6}$ See lllustration 26 for the excerpt from that issue Poets \& Writers.
} 
mother-how she came home to police surrounding her house; how they wouldn't let her in; her shock after forcing her way in, how her little brother, Melvin, had to physically remove her from the premises; and how she had to be temporarily sedated to keep from losing her mind. Also: how her father never served a day in prison, how he never changed addresses, how, whether legitimate or feigned, he was known to be crazy, prone to paranoid "visions" and "dreams," and how she was eventually put out of the only home she'd known because he had a "feeling." Ma's motherlessness and my grandmotherlessness are embedded in my earliest memories. Grandma Gussie's picture is on the mantle, her obituary is nearby, Mama's memories are fresh: that she was murdered, that my father attended my grandmother's funeral-they'd met only months before. I still have no real idea of what happened, neither why my grandfather was never convicted of murder, nor why he was never imprisoned in a mental hospital for the criminally insane. All I know is what my mother told me-none of her siblings ever spoke of it and now I'm too agitated to ask. All I know for sure is that Ma would never keep a baseball bat in the house and she never, ever trusted the white picket fence as a symbol of security. And as a result, neither have I. Just as Mama passed down the stories of her life, she passed on the fear and certainty that the unthinkable could happen on any given day. She gave me her fears, many of which were justifiable, in the same breaths with which she gave me my history. "Of Fences" represents my earliest efforts to voice the unspeakable violences and internalized traumas that make up my own family history, and the histories of other (colored) women and girl in poems like "October 2009," "Rose," and "Oversight. \#1."

"Terminal: A Meditation"—as well as "Of Fences"—dates back to 2006 when I was in Dr. Estella Majozo's creative writing class. In her course, I started to write more explicitly about sickness-mine and my mother's. Though my mother had died years prior, I wasn't able to truly articulate the devastation of her body and our lives by stomach cancer until I started writing poems again. I was determined to dig in, to render the endless eat and waste of her sickness, our disbelieving sorrow, and her incomparable will without flinching, without turning away. "Terminal: A Meditation" and "Of 
Fences" are my attempts to write through silence, to render the ineffable on the page. In order to understand my words, I had to consider intimately what had never been said and construct the best "shape" to contain the voices and silences of the poems: "Each poem has its own silence. Technique but the discerning of that silence. And composition-how you shape the words around the silence. To understand one's own silence is, therefore, to understand one's words. To understand one's silence one must go to the place of silence. In the body. In the words. Dis place- the s/place between the legs!" (Philip "Dis Place" 84). Before 2006, most of my writing about Ma considered my grief and what I missed in her absence, or revisited the many stories she'd told me in the 20 years that we were together. Though I'd been thinking of her cancer as a "sneaky bastard" for years, I'd never truly written down the ugly of it until the first line of "Terminal" forced its way out. This piece was written from my memory as I relived the horrible, insignificant weight of my mother in my arms and smelled the mucus to be suctioned away and retched at the stench of her colostemy bag as I cleaned and replaced the taped tubing. Ten years later, I still remember the exhaustion of the deathwatch in her final days and the guilt of being away at college while my mother was initially going through treatment, and eventually dying. "Terminal: A Meditation" proved to me that I had the nerve to write about my sorrows and fears, to tell these special stories-not for the sake of poetic detail or self-flagellation, but for the sake of others who would or could know what cancer and dying look like. To tell someone that the pain is livable-to tell myself that the pain is livable. That we are not alone in our griefs and the appreciation that living hurts, but is not impossible. "Terminal" provided the practice(?) necessary to write the hell of "On Imperial Avenue" and the loneliness of "As She Passes." In "Terminal" as with other poems in this collection, I am keening my blade, scrutinizing the details-or "sweating the language" as Dr. Majozo says-to translate/render/convey the intimate fears and sensations of living (and dying) in a body, to say what must surely be said, by any means necessary.

"Epistemology" is the first "body" poem I remember writing. Fall 2007 was my last semester of doctoral coursework: I was taking the Humanities Capstone with Dr. Mark Blum and the seminar 
course, Film and the Postmodern with Dr. Tom Byers. The poem itself grew out of an in-class discussion on gender and embodiment and eventually merged with my Capstone project. During a class meeting for the course and discussing the appropriateness of the label "woman" and its relationship to gender essentialism and the body as presented by Judith Butler and Tania Modleski, a simple, though profound question occurred to me. That first question — how do I know my body? - became the first line of my poem. While sitting in class, following the twists and nuances of Butler's and Modleski's arguments, I formulated my answer'. With "Epistemology," my dissertation project began to coalesce and emerge. "Epistemology" is grounded not only in the conception of one's body/"mybody" as an answer to Butler's questions about performing gender, but is a response to my own body as it exists within the alternate norms and the "new normal" of chronic illness and pain. It is an attempt to work through issues of selfhood, the body as self, and normativity of the body as socially constructed-not only as it relates to sex/gender but to wellness. Not until I got home and continued to work and shape the poem did I realize just what I would do with it. The question of knowing our bodies as posed by Butler and to what degree these experiences can be universalized served as a baseline for how I would approach articulating my own "lived experience" of "mybody." In "Epistemology," I am simultaneously self and body (mybody), immersed in the subjective experience of pain while attempting to be objective interpreter. My body is frequently divided into individual systems or layered according to condition, and the perspectives from which it is observed inside and outside can vary greatly. Some of this distance in perspective informs the poem's approach to pain. According to Elaine Scarry's historic analysis of the body in pain, "pain resists verbal objectification" (12). The relationship of the sufferer is "the model of certainty" in which the person in pain is absolute in her awareness and experience of pain, while external observers live in a "model of doubt," always questioning the person's pain. "To have pain," Scarry states, "is to have certainty; to hear about pain"-and by extension invisible illness"is to have doubt" (13). Many times I find myself questioning if my pain is real. Fibromyalgia, and other

\footnotetext{
${ }^{7}$ See Illustrations 23 and 24 for the initial handwritten verses from my class notes that became "Epistemology."
} 
largely invisible conditions that disproportionately affect women-with onset occurring in their midtwenties to early thirties-can make the viable experience of pain and illness invalid because there are, as yet, no material causes, cures, or physical deterioration—only symptoms and treatments. A primary image in the poem is that of "feeling"-affect as well as physical sensation-and the manners in which these "feelings" determine how our 'bodies' are known to our "selves."

"Epistemology" was the first time I found myself able to sift through my frustration, and the changing sense of myself and body, through poetry. I began with a question, but in the writing of the piece, I located the pains and twinges as I felt them in that instant. I wrote what I felt as I felt it I had to process the very real, immediate concerns of translating my physiological reality in that moment: How do I process the act of writing down what may or may not be clear in my mind? How do I process the pain in back, the shooting pains in my fingers as I prop myself up on my left side, hold the page still, cracking my knuckles as I go, pausing to consider what I have written, what I will write next, how it will be received, if it will survive my revisions? "Epistemology" is my earliest attempt to translate the unsayable sensations and questions of my body into a form that could be understood by others. Over the course of compiling this manuscript, I feel less "afflicted" than I used to. I've made peace with my body and am increasingly considering how the world outside sits beside and in conflict with the physiological world(s) within. Nevertheless, I still work to approximate the experience of "feeling," of sensations like pain, of being estranged from one's own body or worse, being betrayed by it. I have not stopped hurting; I've just stopped believing that I am defective. Mostly. I've come to appreciate that this body that I am and that I have, is a wonder. As in "Meditation," one of the embedded poems of Philip's "Dis Place" essay, "Epistemology" and the other pieces that comprise That Terrifying Center consider the following questions and stream of thought: "is we bodies saving we-forcing we to live in them. We coming to understand that surviving needing the body. African. Pulling we down: Source of enslavement/ road to transcendence:holding we up. The Body African. Is Mind" (91). A couple of years ago, while I was at a particularly low point, Ms. Donna, one of my mother -in-law's best friends told me 
something simple that helps me when I'm grasping for peace: "you can't have it all." Considering her words, and these poems, I'm learning to appreciate the not-all that I have.

\section{SCHEMING THE CENTER}

Once the poems were finished, I held onto them for awhile. Though they were technically completed, the manuscript wasn't "finished." They still were not in any order whatsoever-not alphabetical, not thematic, not in order of completion. Nothing. I'd been contemplating the order for months, but I didn't really see what I would do. And so, I decided to read them. I read them all. Annotated them. Commented on them. Remarked about their similarities, and the connections between pieces that I hadn't anticipated. After that, I tabbed them and color-coded them—of course. And then an argument of sorts began to present itself. Reading them with fresh eyes from beginning to end, I began to home in on unconscious thematic tendencies that encompassed and ran throughout the intentional treatments of illness/body/gender/terror that I had included in the poems. Consumption, the malleability of time, and the elemental are three motifs that stood out to me as I read through the poems.

Chiefly, consumption was a major trope that connected and juxtaposed pieces throughout the manuscript. As an idea, consumption changed shapes and contexts. Consume as it means to eat, to use, to occupy, and to destroy is woven into the framework of That Terrifying Center and I didn't pick up on it until they were already written. As the poems consider issues of food and gastric cancer, the body eats, the cancer eats. In considering sexuality, the sensuous and the predatory, consumption is a controlling metaphor in poems like "The 6," "On Imperial Avenue," "The Soucouyant Considers," and others. With cancer's consumption of the body and spirit, and the predator's consumption of fleshy "carcass," there is also consumption with/of/by ideas: of illness and death, of madness, of possibility, of eternity. Even Detroit is framed in terms of "snacking itself" (76) and "eating its tail in earnest." But this consumption isn't just destructive, it is nutritive as well-the soul must also eat ("Selfish") and music is 
able to sustain across time ("31 Years After The Audience with Betty Carter"). And in "Jouissance" tasting is/can be pleasurable, and exists solely for its own enjoyment.

In addition to consumption, issues of time and memory thread throughout the poems.

While I knew that time was an important construct in my work, I was surprised to encounter the various instantiations of time in the pieces. Some thematic trends include memory as transportation/vehicle and the malleability of time. Particularly in the latter half of the manuscript, time and music function as vehicles for making peace with loss and trauma; they connect the living and the dead, and move us through space. In poems like "Rose," we see the tension between the memories and experiences of members of the same family-the inherited "story" vs. the speaker's memory vs. the memories of elders and how these narratives collide in the telling of "the story." The idea of building blocks or elements is also scattered throughout the poems as modes of deconstructing and examining the components of experience or language-"Metaphysics" and "Morphology" are two poems in particular that treat the materiality of being and language (rather than their abstraction). There are other motifs as well: fertility/creativity, qualities of light and darkness(es), dis/articulation, and flight combine in conventional and unconventional ways to explore and question established modes of knowledge and experience. The ideas related to the acquisition and scrutiny of knowledge began to make sense after reading the poems: as I finish my doctorate-a process of formal education that began with Kindergarten, and save for one year after my master's program, has been uninterrupted-I have concerned myself with the notions of learning, the credibility (authority) of texts, the lessons of childhood and womanhood, the gathering of vocabulary and grammars for moving between various communities and geographies. As I hope these last two sentences demonstrate, I have learned the rules, followed their prescriptions, and determined which ones I will break, and to what ends.

\section{Arranging the Center}

With all of this in mind, I present the following arrangement for That Terrifying Center. The manuscript begins with the single poem, "Bananas." After which, the contents are divided into four 
sections, each named after its opening epigram: The Bottom Line, Absurdity, Conjure Woman, and Sunterblooms Ik Tew. I chose "Bananas" as the opening piece because it embodies many of the thematic elements and concerns that characterize the rest of the collection and presents a kind of schema for the remaining poems. Beginning with its one word title, "Bananas" introduces the controlling metaphor of consumption with allusions to food and eating, body matters and (de)composition, aging and desire, and the "oneness" of all things in creation. Though the title is concrete, the poem's stanzas are increasingly abstract as they make existential statements about youth, experience, and desire. This opening idea of consumption-how our bodies are consumed, how we are consumed by ideas of what is appropriate, right and wrong, important and inconsequential-continues throughout That Terrifying Center as voices speak and shift, drawing us toward their various conclusions.

\section{The Bottom Line}

This first section's poems deal with girls' and women's experiences regarding coming-of-age and ritesof-passage, such as first kisses, murmurings on how babies are made, femininity and "ladylikeness." They also consider women's memories of these experiences of gender socialization, including the conflicting rituals of mating, the challenges of sexuality, and the internalization of all these things. In the title poem, the panty-line or what is under the clothes makes the "lady": appropriate behavior and proper underwear are the "bottom line" of everything. Just as William Carlos Williams states that "so much depends" on a red wheelbarrow, for "ma" of the piece's dedication, security begins with good, supportive undergarments. The right "draws" represent the modesty, wisdom, and composure necessary to make a young girl into respectable young lady. Everything depends upon presentation: what can and cannot be seen as it relates to what happens under a girl's skirt. In poems of The Bottom Line, exchanges, experiences, and memories are focused on the external reality of female form: what the (female) body looks like and how femininity is defined. In "Flash" and "Women's Studies"—we see the kinds of lessons involved in becoming a lady, including how to sit in a skirt, and even how to "[piss] 
like a lady" (12). As in the title epigram, "The Bottom Line," these pieces juxtapose elements of the "proper" and the "crass," raising questions of class, language, and society's constructions of what is appropriate and necessary in the lives of its girls. The colloquial and mathematical occur together, in these poems; the sensuous and the terrible of girlhood and womanhood sit side by side. In the early lessons of sitting properly so as not to expose themselves by "taking pictures," girls also receive early lessons in how to behave in the presence of the opposite sex.

In these lessons, we can see the beginning of gendered constructions of fear-i.e. "genealogies of fear" as in Philip's concept "dis place" and bodymemory discussed in Chapter 1-as they relate to interactions with men, that we learn from our mothers and aunties. Just as we learn manners, we also learn how to be afraid. By drawing its material from family histories, stories and edicts passed from woman to girl, these poems ask us to consider what we have inherited and what we will pass on to our daughters. These pieces include depict gender violence, sexual intimidation and murder, rape, street harassment, among adults as well as school children. They consider the lessons that take place outside of schoo —or in the hallways, under the radar of parents and teachers. - the unofficial, but poignant lessons as children maneuver between innocence and experience. While presenting the building blocks of femininity by questioning what it means to be "girl," "woman," and "lady," these poems also challenge the values placed on certain kinds of women in contemporary urban society, particularly those who are not considered to be "ladylike." Philip explains in "Dis Place" that "'missing' becomes a metaphor for the silence around the text that omits the woman's s/place. Words crowd her out into silence. Women have, in fact, left their mark on the many silences that surround language-we must, therefore, learn to read those silences" (85). These more violent poems of That Terrifying Center and "The Bottom Line" work to recover the silences of the "missing," and "unlooked for" (25), to honor their lives, their bodies, and their words as missing texts to be acknowledged and valued.

\section{Absurdity}

Paraphrased, the opening poem of the second section, says: with the exception of the cancer that is killing her, grandma is fit as a fiddle. By contrasting the presence of cancer with the idea of 
"perfect health," (39) this poem begins the discussion of illness and the body that will follow in this section by questioning cultural conceptions of "health": What does it mean to be "sick"? What is the logic of illness for those who are experiencing it? How does the medical establishment help or trouble the understanding of our bodies as it relates to illness? Continuing with the metaphor of consumption-in the cancer poems we see bodily transformation, wasting (as in the archaic name for tuberculosis), death and dying. The subjects in these pieces are consumed with ideas of illness and the uncertainty of the diagnostic process-as in "Waiting" and "Observation." "Guts" and "Epistemology" are locating or attempting to locate illness and dysfunction within the body. The poems in the section are concerned with bodies as specimens-in "As I Am Prepped for a Sleep Study, I Consider Phrenology," for instance, the body is monitored and "surveilled" until "my pathology is determined/\& I am fixed" (54). Poems in Absurdity still look at relationships between women, between generations; however, instead of focusing on "genealogy," these poems consider genetics-e.g. what is being passed down through the genes and what legacies are left to us, such as legacies of loss and grief, of motherlessness and survival, of illness and disease, of displacement and silences. This section's poems articulate the fears that consume us, the terrors we may never say aloud: that we will die, that we will be eaten from the inside out, that we will become our mothers, that we will succumb to their diseases and inherit their frailties. An emerging concern in Absurdity is one's relationship to her own body--the same body that seems to go haywire in adolescence, but should stabilize in adulthood--changes in the wake of illness, whether one's own or the illness of a parent (mother). How do our corporeal understandings of ourselves transform as we experience illness, undergo medical procedures, experience the pains and uncertainties of a body that may be dying?

Stylistically, the poems in this section employ unconventional syntax, such as disruptive line breaks and shifting uses of space (e.g. by either running words together or creating spatial gaps within and between lines). These disruptions are meant to simulate increasing uncertainty and fragmentation, competing realities, and speculation (as in the mysteries of dying or of what the body is "doing").

Increasingly, the focus of the poems is thought and process-the process of feeling and the movement 
of thought, the mechanics of sensation and the representation of dysfunction (as in "Synapse," "Enjambment," and "Aphasia"). The supposed divisions between body and mind are scrutinized and considered as the view of the body shifts from the externalization of experience to internal realities as related to sensation, grief, and illness.

\section{Conjure Woman}

Whereas Section II - Absurdity is oriented toward interpreting sensation and phenomenological experience (illness, "feeling," and physiological processes in poems like "Synapse," "Enjambment," "Aphasia," and "Epistemology"), Section III - Conjure Woman considers performance and the materiality of the body: how to make sense of this changing body through the creative (the use of poetry, music, and dance). In these pieces, meditations on illness and brokenness give way to constructive experiences of embodiment and performativity such as memory and the body, memory embedded in the body, thought and creativity juxtaposed with the fleshy experiences of race. While memory factors in the earliest poems of That Terrifying Center, the boundaries between discrete memories, storytelling, and one's own subjective experience are noticeably thinner in this section. Rather than considering memory as it takes place in the mind alone, memories in these poems merge and shift. They are etched in the body as in "Muscle Memory"; they merge with historical remembrances as in "Entering the Therapy Spa, I Remember Dorothy Dandridge"; they seem to spontaneously generate themselves from song or spring from collective memory in "Strange Fruit."

Beginning in Section III - Conjure Woman, we get the emergence of multiple selves, the mystical/magical, and the "immaterial" with the sudden disappearance of the body or the utter flooding of the mind with feeling. Rather than terror or the absence of feeling alone, we experience the sumptuous, if complex, pleasures of physical sensation and intimacy (e.g. "Intercourse" and "Jouissance"). What we know about reality is further scrutinized--what is "dead"? ("In Response to TMME," "Here, After" and "Witness"), what does it mean to "be"? The tenuous nature of life and its attendant questions-where are we? when are we? who is we?-that develops in III. Conjure Woman, 
becomes a given in the final section. With the assertion in "Mortal Paradox" that we are simultaneously living and dying, degenerating and regenerating at once (on cellular level) and "Black Girl Eternal's" pronouncement that she has "never not been," Conjure Woman signals our transition into the antigravity terrain of the final section's poems.

\section{Sunterblooms Ik Tew}

The poems in That Terrifying Center are increasingly abstract: we begin with talking about the body and physical phenomena, venturing toward the internal. When we enter the poems of Sunterblooms Ik Tew, the physical body that we are consumed by in the beginning ceases to exist as we know it. In the title poem, the focus is on rhythm, experimentation with language, the re-combining of sound units, and connotation-meaning gathered from feeling, rather than denotation. Through the poems of Abusurdity and Conjure Woman, we encounter aphasia and the interruption of language. Following this fragmentation of language, Sunterblooms Ik Tew gathers the sense-making pieces (i.e. emes) of language and meaning ("Morphology," "Being Contrary," and "Originary") and reevaluates the need for the words. In Sunterblooms Ik Tew, disarticulation is not only imminent, it is necessary. In the closing segment of That Terrifying Center, we have transcended language as we understand it: what exists is sound and connotation. We have translated from thought to flight. Continually moving beyond individual memory and bracketed, discrete time, the poems in this final section accept the reality of the eternal and the coexistence of paradox. These pieces are musings on art, time, and memory. In them everything is possible. If Conjure Woman is the sorting and the processes of interpretation, Sunterblooms Ik Tew contains its conclusions; however, it is not the end. There is no neat resolution, if any at all, only paradox and coexistence.

As in "Bananas," the opening poem, we find rest in the sprawl of eternity and "the everything that has always been." asking questions about the esoteric and metaphysical--the nature of reality, the building blocks of experience, the elements that are suggested in "Elementary Lessons" take center stage in this final segment of the manuscript. Everything is material--"even thought is meat," body and 
mind, concrete and abstract merge. What is emphasized is interconnectedness of the realities internal and external to one's body. A possible subtitle for this dissertation could be "everything is everything" after the vernacular saying, the Donny Hathaway song, and the sentiment that all will be alright. Increasingly, That Terrifying Center is focused on the eternal and the indescribable. In some ways, the Sunterbloom poems go back in time toward the metaphysical, pre-Copernican constructions of material reality suggesting Aristotelian and Pythagorean cosmological approaches to the universe's order and elements--concrete music, celestial, music of the spheres, metaphysics-while holding also to the modes of questioning and exploration of post-Enlightenment thought. The placement of "Metaphysics" and "After Source Code" sequentially, with their competing modes of interpreting existence is emblematic of Sunterblooms Ik Tew's peculiarity. In the universe of That Terrifying Center, both modes are not only possible and equally valid, but both are essential. Music, language, memory, flight singing, film-all of these are the resources that BlackGirl conjures, or employs to heal herselfundermine the conventions of linear time. The otherworldliness of intuition, flight, creativity, point through the flesh toward what we know we feel, even when it cannot be seen. The collection concludes with a sense of peace with the questions, and reconciles the contradictions of embodiment, thought, pain and illness by allowing them to coexist.

The forms of the poems change with the introduction of the Flying From Home cycle, lyric essays, and even shorter lines. Just as the opening piece "Sunterblooms Ik Tew" takes leave of recognizable language, "Undermining Cynicism in the Universe" leaves blanks for the reader to fill. Rather than treating spaces as evidence of aphasia, these spaces represent possibility and meaning beyond any single word. Once the pattern is established, and the momentum built, it is my hope that the sense of what can/should go in the "___ will prevail. That we can more or less agree with what goes in the "___ without needing a literal word to fill the space. That collective readings of the poems, and filling in their blanks, augment the possibilities for engagement. I'm thinking here about Emily Dickinson again and the power of herPoem \#19: "Pain—has an Element of Blank." (1). Though she uses the next five lines to contextualize the "blank" of pain, what remains there is a space for us to fill in 
our understanding of pain's "blankness." Whether we agree with Dickinson's position regarding the nature or quality of pain's "infinite contain" or ability to recollect its origins or future, we do know that the experience of pain is particular and ineffable. We work to find the right cocktail of analogy and articulateness to convey just what pain feels like to us, but ultimately, we must supply our recollection of pain in order to complete the poem's circuit. I was first introduced to Dickinson's poem XIX by Cynthia Hogue's essay on pain, "An Element of Blank" where she considers the impact of chronic pain —hers and Emily Dickinson's-on the poet and how it is borne out in the poems. The "blanks" or "__" in "Undermining Cynicism in the Universe" are my attempt to pull the reader into the poem, to nudge a space for the reader(s) to share in the grasping that I believe is part of poetry's mystery.

These latter poems, truly embody the experimental thrust of my poetry. My goal in That Terrifying Center is to cross the conceptual terrain of the page to connect with my readers in such a way that encourages (even provokes) their engagement. I want my work to resist and disrupt the expectations and assumptions of a singular, autonomous reader "to encourage an enactment of audience that is communal and polyvocular within a culture of dispersed codes and discourses, unowned and unrecognized by any one individual alone" (Kinnahan 88). In much the same way that the speaker in The Ailey Suite can't help but to want to jump up and shout and growl in concert with the dancers' movements ("Breath" 69-70), my poems (and songs and performances) are rooted in the belief that time and space converge to make the sparks of human connection not only possible, but imminent. I conceive of my work as a catalyst for this connection and spark.

\section{Surviving the Borderlands}

As I worked to complete these chapters, I revisited Philip's "Dis Place-The Space Within" and read it with new urgency and connection. I now see That Terrifying Center, and in particular, the Sunterblooms Ik Tew pieces as voicing and translating the language(s) of my inner space. In these poems, I am "peeling back the layers of silencing and finding what 'dis place' is really about. Silence. A different text lying there, a spirit world, an imaginative universe" (103). Using poems and essays, I have 
worked to meet (and exceed) the criteria for obtaining a doctorate in Humanities at the University of Louisville. The nature of this project and its mode of inquiry, were designed with an over-arching project in mind. The poems that I present and contextualize here are my attempts to voice the ineffable. I have channeled my passions, myths, and dreams into poems that invoke the vitality and possibility of living. As black girl and colored woman, as the hunted and the silenced, these pieces collect my earliest attempts to speak in my poet's voice, to articulate my own inner space, and make sense of my own experience of living as contradiction, as soul and body:

To move beyond the boundary of fear-of penetration-unwanted and unwanting$c(o)$ untouring the inner space-to find the source and sound of our silencing, we must become cartographers of silence, mapping not only the known edges-the boundaries of our inner space - but moving beyond the boundary. To take soundings of the deep, where the voice is not one but 'the many-voiced one of one voice/ours...' Polyvocal and many-tongued." (Philip "Dis Place" 106)

When I finished the poems, put them in sections, and re-read them, I learned and began to appreciate the "c(o)untours" of my own silences." The work to recover this space and voice is governed by memory — bodymemory—-that undoes (envelops) the prohibitions of "the outer space" -the MUSN'T DO-and the genealogy of fear. By writing these poems of myself and my mothers and sisters-those known and unknown to me-I am answering Philip's call for "the jamette poet": "Jamette-'A woman possessing both the space between her legs and the space around her. Knowing her place. On the streets [...]To read the silence around the text one must become a jamette poet-possessing the space between the legs-the inner space-uncompromisingly-as the outer space ("Dis Place" 77, 86). Following the lead of warrior poets, artist-theorists, these jamette-poets Audre Lorde, M. NourbeSe Philip, Gloria Anzaldua, Sandra Cisneros, Adrian Piper, Ntozake Shange, Toni Morrison, I am writing beyond fear-of death, of victimization, of shame; I am writing to recover the voices of the lost and silent, to re-territorialize and remap the linguistic and experiential terrains that circumscribe the inner spaces of colored women and girls, the spaces that define us into silence. 


\section{CHAPTER FOUR \\ SHIFTING: GETTING FROM THERE TO HERE; OR, WEIRD WOMEN: A MEDTTATION}

\section{The Problem}

When this project was still. in flux, the title seemed to shift every few months. For a time, at one point it was "Mimeographs." For a time, I was certain it would be "The Acquisition of Vocabulary." Other possibilities burbled up out of the readings and poems, but "That Terrifying Center" has held. It is truly the most appropriate title. This project, these poems-writing about them and about myselfterrified me. I encountered numerous challenges, but some challenges and revelations were more poignant than others. The chief difficulty of writing this dissertation was to produce a creative artifact that could stand on its own, through which I could attempt to articulate my conceptual vision of embodiment and identity. I grappled with approaches to disclosure, negotiating what I must say, what ought to remain unsaid, and the degrees of openness between. But while the writing of a dissertation about my own creative work feels counter-intuitive, artificial, and at times, arbitrary, I've always wanted these poems to retain their magic. I want them to stand within the artistic and cultural contexts of my studies while simultaneously transcending the utilitarian function of the project. I struggled with creating a structured treatment of the poetry manuscript and its themes, as well as plotting its affinities with artists whose works inspire mine. I wanted to present a critical framework shaped by the concepts and strategies of artists/cultural critics Sandra Cisneros, Audre Lorde, Marlene NourbeSe Philip, and Harryette Mullen.

To accomplish the goals of this dissertation, I asked myself questions. Lots of questions. I stalled and I paled. I endured lots of nausea. I scribbled and I typed. I answered the questions that 
Dr. Chandler sent me to prompt my writing. Questions like: "How has the desire to write about illness and pain led me to write about the body and language?" I asked myself. "What does a poetry/creative dissertation accomplish that a research dissertation would not—or could not?" Ultimately, a hybrid, multivalent project is most appropriate for my elastic, multidimensional subject matter-selves, bodies, memories. Poetry allows me room for contradictions, questions, processes, subjectivities, profundities, fragments, experimental grammars; I can run on and on, connecting my clauses with conjunctions and fancy-free punctuation, and let them go completely nude as commas go, mixing my metaphors in ways not readily acceptable in expository or scholarly writing. I can reconsider the rules-even my own-for the sake of what's needling and stammering for articulation. In the domains of poetry, I can tinker with space and time in ways that are impossible elsewhere. I can consider vernacular magics and folk beliefs, ritual, incantation alongside ruminations on feminist theory and cultural critique, make them trade $2 s$ or $4 s^{8}$, switching between rhythms to simulate sensation and the whir of thought. Poetry allows me to explore more thoroughly the paradoxes of being many-selved in an ever-changing body, in ever-changing times and contexts, with ever-changing perspectives. The critical chapters are necessary because they push me to explain what I mean, to show my work, to clarify and unravel. Each element, whether creative or discursive, challenges me to say what I mean. In this chapter, I want to consider the poems of That Terrifying Center and the accompanying chapters through a more fluid and lyrical narrative approach.

Getting Into The Project

In this creative project, I excavate my own interior thoughts and sensations; I attempt to narrate my discoveries and experiences of embodiment, as well as those of speakers and personae who are not me. My collection of poems asks questions and works to translate languages of femininity, of becoming woman, of demystifying fear, tracing genealogies of pain, narratives of survival, and

\footnotetext{
${ }^{8}$ In jazz, players within a band may alternate brief solos in the course of a song. These solos occur in increments of two (or four, or eight) measures. This is referred to as trading twos (fours, eights, and so forth). The aim is to disrupt the current rhythm by inserting increasingly intense rhythmic and melodic themes before returning to the main body of the song.
} 
strategies for creativity. To do this, I have appropriated approaches to autography and self-portraiture from artists whose work prefigures mine. This nucleus, chambered and robust, was not apparent when I began planning for my dissertation topic back in 2007. This project started as a way of understanding the body that I first believed to be dying - and later, to be treasonous. The direction to study bodies, pain, and sickness was an attempt to codify the development of my self-concept as a chronically ill person. The creative exercise would give me permission to experiment, to navel-gaze in ink and graphite. But as I have come to understand better what my body was telling me, as I have come closer to translating the internal chaos, and transmitting this chaos to others who were willing to understand the mysteries of chronic, debilitating, phantom illness, I have begun to recognize the shifting, changing selves that I'd always been.

Ruminations on sickness, pain and the polyvocal possibilities of poetry coalesced in $\mathrm{Dr}$. Simona Bertacco's Spring 2007 course, Postcolonial Bodies. I had been chronically sick for about two years and still did not know why. I was undergoing numerous expensive and increasingly exploratory diagnostic tests that were ultimately fruitless. At the same time, I was being introduced to new poets and gaining the language to talk about materiality and subjectivity; I was reading Fanon's "The Fact of Blackness" in Black Skin, White Masks for the first time. M. NourbeSe Philip's "Meditations on the Declension of Beauty" was one text that really snared me. There were so many voices asking repeating questions: "If not in yours/in whose/lan lan lan language/am I/ beautiful? (Philip 52, 53) Philip was doing it all with language, using grammar's rules, space, and structure to interrogate racialist notions of beauty and worth. It all resonated with me. In Dr. Bertacco's class, we were looking closer at what conventional Western wisdom supposes to be irrefutable - the Cartesian separation of mind and body, geographies, and social landscapes. These new questions and readings revitalized my research and dissertation thoughts. I wanted to explore blackness, beauty, and other extensions of embodiment as considered in Fanon and Philip's work in more focused ways; I wanted to put to good use the new terminologies I was encountering in my courses. I started looking for answers to my multiplying 
questions. I was reading Bhabha and Butler and Rich and having trouble finishing my papers because of the migraines. This intersection of theory, narrative, and my own life made the project of embodiment and identity both imminent and necessary for me.

\section{Shifting Perspectives: Writing Illiness, Embodiment, and Identity}

I began writing poems and researching embodiment with the desire to explore how the shifting sense of oneself must change to accommodate the body, and accept the new "sick identity" and its realities, e.g. its uncertainties, prescriptions, examinations, procedures, medicalized languages, and its provisional and capricious composition of "good days" and "bad days." My own physical pain was constant; the severity, location, duration, and other particulars were unpredictable. But as I began to interrogate my body and settle into the routines of pain, self-protection, and daily management, I understood more fully that my body, myselves, enmeshed and interpenetrating, have always been broader and deeper than pathology and pain. At first, pain and illness were all I could see. Every day was uncertainty, vulnerability, fear that I was either dying or out of my mind-this creative project grew out of dysfunction-like Vivian Bearing in Margaret Edson's play, Wit, I was "distinguishing myself in illness."

In the five or so years since I began to document my illness-in life, in research-I'd been thinking about bodies. Selves. Interiors. How to share, to bear, to trust. Disclosure. Composure. Desire. Revulsion. Exclusion. Attraction. I have always been enamored with language. I wanted to look closer at how what we say and how we mean affect the way we receive-and how we are perceived by-others. How do we make sense of the body? How to understand and articulate what the body says, even without speaking? What it meant to be myselves in this body was changing-and yet, it had never not been changing. My body and identity had always been shifting and provisional. Only in looking more closely at the subject of my studies-myselves-was I able to regard its impossible angles. This gradual shift in focus regarding mybody parallels my changing perspective of my mother's illness from stomach cancer, her death, and-more imminently, it seemed-my own. Taking a moment to look at 
how my life as a poet was initially linked to grieving for my mother and processing this grief and my changing relationship to her, I hope it'll be a bit clearer how and why this dissertation's focus has shifted from a study of an illness-centered identity to the articulation of the many selves that are housed in any one body.

I started to really write after my mother was already dead. She died the May before my senior year of college. The stomach cancer that she'd been bargaining with finally took her from us two weeks after Mother's Day in 2001. In the latter months of her illness, I began feeling the pull to write. More than the school essays and papers I'd written since the 9th grade, different from the close readings of literature for my courses, or for fun, this was a new kind of writing. I began to feel stirrings of more that needed to be articulated, but instances of more personal writing had soured me on opening myself to the scrutiny that creative writing could bring. I did some reluctant writing; interpretation of established literature was safer. In that period following Ma's passing, however, I became desperate: I was in my senior year of college and a "deep," brooding English major/musician and I needed answers. And so I began to write--first dense, inscrutable poems in the style of Donne and Jonson just infected with poorly executed metaphysical conceits. Consequently, I was the only one who had any clue of what I was talking about. Then in a course with Dr. Karah Stokes, I started experimenting with creative nonfiction. It enabled me to explore more volatile emotional terrain, while using a format that was comfortable to me. I used those essays to revisit my mother's stories, to examine her absence and her legacy; I was plumbing my memories of her and trying to keep them close. In this writing, some of which is included in That Terrifying Center, there was the shocking immediacy of my grief, my outrage at the ravage of cancer. I collected her lifetime-worth of stories, her warnings, what she loved, and what she'd left to me. I gained confidence enough to try poems. And I even won Kentucky State University's Richard Taylor Creative Writing Award for one of my essays, "Walking in Borrowed Shoes," and a handful of my poems were published in the university literary journal, The Kentucky River. It was in those early days of writing, of chancing looks into my past and scribbling my findings, that helped me trust what poetry could do. 
This May (2011) marks 10 years since my mother's passing. In those 10 years, I've continued to write poems-thankfully more coherent than one in particular I wrote for Dr. Taylor's poetry course my senior year-but I've started writing songs, too. I've finally started submitting my work and seeing it published, as Dr. Stokes had been urging me to do since 2001 or so. I'm being accepted among poets that I respect. I've continued to explore my experiences, consider my messages, and share my mother's life in song. With the distance and remove of time, my perception - of Ma's death, her life, her struggles; our similarities, our differences; the evolution of my own life- had been augmented. I can see her more clearly. Though in linear time she does not change-at least not in any way that I want to consider at the moment-the vantage points at which I am able to view her, are continually shifting through time, memory, and maturity. As these perceptions of my mother shift, our relationship shifts. I can question her accounts of things now without fear of blasphemy. I can see her as a woman in context now, not just "Ma," because I am a woman now. I can see her in my face. Now, I can recognize her in myself, now, I can better appreciate where we diverge. My work on my mother, just like my work on illness, bodies, and selves, has been shifting incrementally, and with it, the framing of this project. That Terrifying Center is a collection of poems about space, materiality, and the terrain of memory. It is a creative and critical experiment in capturing the grueling, beautiful work of becoming.

These poems consider black girlhood as it matures within landscapes of fear, transmitted narratives of exploitation and agency, of vulnerability and stubborn survival, of power and weakness, illness and health, pain and ecstasy. It would be impossible to render the lived experience of pain and illness of mybody with any integrity if I neglected also to present the magic of healing and performance, the otherworldly transubstantiation of space that only human bodies-even painful, sick ones-can mediate. I could not truly represent mybody without considering fleeting pleasures of touch and companionship and passion, the conjure of collective selves. How could I write mybody and its daily regeneration, its making, its fleshy selves, and not explore singing and the mystery of performance? I have been soothing myself with song since I was too small to know any better and singing for others since I was 10 years old. I can't truly represent what it means to be a multiplicity of 
selves without the presence of music, of hums. That's who I am and have been for two thirds of my life. Even still, I only recently learned to appreciate my voice as being uniquely mine. Only in the last handful of years have I explored the flexibility and value of my singing voice, of my composer's voice. Only recently have I truly acknowledged that songs of encouragement and of beauty come through me. That I am a kind of channel for vocalization—through song, through language, through poetry. These gifts come through the same body that creaks and slows-the same body that I sometimes believe betrays me is the same body that saves me. The mind, weighted with melancholy and circuitous in its grooves, receives and transmits images of wonder and hope. The perspective that is fearsome and painful can serve, on the most miraculous of days, as a conduit of understanding and peace. And so the questions that I posed in my comprehensive exams and proposals are still relevant. I suspect they always will be: what are the languages of bodies? Where do bodies and selves converge, where do they part? How can I articulate contexts of historical "readings" of bodies--race, class, gender, ability, beauty? How are these bodies read? How do we read ourselves? What can we disclose about ourselves and why? Are there degrees of openness? How do we compose and fashion our selves for the consumption by and interaction with other selves? These are the questions I'm still working to phrase. These are questions that I'm still working to answer.

\section{Emerging from the Core}

As the project at hand draws to a close, I realize these questions of embodiment and selvedness are ongoing for me. That in a way, I'll be writing some version of the same poem throughout my life. That as my physical condition changes due to improving or worsening health, the natural wear $\&$ tear of living, or my otherwise unknowable future, my poetics may very well change, too. I can look at these poems and see how varied, yet similar they are; how they resonate with works by other poets that I'm only now discovering; how they remind me of pieces and circumstances that I read years ago. I'm finding out that the questions I'm asking aren't so strange after all, that women have been forming and posing - living - their questions since before I was born, concurrent with my life, and somehow, the discussion has waited for me, is still moving forward and backward through 
time. I'm able to offer my own questions. And render some strategies for better navigating the boundaries and openings of flesh and of gristle.

So-what is my "terrifying center"? As it appears to me now, at the middlest point where myselves and mybody meet, fear has suspended itself there. My poems have shown me that I am afraid: that my offerings, my deepest stirrings of poems and songs, will be rejected, ignored-or worse- misunderstood. That my motives for writing these poems, and these pains, will be scrutinized and misread. That calling up these poems from the center of my interlocking darknesses will only invite ridicule-not understanding. I am afraid that I will always be afraid. And yet, this fear keeps me moving. If I can call my fears by their names, if I can admit that I am afraid without shame, if I can drag them into the light, gut and study them, then nothing is impossible. I can keep writing, keep singing, keep extending myself, pushing through what hurts me so "that the pain be not wasted" (Lorde 10), so that others can believe and endure and know what everyday folks made of wind and muck and stardust can do.

Looking through these poems and realizing how macabre and painful they are, I have winced and blanched. But now that I can see and articulate how the work of warrior poets like Lorde, Cisneros, Philip, and Mullen girds mine, when I stand back from this collection and attempt to read it with the eyes of someone outside of myself, I'm only mildly horrified. And when I'm not horrified by the admissions and the death and the fear, I am sometimes moved. By the bravery. The play. The sweetness. But mostly, I ask questions-Why do I write women consistently-and then so grimly? Why so much fear and caution? And death. Plenty of death. Because learning to be alive and woman, is learning to navigate fear and death, but beauty and magic, also. What about men? Why are they portrayed so negatively? All men aren't portrayed negatively, only the malevolent, abusive, lecherous ones. Murderers and misogynists and catcallers and ragtag men who follow women around libraries masturbating into books? Well, I seem to have drawn the devil horns on them, haven't I? But I suppose villainy is relative: many of those kinds of men get away with their badness and so they actually seem to fare pretty well-regardless of my representation of them here, in these pages. And very likely, those 
men will not read these poems. The women who bear these incidents inside themselves-they will these fears like treasured heirlooms through their flesh to their children, to generations of children. And not only women propagate these lineages of fear-my father taught me to be wary of men. I don't mean by his actions or attitudes, but literally. He told me not to trust boys, to protect myself from men-that they would say anything, do anything. And that caution was reinforced in the stories he told, the warnings that I was to heed. And by the things that he never said. Even though he-and my husband and brother and friends - are usually exempted as "a good man" (inasmuch as any of us are good), many, many more are not. Too many are "ferocious for little girl flesh." Boys often do get away with intimidating and harassing girls in school. And those mannish boys can be goaded or neglected into becoming mean, aggressive, murderous men who believe that meanness is the measure of a man. Or when I am feeling sympathetic and want to remember that I believe in grace, I think: even those men belong to someone. Perhaps the men who are/become our society's sexual deviants and so-called perverts are victims as well. Perhaps they are heirs to painful, fearful legacies as well. I write these things because I was raised to be afraid. To believe that I was precious-precious enough to protect, precious enough to be hunted and abducted. Sweet enough to be ravaged. And if I didn't want to be another stupid/pitiful/dense/pregnant/dead black girl in Detroit, I'd lock myself in a fortress and fight to stay alive-and alone. That living to see 45 meant being impregnable and nobody's fool.

Stories like "Rose" and that of Debbie's mother in "Of Fences" are true-they represent Marlene NourbeSe Philip's notions of "bodymemory" and "dis place." They are not all my personal stories. I am not always myself in these poems-even when wearing the same face. But the fear and caution are always true. I witnessed and understood genealogies of pain in practice long before I ever encountered them in print. I've known these fears-and their attendant contradictions-all of my life. Audre Lorde's "Litany for Survival" told me that I wasn't alone: the image of fear imprinted on our foreheads and passed through our mother's milk stirred me up. It was the first time I could actually know why I was so afraid, protective over my body, why I walked so fast and was slow to smile or speak. Why I just might cut a mother over the exploitation and victimization of girls and women. One 
of my earliest movie memories is the rape scene in The Accused. I was about 8 years old. I can still see the flex and thrust of the man's pale buttocks, and the other men watching, waiting for their turn. I remember my mother's warnings as I got older, long before I needed them-giving them time to soak and fuse as my bones lengthened and fused. I wasn't alone in my fear and caution. There were others like me who'd internalized the stories-of mickeys in drinks, of foiled rapes, of great uncles who'd been stabbed for trying to "mess with" somebody's little girl—or little boy. And no matter what my mama or the afterschool specials said, I feared I'd never be safe enough and that should something happen, well, maybe I hadn't been careful enough; maybe I shouldn't be so sweet/pretty/mouthy/mean/bossy/stuck up-maybe I deserved it because I let it happen.

While I am writing this meditation, I'm thinking of my high school friend, Daphane Ramey, who was murdered this past March, just outside Detroit's city limits. When I initially began this meditation—-this sentence read "who was murdered last week." And while the months have passed, I still remember how we sang together in school, and thinking-she was only 28 years old, with dimples like commas, who taught autistic babies, who was a mama, and who is now not-she no longer is. She's not soaking up her summer break before the school year begins, and her classroom awaits her, new challenges await her, because the ex-con that she was breaking up with had different ideas. I don't know how long they were together or the nature of the break-up. But I do know that he shot her in the doorway of her house. I know that he shot her once and she fell. And then he stood over her and fired three more shots to make sure. I know that he turned, walked back to his car across the street and drove away. The security footage of the liquor store across the street tells me so. I know that her 7 year old son was home. And her 12 year old niece had to call the police and shuttle the little one past his only mama bleeding out in the doonway of their home. I know that Daphane probably had no idea that he hated her enough to kill her. I don't know where he went after he murdered my friend. But I do know that the police said -you can run but you can't hide - but he ran and hid anyway, and that he got away, that he rode out on the slug that he put in his own brain. I'm thinking of Daphane and Aunt Rose and Grandma Gussie and those eleven women (and who knows how many others) slain and stowed in 
Cleveland and the others whose stories ended before page 45. And the little girl in California who got pretty for the dance but ended up dirty and torn. And little girls who ride buses and who are unafraid. I wonder whether I want them safely and firmly entombed in fear-or to know that the streets and the buses and their bodies are theirs. And their stories are theirs to tell or keep. And their voices, wonderful and growing and changing, are beautiful. And as I think these things, I know that I am changing, that I am "flowing through selves" toward me.

These poems—while varied in their subject matter and forms to an extent-are an attempt to write my stories, and my mother's mothers' stories, to capture our voices-my voices-and to speak for those who are afraid to break the silence, too afraid to pose the question, who died before they could, or who've been cowering for so long they've forgotten why they are afraid. They've been afraid so long, they fear themselves. That is the heart of these poems. The fearsome examination of what we don't want to believe is true, or what we want to forget, of what we can only imagine. And the telling of it as jamette, as forked-tongued poet, bearer of truth and testimony. That terrifying center is indeed a poem, "a universe drawn tight by memory" (Philip "Meditations" 105). It is the sounding of the inner spaces. These voices, these poems, this flesh. Laying the deepest folds of our selves open to consider the dazzling, meaty, contradictory interiors that we carry within we. These interiors that we have inherited, that we pass on. That we become. That become us. The tangle of questions that have always been; the answers that have always been yes.

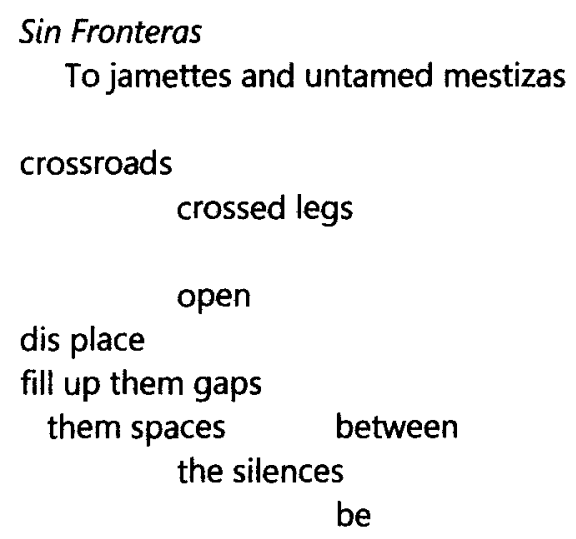




\section{REFERENCES}

Abdulatief, Soraya. "Disciplined Bodies and (Dis)orderly Women in Tsitsi Dangarembga's Nervous Conditions." Inter Action 3: Proceedings of the Third Postgraduate Conference. Ed. Chris Roper, et. al. Bellville: UWC $P$, (1995): 10-15. Print.

Alexander, Elizabeth. "Coming Out Blackened and Whole: Fragmentation and Reintegration in Audre Lorde's Zami and The Cancer Journals." Skin Deep, Spirit Strong: The Black Female Body in American Culture. Ed. Kimberly Wallace-Sanders. Ann Arbor: The U of Michigan P, 2002. 218-36. Print.

---. "Memory, Community, Voice." Callaloo 17.2 (1994): 408-421. JSTOR. Web. 28 Nov 2006. Ankori, Gannit. Imaging Her Selves: Frida Kahlo's Poetics of Identity and Fragmentation. Westport: Greenwood P, 2000. Print.

Anzaldua, Gloria. La Frontera/Borderlands: The New Mestiza. $2^{\text {nd }}$ ed. San Francisco: Aunt Lute, 1999. Print.

Bakare-Yusuf, Bibi. "The Economy of Violence: Black Bodies and the Unspeakable Terror." Feminist Theory and the Body: A Reader. Ed. Janet Price and Margrit Shildrick. New York: Routledge, 1999. 311-23. Print.

Baker, Houston. Workings of the Spirit: The Poetics of Afro-American Women's Writing. Chicago: U Chicago P, 1991. Print.

Ball, M. Charlene. "Old Magic and New Fury: The Theophany of Afrekete in Audre Lorde's 'Tar Beach"' NWSA Journal 13.1 (2001): 61-85. Print.

Bauer, William R. Open the Door: The Life and Music of Betty Carter. Ann Arbor: U of Michigan P. 2003. Print. 
Bennett, Michael and Vanessa D. Dickerson, eds. Recovering the Black Female Body. New Brunswick: Rutgers University Press, 2001. Print.

Betterton, Rosemary. An Intimate Distance: Women, Artists, and the Body. New York: Routledge, 1996. Print.

Bhabha, Homi K. "The Other Question: Difference, Discrimination, and the Discourse of Colonialism." Black British Cultural Studies: A Reader. Ed. Houston A. Baker, Jr., Manthia Diawara, and Ruth H. Lindeborg. Chicago: $U$ of Chicago P, 1997. 87-106. Print.

Borsa, Joan. "Frida Kahlo: Marginalization and the Critical Female Subject." Third Text 12 (1990): 21-40. Print.

Butler, Judith. "Bodily Inscriptions, Performative Subversions." Gender Trouble: Feminism and the Subversion of Identity. New York: Routledge, 1990. 128-41. Print.

---. "Gender is Burning: Questions of Appropriation and Subversion." Undoing Gender. New York: Routledge, 1993. 121-40. Print.

Carr, Brenda. "To 'Heal the Word Wounded': Agency and the Materiality of Language and Form in M. Nourbese Philip's She Tries Her Tongue, Her Silence Softly Breaks." Studies in Canadian Literature / Études en littérature canadienne 19.1 (1994): n. pag. Web. 3 Nov. 2011.

Charon, Rita. Narrative Medicine: Honoring the Stories of Illness. New York: Oxford UP. 2006. Print.

Cisneros, Sandra. "A Writer's Notebook: 'Ghosts and Voices: Writing from Obsession," "Do You Know Me? I Wrote The House on Mango Street," and "Notes to a Young(er) Writer." The Americas Review 15.1 (1987): 69-73,74-76, 77-79. Print.

---."Guadalupe the Sex Goddess." In Goddess of the Americas, ed. Ana Castillo. New York: Riverhead, 1996. Print.

---."It Occurs to Me I Am the Creative/Destructive Goddess Coatlicue." The Massachusetts Review 36.4 (1995): 599. Print. 
---.My Wicked, Wicked Ways. Berkeley: Third Woman, 1987. Print.

--.. "On the Solitary Fate of Being Mexican, Female, Wicked and Thirty-three: An Interview with Writer Sandra Cisneros." Aranda, Pilar E. Rodriguez, ed. The Americas Review 18.1 (1989): 64-80. Print. Cliff, Michelle. "Object into Subject:" Making Face, Making Soul/Haciendo Caras: Creative and Critical Perspectives by Feminists of Color. Ed. Gloria Anzaldua, 1990. 271-90. Print.

Clifton, Lucille. Good Woman: Poems and a Memoir 1969-1980. Rochester: BOA Editions, 1987. Print.

---Quilting: 1987-1990. Brockport: BOA Editions, 1991. Print.

Cottingham, Laura. "The 'Autobiography' of Adrian Piper." Adrian Piper: A Retrospective, 1965-2000. 1999. 60-74. Print.

Cummings, Allison. "Public Subjects: Race and the Critical Reception of Gwendolyn Brooks, Erica Hunt, and Harryette Mullen. Frontiers 26.2 (2005). Project Muse. Web 23 Feb 2011.

Davies, Carole Boyce. Black Women, Writing and Identity: Migrations of the Subject. New York: Routledge, 1994. Print.

DeShazer, Mary K. "'Sisters in Arms': The Warrior Construct in Writings by Contemporary U.S. Women of Color." Writing the Woman Artist: Essays on Poetics, Politics, and Portraiture. Ed. Suzanne W. Jones. Philadelphia: U of Pennsylvania P, 1991. 261-86. Print.

DuPlessis, Rachel. The Pink Guitar: Writing as Feminist Practice. New York: Routledge, 1990. Print. Edson, Margaret. Wit. London: Faber \& Faber, 1999.

Eliot, Thomas Stearns. "The Love Song of J. Alfred Prufrock." The Collected Poems: 1909-1962. Centenary Edition. New York: Harcourt, 1991. 3-7. Print.

Fanon, Frantz. Black Skin, White Masks. Berkeley: Grove Press, 1969. Print.

Farris, Phoebe, ed. Women Artists of Color: A Bio-Critical Sourcebook to $20^{\text {th }}$ Century Artists in the Americas. Westport, CT: Greenwood, 1999. Print.

Finney, Nikky. "My Centipeding Self." Rice. Ottawa, Ontario: Sister Vision, 1995. 46-47. Print. 
Frank, Arthur. The Wounded Storyteller: Body Illness and Ethics. Chicago: U of Chicago

P, 1995. Print.

Frost, Elisabeth. Feminist Avant-Garde in American Poetry. Iowa City: U of Iowa P, 2003. Print.

--.. “'Ruses of the Lunatic Muse': Harryette Mullen and Lyric Hybridity. Women's Studies 27 (1998): 465-81. Print.

---. "Signifyin(g) on Stein: The Revisionist Poetics of Harryette Mullen and Leslie Scalapino." Postmodern Culture 5(3): 1995. Project Muse. Web. n. pag. 23 Feb 2011.

---." 'Sleeping with the Dictionary: Harryette Mullen's 'Recyclopedia'" Rankine and Spahr, Print.

Himid, Lubaina. "Mapping: A Decade of Black Women Artists 1980-1990." Passion: Discourses on Blackwomen's Creativity. Ed. Maud Sulter. Hebden Bridge: Urban Fox P, 1993. 63-72. Print. Hinton, Laura and Cynthia Hogue, eds. We Who Love to Be Astonished: Experimental Women's Writing and Performance Poetics. Tuscaloosa: $\mathrm{U}$ of Alabama P, 2002. Print.

Hirsch, Marianne and Valerie Smith. "Feminism and Cultural Memory: An Introduction." Signs 28.1 (2002): 1-19. Print.

Hogue, Cynthia. "'An Element of Blank': On Pain and Experimentation." Titanic Operas: A Poet's Corner of Responses to Dickinson's Legacy. Web. n. pag. 6 October 2007.

Howe, Fannie. "The Future is Like Magic: A Notebook." Poetry 193.3 (2009). 537-48. Print.

Jones, Suzanne W., ed. Writing the Woman Artist: Essays on Poetics, Politics, and Portraiture. Philadelphia: $U$ of Pennsylvania P, 1991.

Kahlo, Frida. The Broken Column. 1944. Painting. Museo Dolores Olmedo, Xochimilco, Mexico City, Mexico. Art Through Time: A Global View. Web. 1 Dec 2011. e --. Study for Remembrance of an Open Wound. 1938. Drawing. Frida Kahlo: The Paintings. Ed. Hayden Herrera. New York: Harper Collins, 1991. Print.

Kinnahan, Linda A. Lyric Interventions: Feminism, Experimental Poetry, and Contemporary Discourse. Iowa City: U of Iowa P, 2004. Print. Lauter, Estella. "Re-visioning Creativity: Audre Lorde's Refiguration of Eros as the Black 
Mother Within." Writing the Woman Artist: Essays on Poetics, Politics, and Portraiture. Suzanne W. Jones, ed. Philadelphia: U of Pennsylvania P, 1991. 398-417. Print.

Lempert, Brian. "Harryette Mullen and the Contemporary Jazz Voice." Callaloo 33.4 (2010). Project

Muse. Web. 23 Feb 2011.

Lorde, Audre. A Burst of Light: Essays by Audre Lorde. Ithaca: Firebrand Books, 1988.

---. The Cancer Journals. San Francisco: Aunt Lute Books; Special edition, 2006. Print.

---. The Collected Poems of Audre Lorde. New York: Norton, 2002. Print.

---. Sister Outsider: Essays and Speeches. Berkeley: The Crossing P, 1984. Print.

Luck, Jessica Lewis. "Entries on a Post-Language Poetics in Harryette Mullen's Dictionary."

Contemporary Literature 49. 3 (2008). Project Muse. Web. 23 Feb 2011.

Mackey, Nathaniel. "Cante Moro." Sound States: Innovative Poetics and Acoustical Technologies. Ed.

Adalaide Morris. Chapel Hill: U of North Carolina P, 1997. 194-212. Print.

Mance, Ajuan Maria. "Re-locating the Black Female Subject: The Landscape of the Body in the Poems of Lucille Clifton." Recovering the Black Female Body Self-Representations by African American Women. New Brunswick: Rutgers UP, 2001. 123-140.

Martin, Rosy. "How Do I Look?" Foreword. The Art of Reflection: Women Artists' Self-Portraiture in the $20^{\text {th }}$ Century By Marsha Meskimmon. New York: Columbia UP, 1996. xv-xvii. Print.

McKittrick, Katherine. " 'Who Do You Talk To When a Body's in Trouble?': M. Nourbese Philip's (Un)Silencing of Black Bodies in the Diaspora." Social \& Cultural Geography 1.2 (2000): 223-36. Print.

Merleau-Ponty, Maurice. "The Experience of the Body and Classical Psychology." The

Body: A Reader. Ed. Mariam Fraser and Monica Greco. New York: Routledge, 2005. 52-54. Print. Meskimmon, Marsha. The Art of Reflection: Women Artists' Self-Portraiture in the $20^{\text {th }}$ Century. New York: Columbia UP, 1996. Print. 
Modleski, Tania. "Postmortem on Postfeminism." Feminism Without Women: Culture and Criticism in a 'Postfeminist' Age. New York: Routledge, 1991. 3-22. Print.

Morris, Margaret. "Audre Lorde: Textual Authority and the Embodied Self" Frontiers: A Journal of Women Studies 23.1 (2002). 168-88. Print.

Mullen, Harryette. "Poetry and Identity." Telling It Slant: Avant-Garde Poetics of the 1990s. Ed. Mark Wallace and Steven Marks. Tuscaloosa: U of Alabama P, 2002. 27-31. Print.

---. "Conversation with Harryette Mullen: From A to B." With Barbara Henning. Series. Web. n. pag. 15 Mar 2011

---. "Interview with Harryette Mullen." With Cynthia Hogue. Postmodern Culture: An Electronic Journal of Interdisciplinary Criticism 9.2 (1999): 36 pars. 8 Jul. 2005 Project Muse. Online. n pag. Web. 15 Mar 2011.

---. Recyclopedia: Trimmings, $S^{\star} P e R M^{* \star} K^{\star} T$, and Muse \& Drudge. Minneapolis: Graywolf $\mathrm{P}, 2006$. Print. --.- "The Solo Mysterioso Blues: An Interview with Harryette Mullen." By Calvin Bedient. Callaloo 19.3 (1996) 651-69. Print.

---.Sleeping with the Dictionary. Berkeley: U of California P, 2002. Print.

Neumaier, Diane, ed. Reframings: New American Feminist Photographies. Philadelphia: Temple UP, 1996.

Perreault, Jeanne. Writing Selves: Contemporary Feminist Autography. Minneapolis: U of Minnesota P, 1995. Print.

Philip, Marlene NourbeSe. "A Poet of Place: An Interview with M. NourbeSe Philip." Interview by Kristen Mahlis. Callaloo 27.3 (2004): 682-697. Print.

---."Dis Place-_"The Space Between." A Genealogy of Resistance:

And Other Essays. Georgetown, Ontario: Mercury P, 1998. 74-112. Print.

---."The Habit Of: Poetry, Rats and Cats." A Poetics of Criticism. Ed. J. Spahr and M. Wallace. Buffalo, NY: Leave Books, 1994. 209-13. Print. 
---. Looking for Livingstone: An Odyssey of Silence. Toronto, Ontario: Mercury P, 1991. Print.

--.."Meditations on the Declension of Beauty by the Girl with the Flying Cheekbones." She Tries Her Tongue, Her Silence Softly Breaks. Charlottetown, PEI: Ragweed P, 1988. 60-61. Print.

Pindell, Howardena. Autobiography: AIR/CS560, 1988. Mixed Media on Canvas. Detroit Institute of Arts, Detroit. Art at the DIA. Web. 1 Dec 2011.

--.. Autobiography. Earth/Eyes/Injuries, 1987. Mixed Media on Canvas. G.R. N'Namdi Gallery, Chicago. G.R. Nanmdi Gallery. Web. 1 Dec 2011.

---.Autobiography: Water/Ancestors/Middle Passage/Family Ghosts. 1988. Mixed Media on Canvas. The Wadsworth Athenaeum Museum of Art, Hartford, CT. The Legacy Project. Web. 1 Dec 2011.

-... Free, White, and 21. 1980. Video. Museum of Modern Art, New York. Museum of Modern Art Collection. Web. 1 Dec 2011.

Pindell, Howardena and Lowery S. Sims. The Heart of the Question: The Writings and Paintings of Howardena Pindell. New York: Midmarch Arts P, 1997.

---Paintings and Drawings: A Retrospective Exhibition, 1972-1992. Potsdam: SUNY, Roland Gibson Gallery, 1993. Print.

Piper, Adrian. Adrian Piper: A Retrospective, 1965-2000. Issues in Cultural Theory, No. 3

Ed. Maurice Berger. Text by Laura Cottingham. Baltimore: UMBC Fine Arts Gallery, 1999. Print. --. Self-Portrait as a Nice White Lady. 1995 .Photograph altered with Oil Crayon. Collection of the Artist. "Adrian Piper. A Conversation" with Thomas Sokolowski. Carnegie Magazine. 1 Dec 2011 ---. Self-Portrait Exaggerating My Negroid Features. 1981. Pencil on Paper. Collection of Eileen Harris Norton. The Twentieth Century Art Book. New York: Phaidon. 396. Print.

--.."The Problematic Solution. Out of Order, Out of Sight: Selected Writings in Art Criticism 1967- 1992.

Vol. 2. 93-104. Print.

---. "The Triple Negation of Colored Women Artists." The Feminism and Visual Culture Reader. Ed. Amelia Jones. New York: Routledge, 2003. 239-248. Print. 
Rankine, Claudia and Juliana Spahr, eds. American Women Poets in the 21st Century. Where Lyric Meets Language. Middletown, CT: Wesleyan UP, 2002. Print.

Reneau, Ingrid. "Introduction." Blessings for a New World: Poems by Estella Conwill Majozo.

Paintings by Tom Feelings. Chicago: Third World, 2007. xi-xiii. Print.

Rich, Adrienne. "Notes Toward a Politics of Location." Blood, Bread, and Poetry: Selected Prose 1979-1985. New York: W.W. Norton \& Co., 1986. 210-33. Print.

-.-."When We Dead Awaken: Writing as Re-Vision." College English 34.1 (1972): 18-30. Print.

Robbins, Amy Moorman. "Harryette Mullen's Sleeping with the Dictionary and Race in

Language/Writing." Contemporary Literature 51.2 (2010). Project Muse. Web. 23 Feb 2011.

Rose, Gillian. "Women and Everyday Spaces." Feminist Theory and the Body: A Reader.

Ed. Janet Price and Margrit Shildrick. New York: Routledge, 1999. 359-70. Print.

Rudnitsky, Lexi. "The 'Power' and 'Sequelae' of Audre Lorde's Syntactical Strategies" Callaloo

26.2 (2003): 473-85. Print.

Saar, Betye. Black Girl's Window. 1969. Mixed media assemblage. Michael Rosenfield Gallery, New York.

Artconversations Archive. Web. 1 Dec 2011

-.-. In My Solitude. 1983. Installation. California State University, Fullerton, CA. San Francisco Museum of Modern Art Video Archive. Web. 1 Dec 2011.

---. Self-window with Reflection. 1970. Mixed Media Assemblage Window. Private Collection. Betye Saar By Jane H. Carpenter with Betye Saar. Beverly Hills: Pomegranate. Plate 13. 2003. Print.

Sanborn, Geoffrey. "Keeping Her Distance: Cisneros, Dickinson, and the Politics of Private

Enjoyment." PMLA: Publications of the Modern Language Association of America 116.5 (2001):

1334-48. Print.

Scarry, Elaine. The Body in Pain: The Making and Unmaking of the World. New York and Oxford:

Oxford UP, 1985. Print.

Simone, Nina. "Definition of an Artist." Protest Anthology. (p) 2007 Andy Stroud, Inc. Audio.

Simpson, Megan. Poetic Epistemologies: Gender and Knowing in Women's Language-Oriented 
Poetry. Albany: SUNY P, 2000. Print.

Sleigh, Tom. Interview with a Ghost. Minneapolis: Graywolf P, 2006. Print.

Sulter, Maud, ed. Passion: Discourses on Blackwomen's Creativity. West Yorkshire: Urban Fox Press, 1990. Print.

Williams, Carla. How to Read Character. 1990-1991. Photographs and Photocopy Transfers. Artist's Collection. "The Unconventional Photographic Self-Portraits of John Coplans, Carla Williams, and Laura Aguilar" by Alice Di Certo. Georgia State University Digital Archives: Art and Design Theses. Paper 4. Web. 1 Dec 2011.

Willis, Deborah. "Searching for Memories: Visualizing My Art and Our Work." Sister Circle: Black Women and Work. Ed. Sharon Harley and The Black Women and Work Collective. New Brunswick: Rutgers UP, 2002. 218-30. Print.

---. "Women's Stories/Women's Photographies." Reframings: New American Feminist Photographies. Ed. Diane Neumaier. Philadelphia: Temple UP, 1995. 84-92. Print.

Yamamoto, Traise. Masking Selves, Making Subjects: Japanese American Women, Identity, and the Body. Berkeley: University of California Press, 1999. Print. 


\section{It}

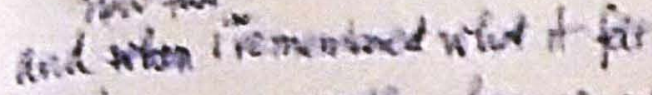

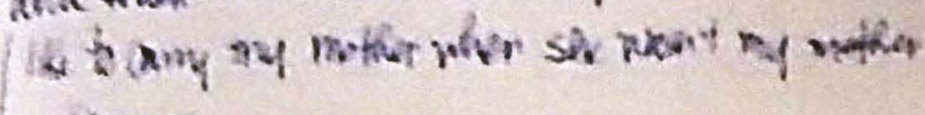

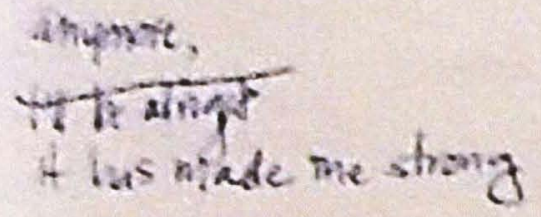

Lot nglel was vokd by a vilane

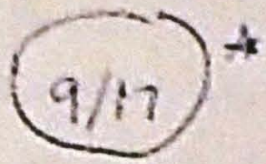
hat in kind they say it faks to mase

3 Jild.

bet the tond if takes to rise a Nowian

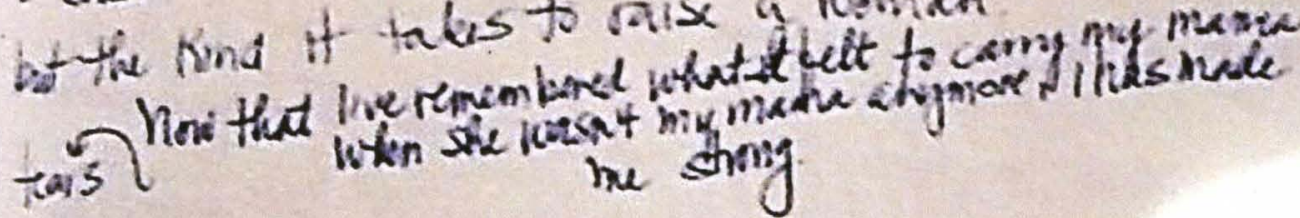
ains

vary cockes of langits ivaning songing and play - veyue

Letme. This moning -

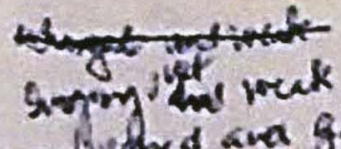

entivend ara groting divine, Ste who is live

from ny ercounter vith fke disine, $A *$

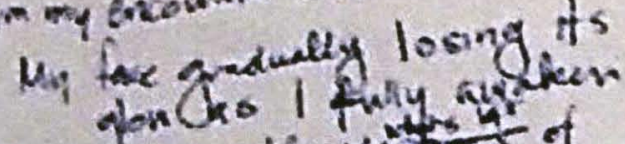

Ya siphoning the wastis? of

the viston, through my

Illustration 3: Handwritten draft of "Last Night" referenced in Chapter 1. 


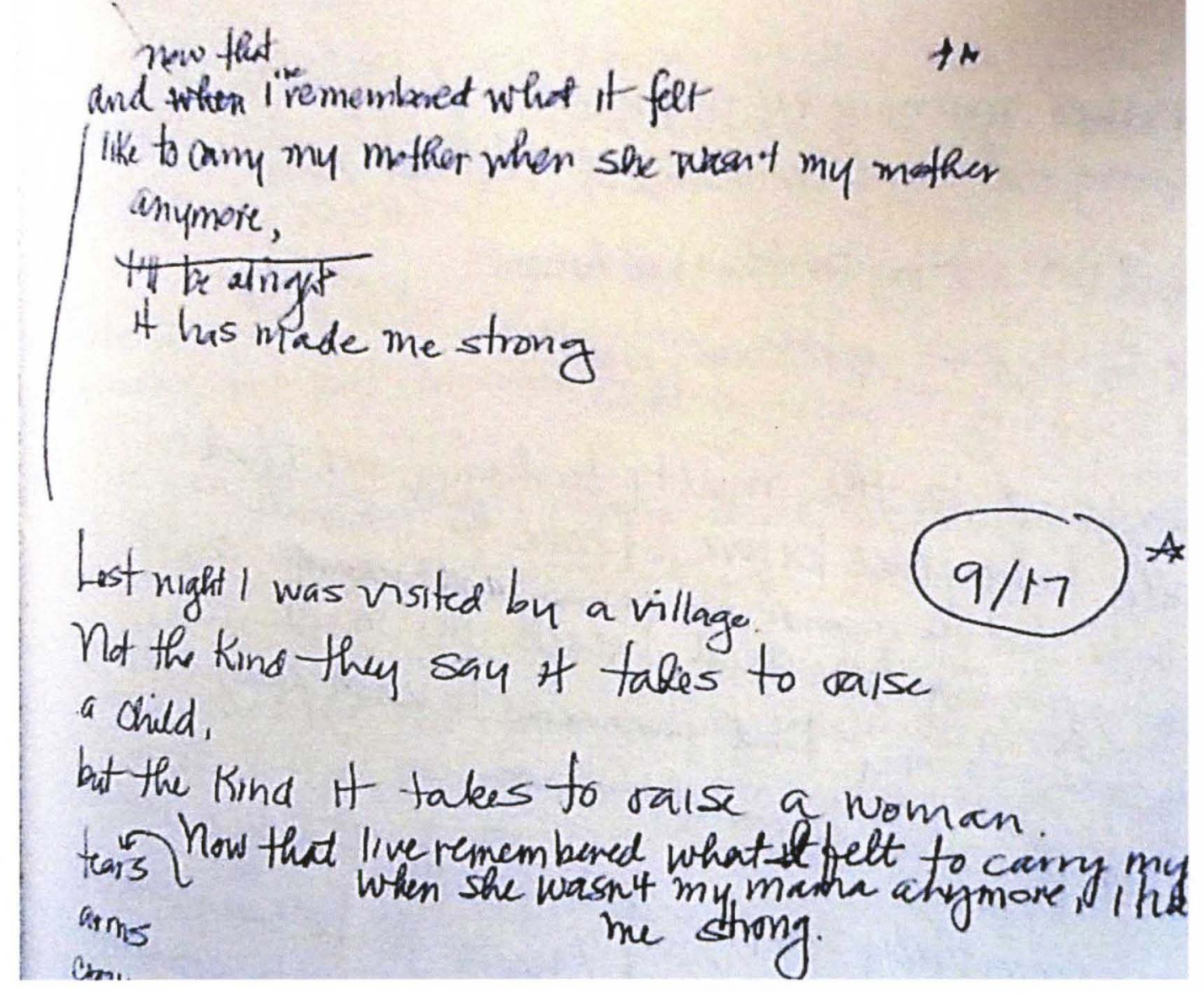

Illustration 4: Sharper close-up of "Last Night" poem. 


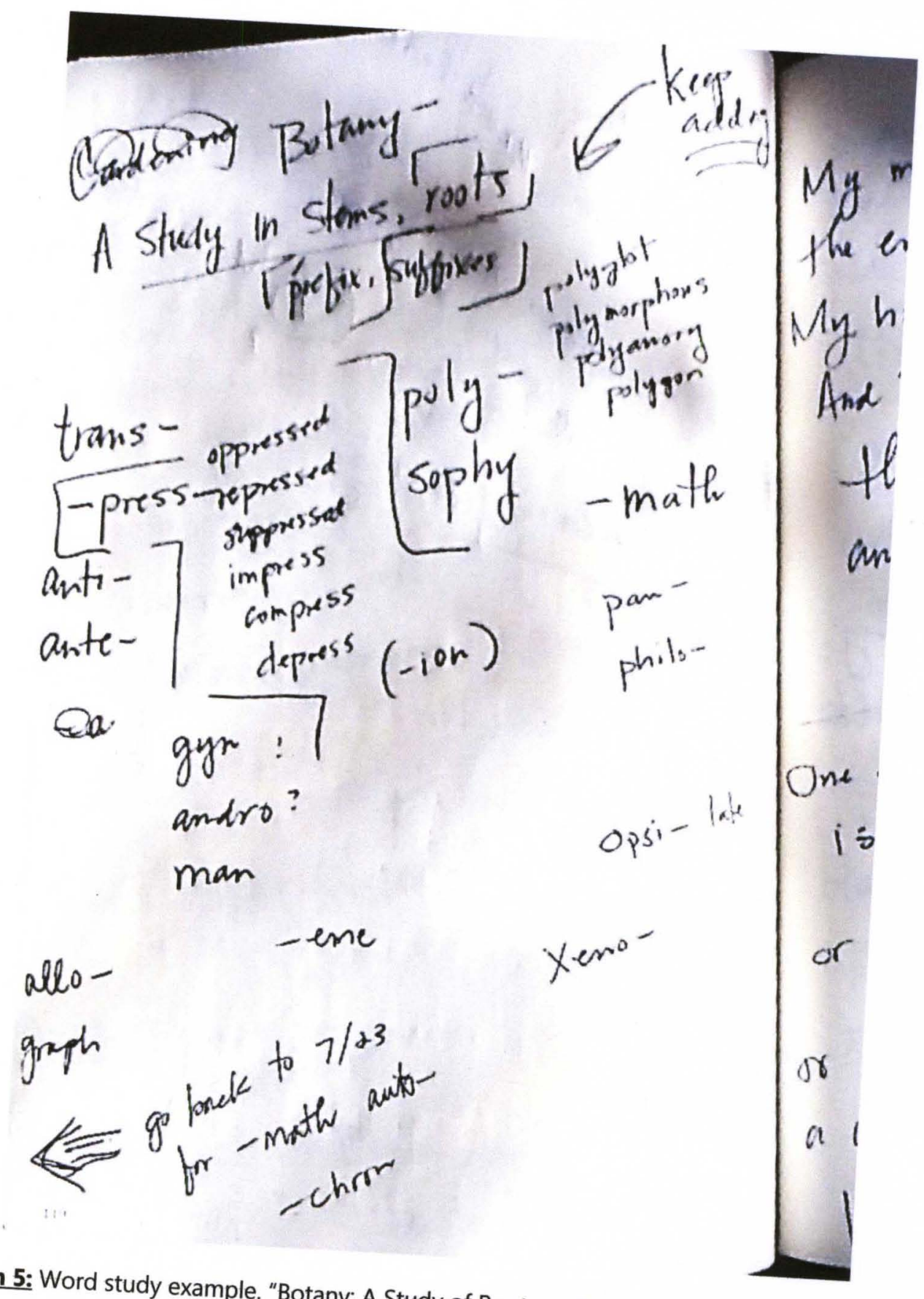

Illustration 5: Word study example. "Botany: A Study of Roots and Stems" notebook draft. 


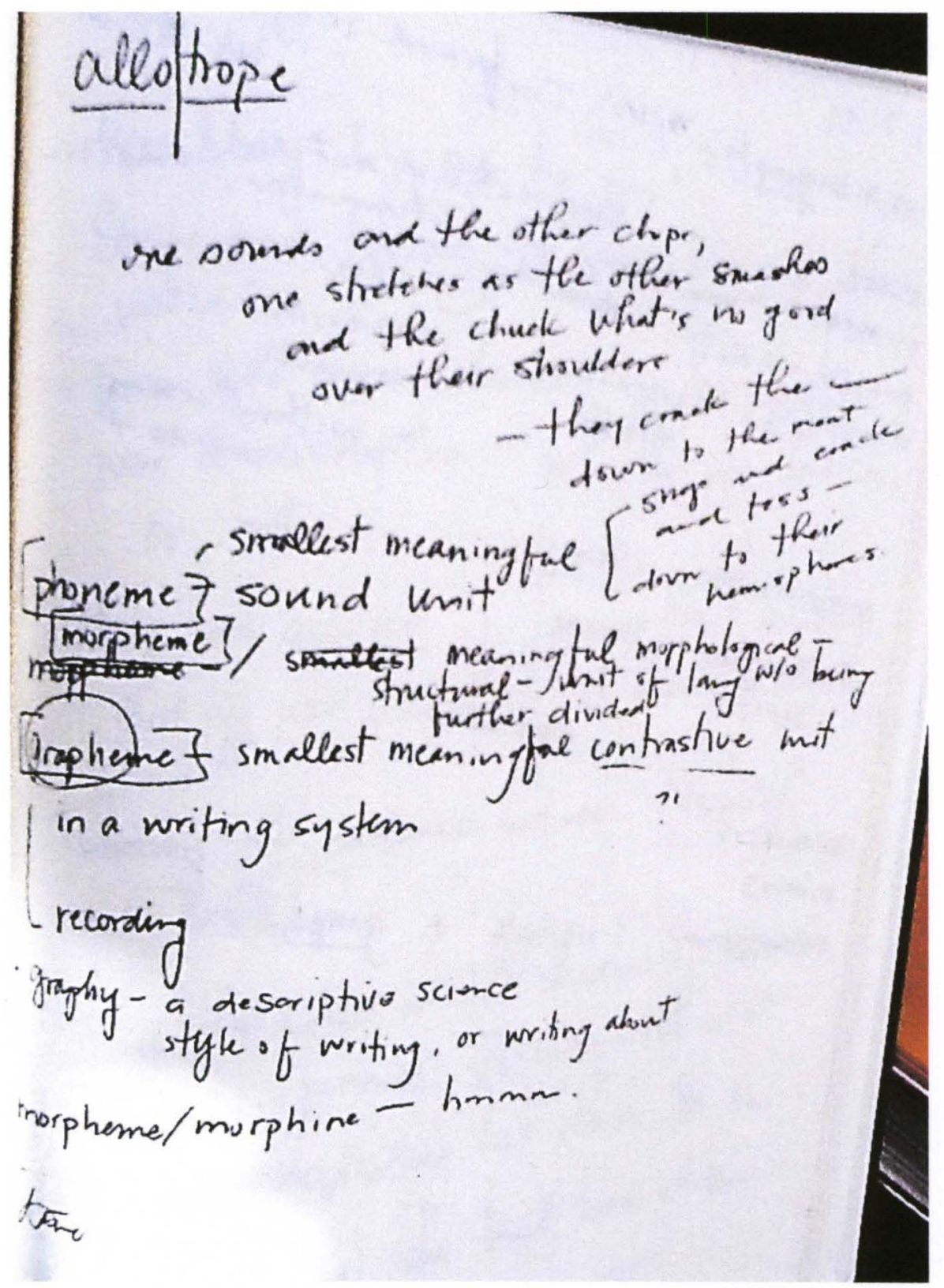

Illustration 6: Word study that accompanied the initial draft of "Morphology" in my notebook. 


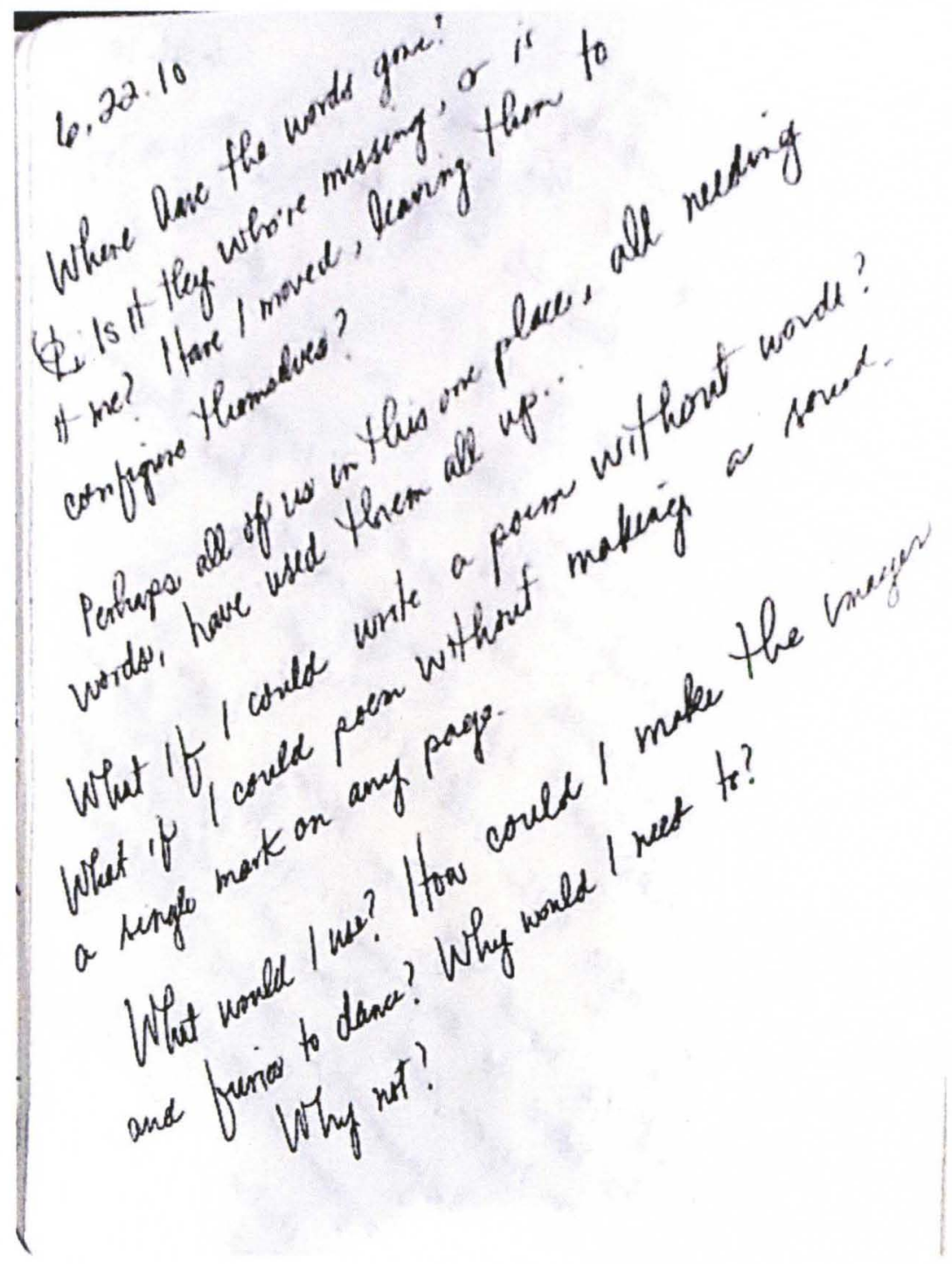

Illustration 7: Wordless Poem Musing page 1--The journal entry during my Cave Canem retreat that was the impetus for my wordless poem experimentation. The text reads: "Where have all the words gone? Is it they who're missing, or is me? Have I moved, leaving them to configure themselves? Perhaps all of us in this one space, all needing words, have used them all up... What if I could write a poem without words? What if I could poem without making a sound, a single mark on any page. What would I use? How could I make the images and furies to dance? Why would I need to? Why not?" 


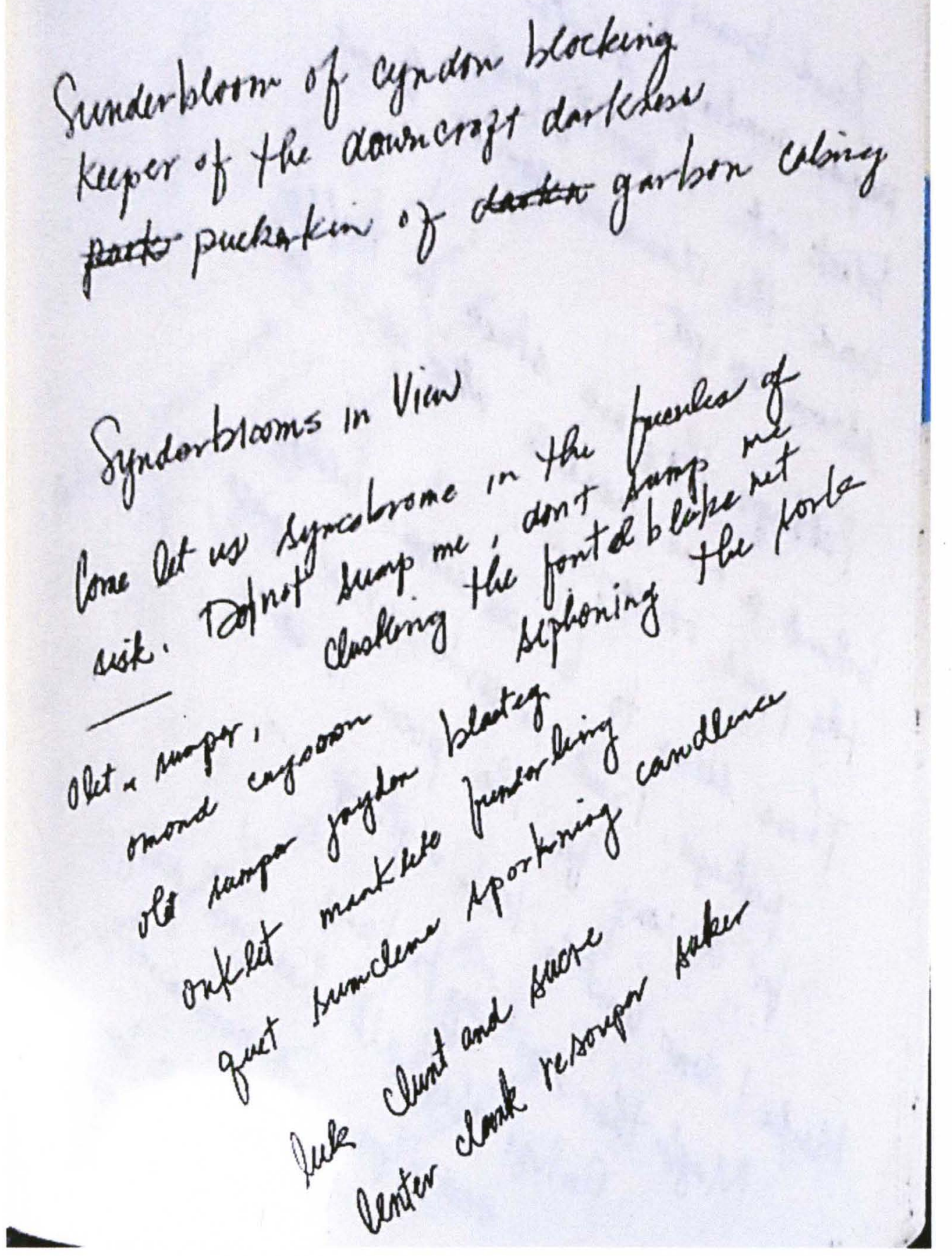

Illustration 8: Wordless Poem Musing page 2 "Sunderblooms Ik Tew" original notebook entry. Originally entitled, "Synderblooms in View." In it, both actual words and my own "nonwords" make up the text of the poem. In revision, I removed all "known words." 


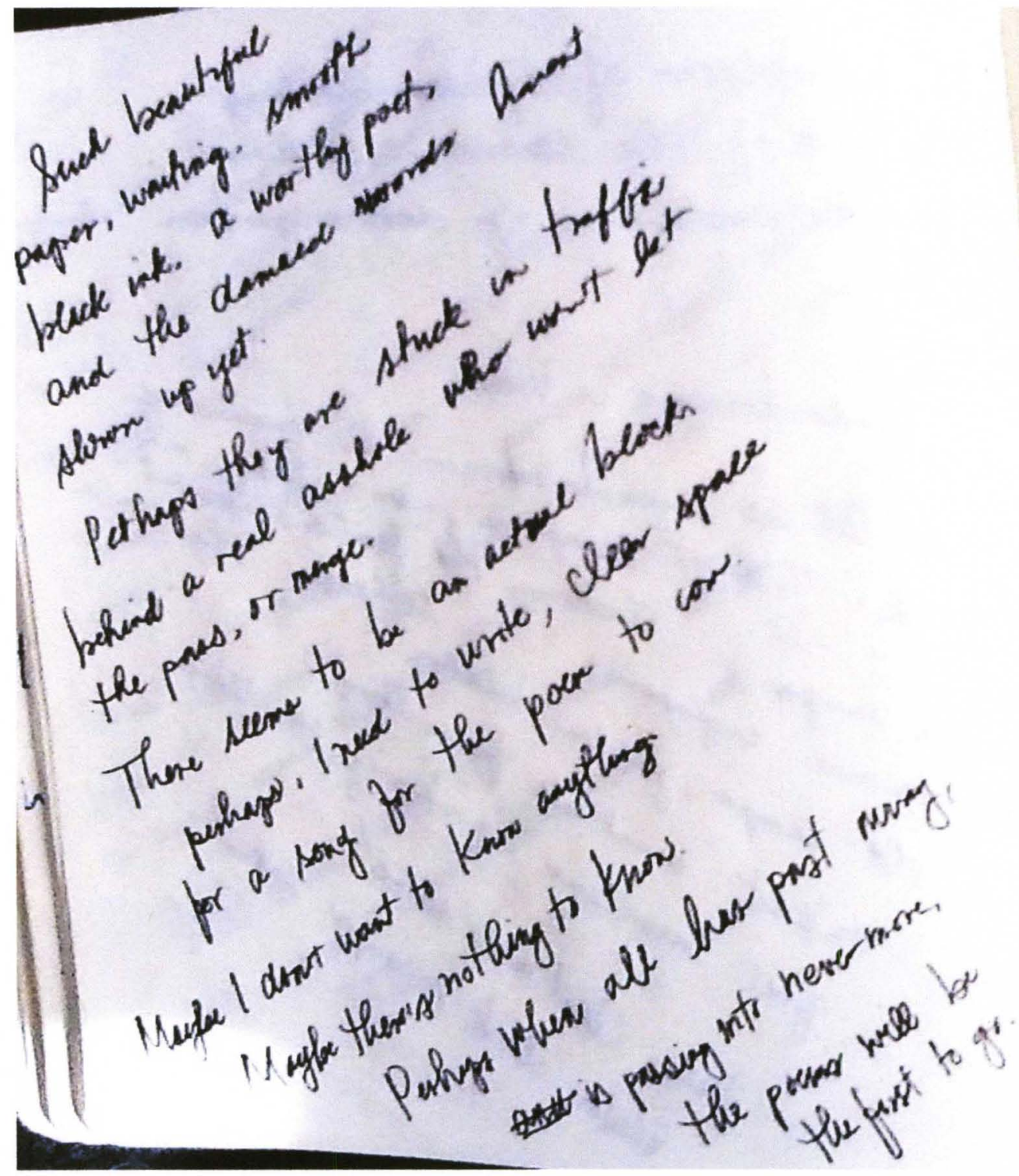

Illustration 9: Wordless Poem Musing page 3- Later the same day while still waiting on a poem (I didn't consider "Synderblooms in View" to be a poem yet, I continued to muse: "Such beautiful paper, waiting. Smooth black ink. A worthy poet, and the damned words haven't shown up yet. Perhaps they are stuck in traffic behind a real asshole who won't let them pass, or merge. There seems to be an actual block, perhaps I need to write, clear space for a song for the poem to come. Maybe I don't want to know anything. Maybe there's nothing to know. Perhaps when all has past [sic] away, is passing into nevermore, the poems will be the first to go." 


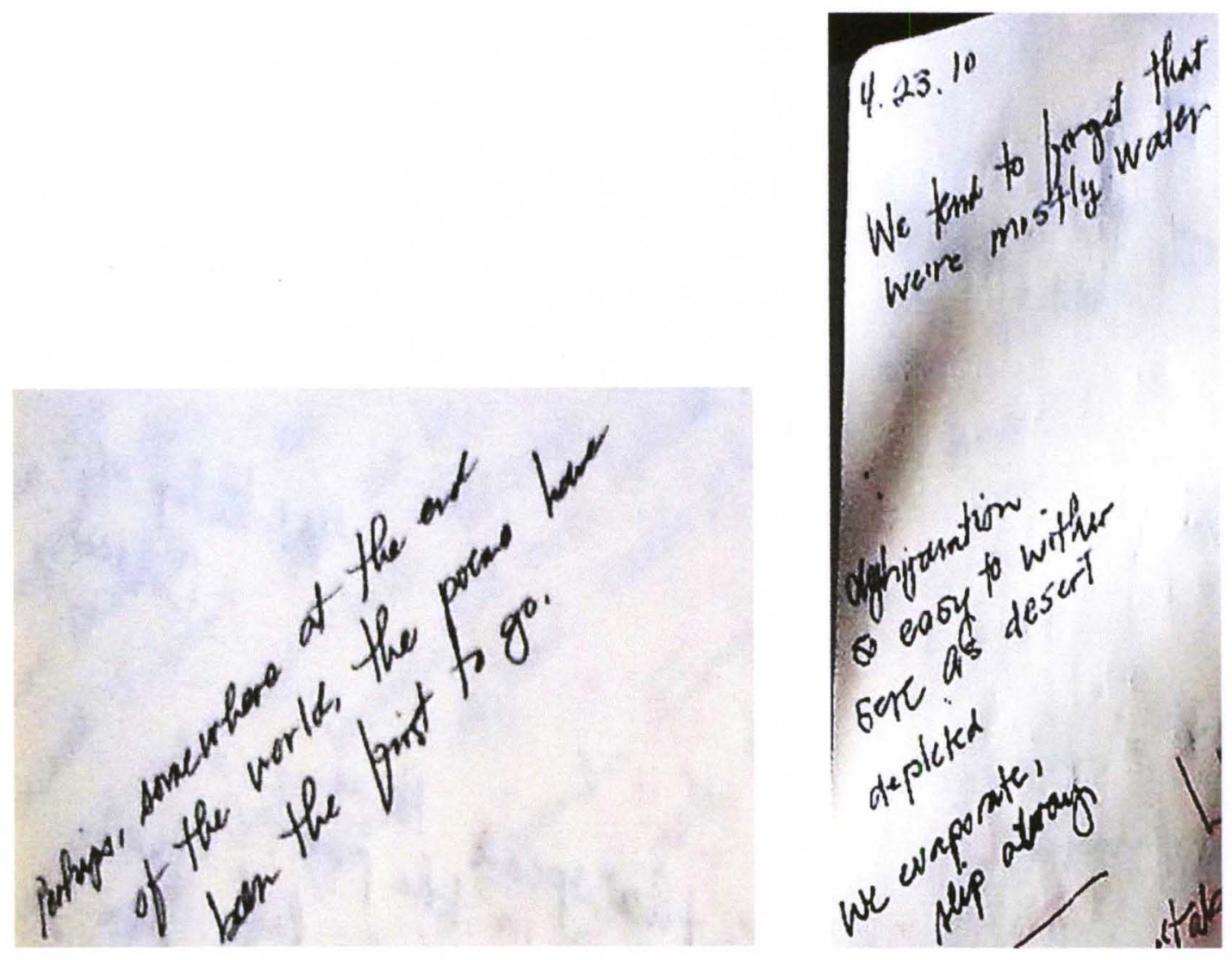

Illustration 10: Wordless Poem Musing page 4 - On this final page: "Perhaps somewhere at the end of the world the poems have been the first to go." The musings of pages 3 and 4 were precursors for "Provision." I combined with these new lines a couple of verses that I scribbled in April after being hospitalized for a bowel infection and dehydration for the better part of a week: "We tend to forget that we're mostly water" and "dehydration/ so easy to wither/ sere as desert/ depleted/ we evaporate,/ slip away." Even a week after being home from the hospital, I was having trouble keeping hydrated. The implications of water on my own mortality were in the front of my mind in those days. These verses together with those on wordlessness provided the context for writing about disappearing poems, our being "more water than word," and the impending doom of poets that necessitates the speaker's "covenant with spiders." 


\section{\& L. 2110 \\ 9: 13 an \\ CC}

ceopung

1 flowenng thing

to unching, clembing blatming thing to bunsting Alnuing, runnng, flying couving, thining. budang, psiviving kwomming, diving. leping, fluoring roting, flouting, d Phedding, molting lowing thing sou stop

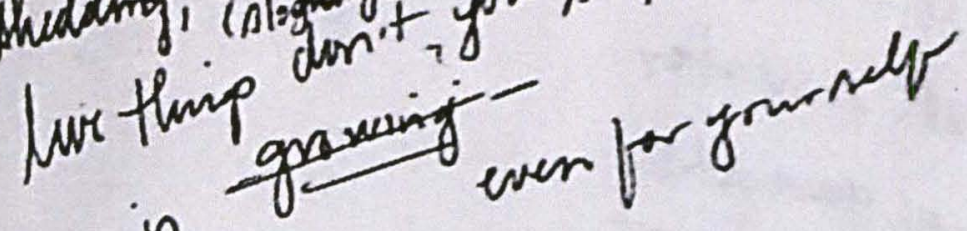

bewhoyon kecping

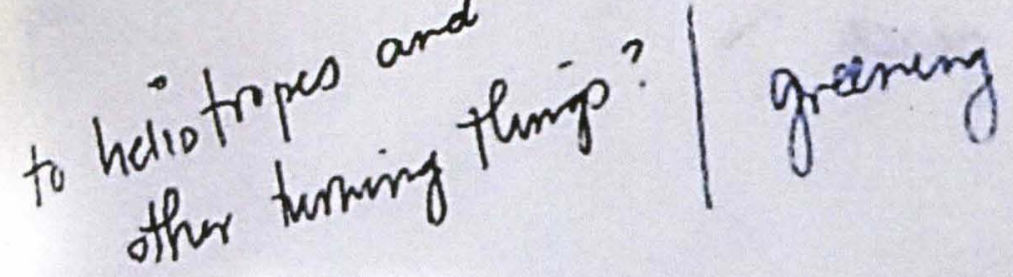

Illustration 11: The start of "Undermining Cynicism in the Universe" before I knew how to make it a poem. 


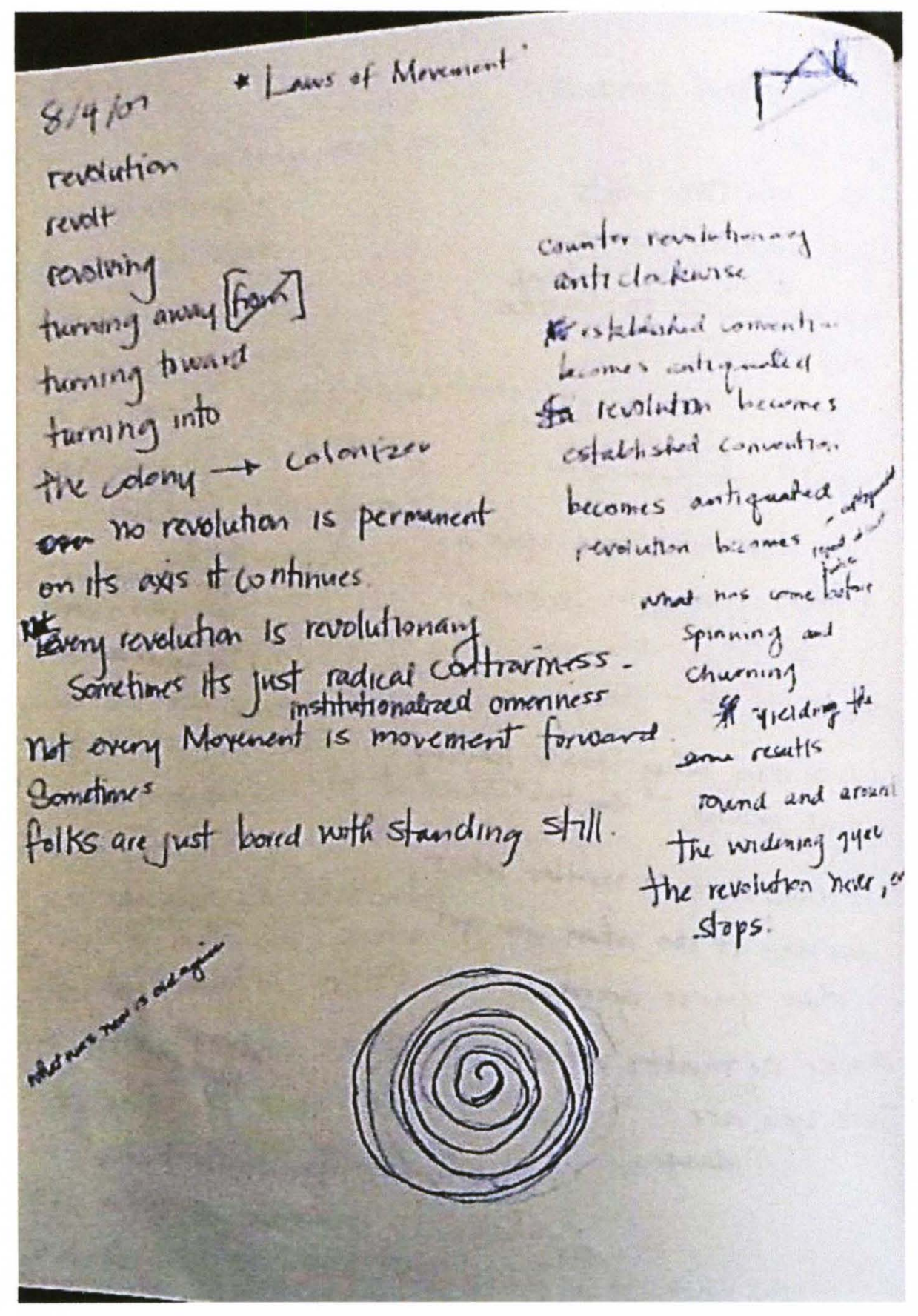

Illustration 12: Rough draft of "Laws of Movement" from my poetry notebook. As I was writing the poem, I was conscious of a rhythmic swaying in the language that I wanted to translate visually. Thematically, the poem implies the circularity of revolution, that "movements" go around and around. I wanted the words to follow the movements of the spiral at the bottom of the page. 


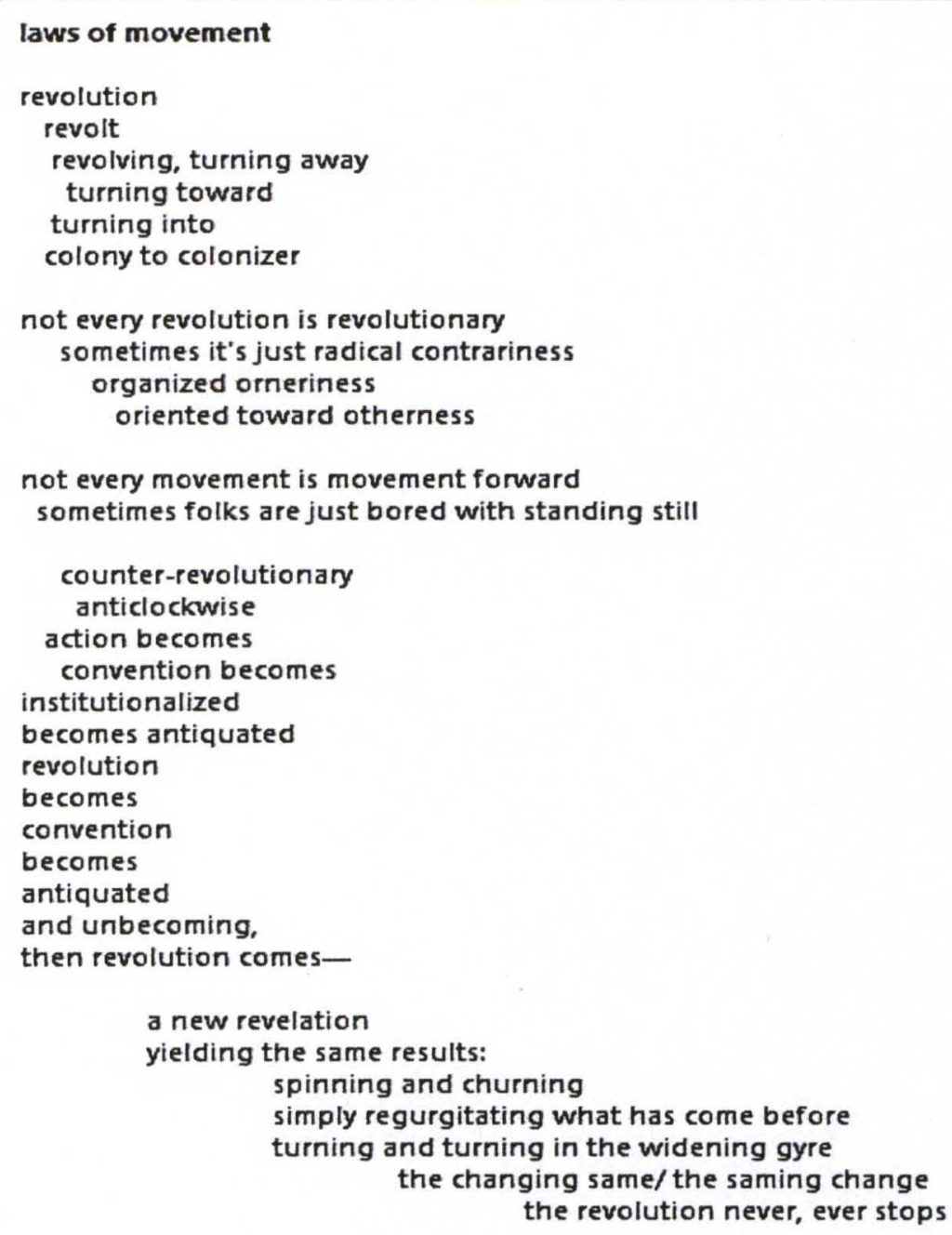

Illustration 13: In the Word draft of "Laws of Movement," I was obviously limited in terms of the graphical qualities I was able to present in the poem. In this way, the handwritten draft is more "true" to the essence of the piece. While saving the text as an image file, then manipulating afterward to create slight distortion lends a modicum of flexibility, it does not capture my original intent. 


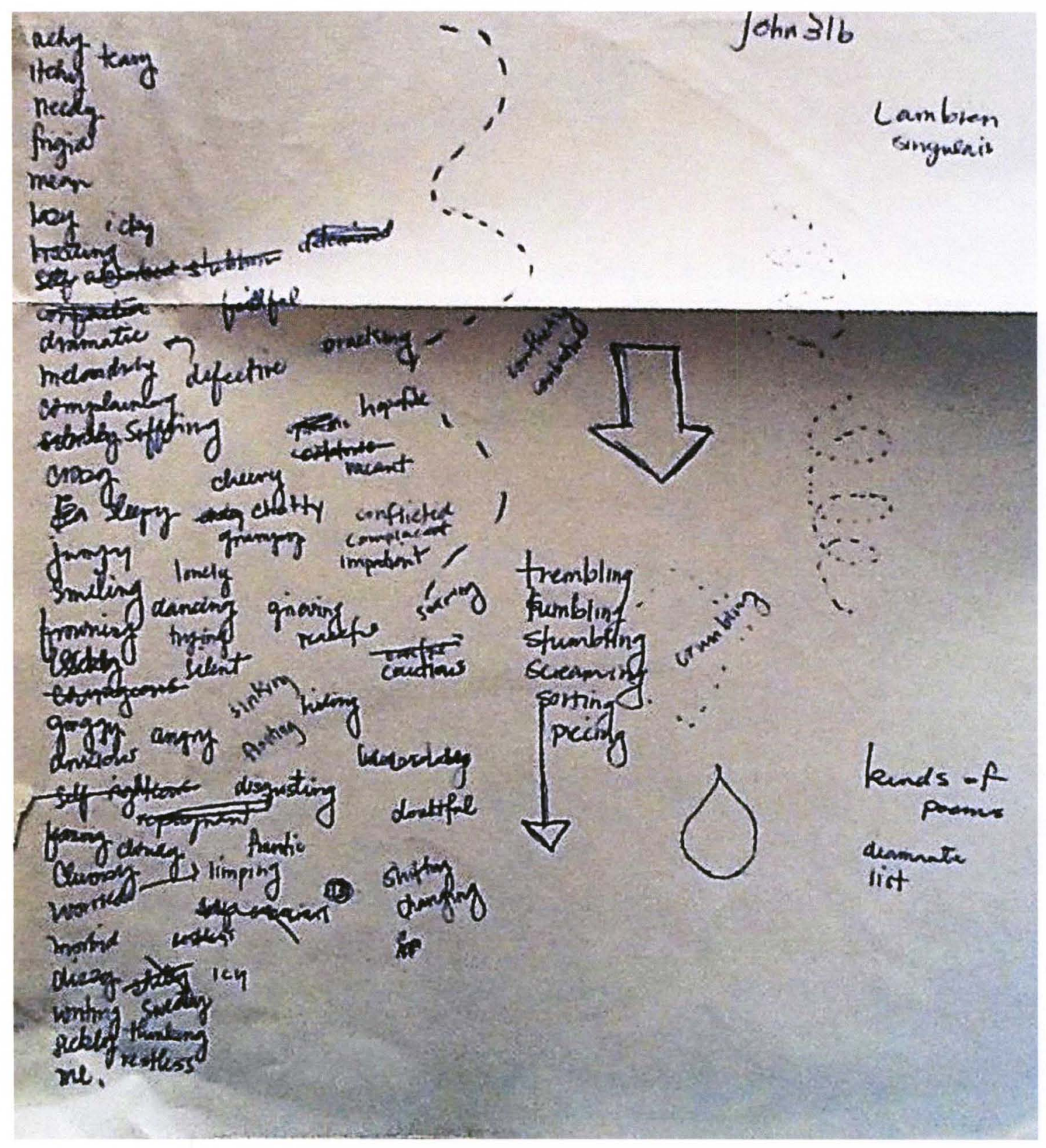

Illustration 14: This rough draft of an untitled poem is another example of my impulse to present the clustering of ideas and attributes of a poem in a visual way. The various adjectives that make up the poem's text are meant to be descriptions of myself, the ways I think of myself and mybody. The arrows and dotted lines simulate the movement and momentum of the pieces. The scratched-out and scribbled-over words are intentional. Because of the difficulty translating concept to Word documents, this poem has never been revised. 
With the word clouds, I experimented with color, font, and fills in addition to the number of words included in the cloud. Though they were generated randomly, I enjoy looking at them all. The way the words cluster together are themselves suggestive of poems to me.

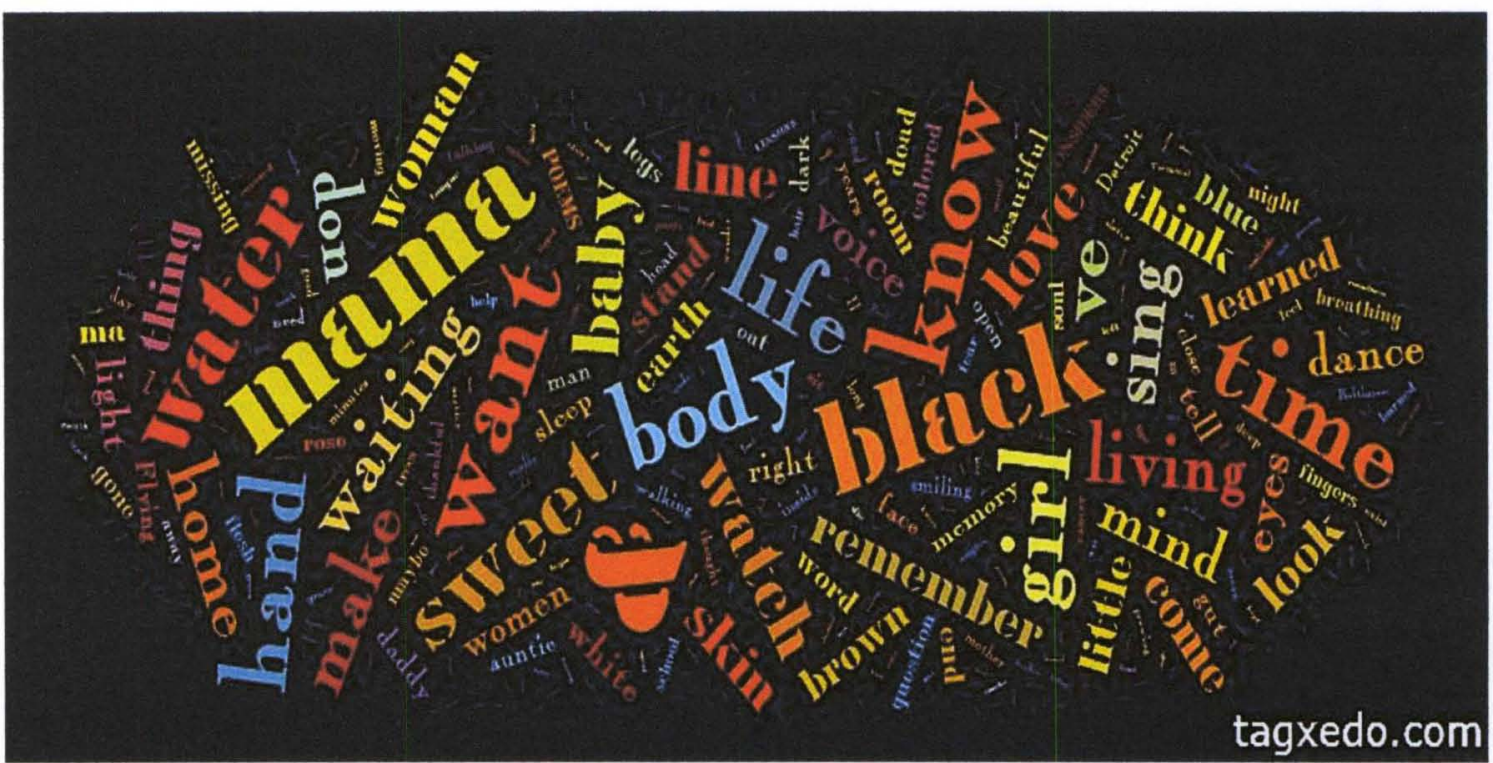

Illustration 15: Word cloud 600 words.

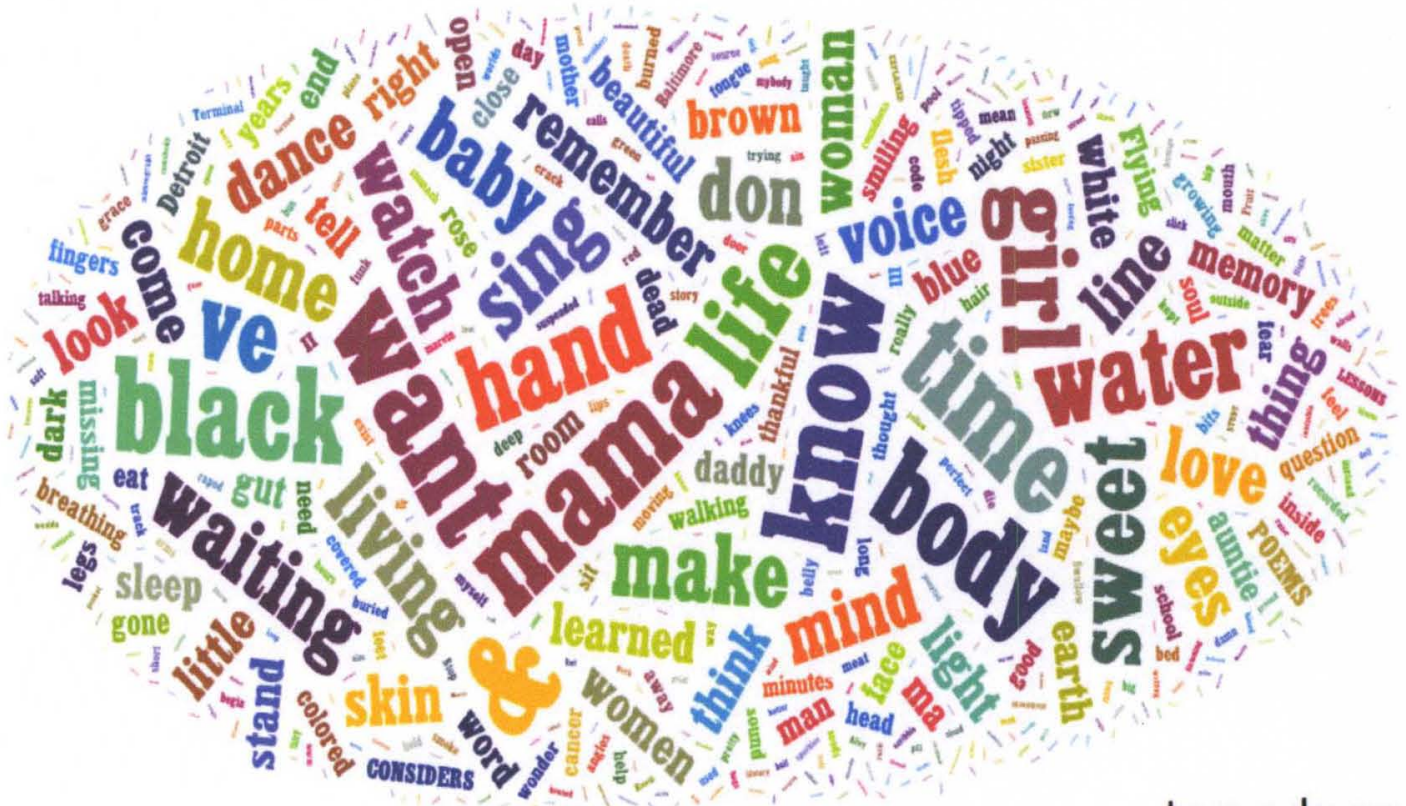

tagxedo.com

Illustration 16: Word cloud of top 600 words 


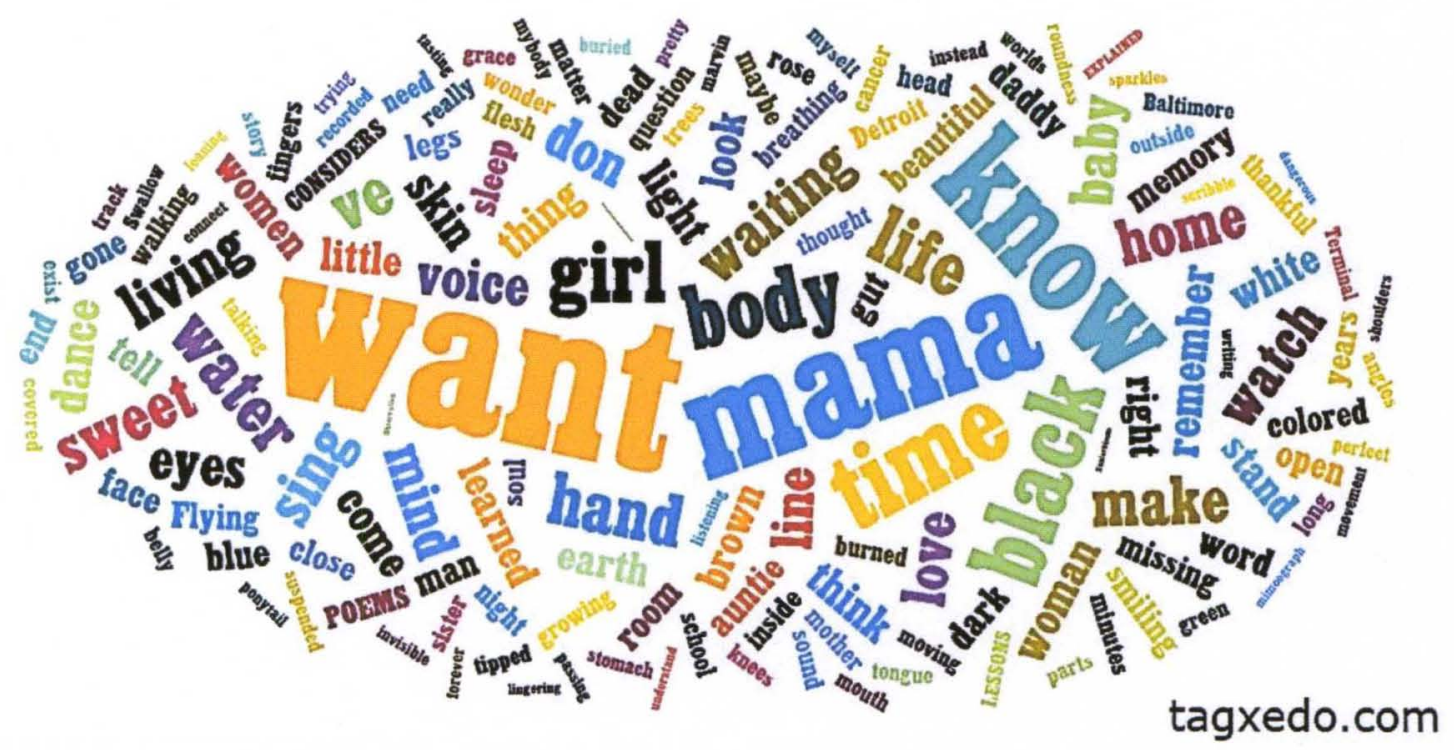

Illustration 17: Word cloud of 250 words.

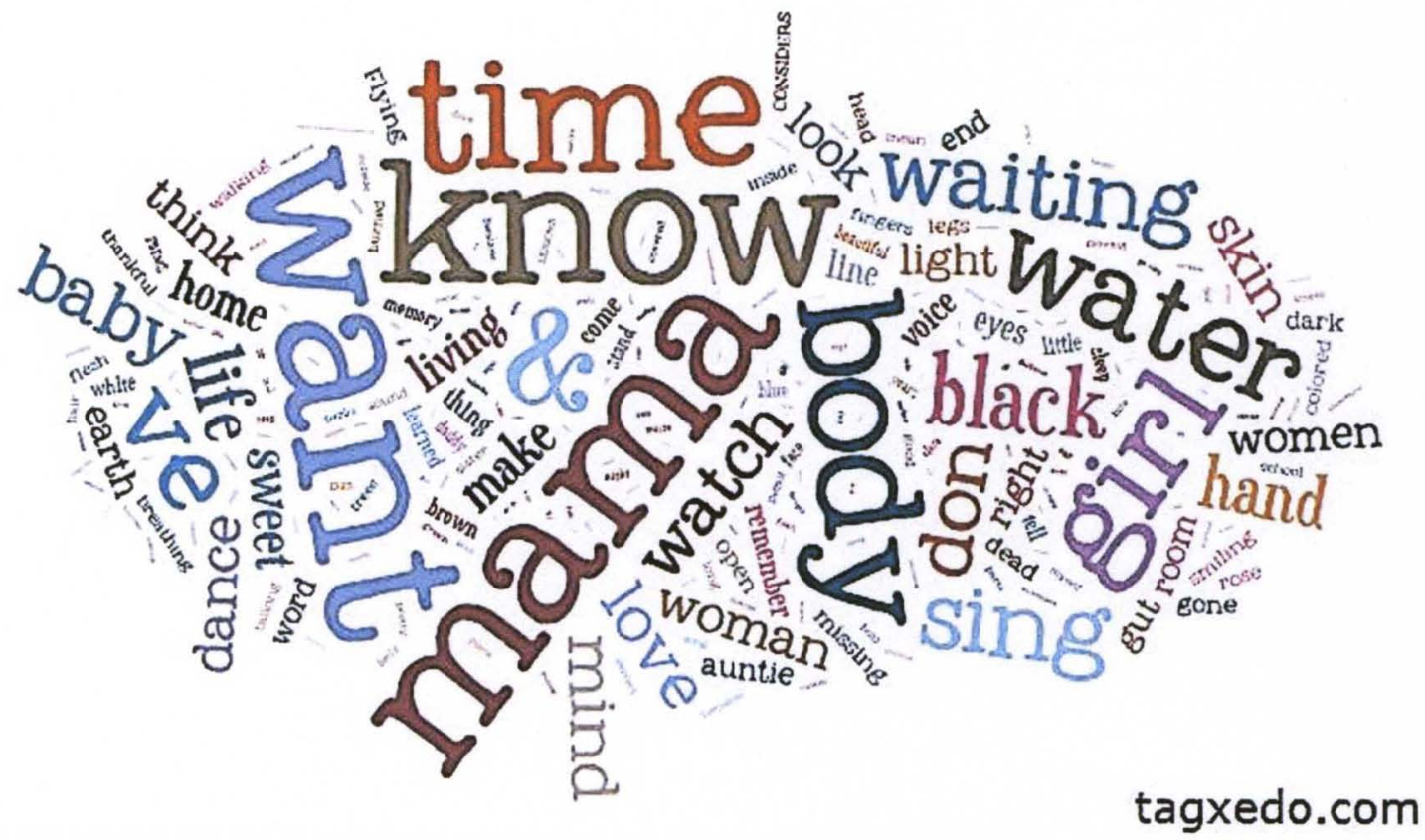

Illustration 18: Word cloud of 250 words in different font and color scheme. 


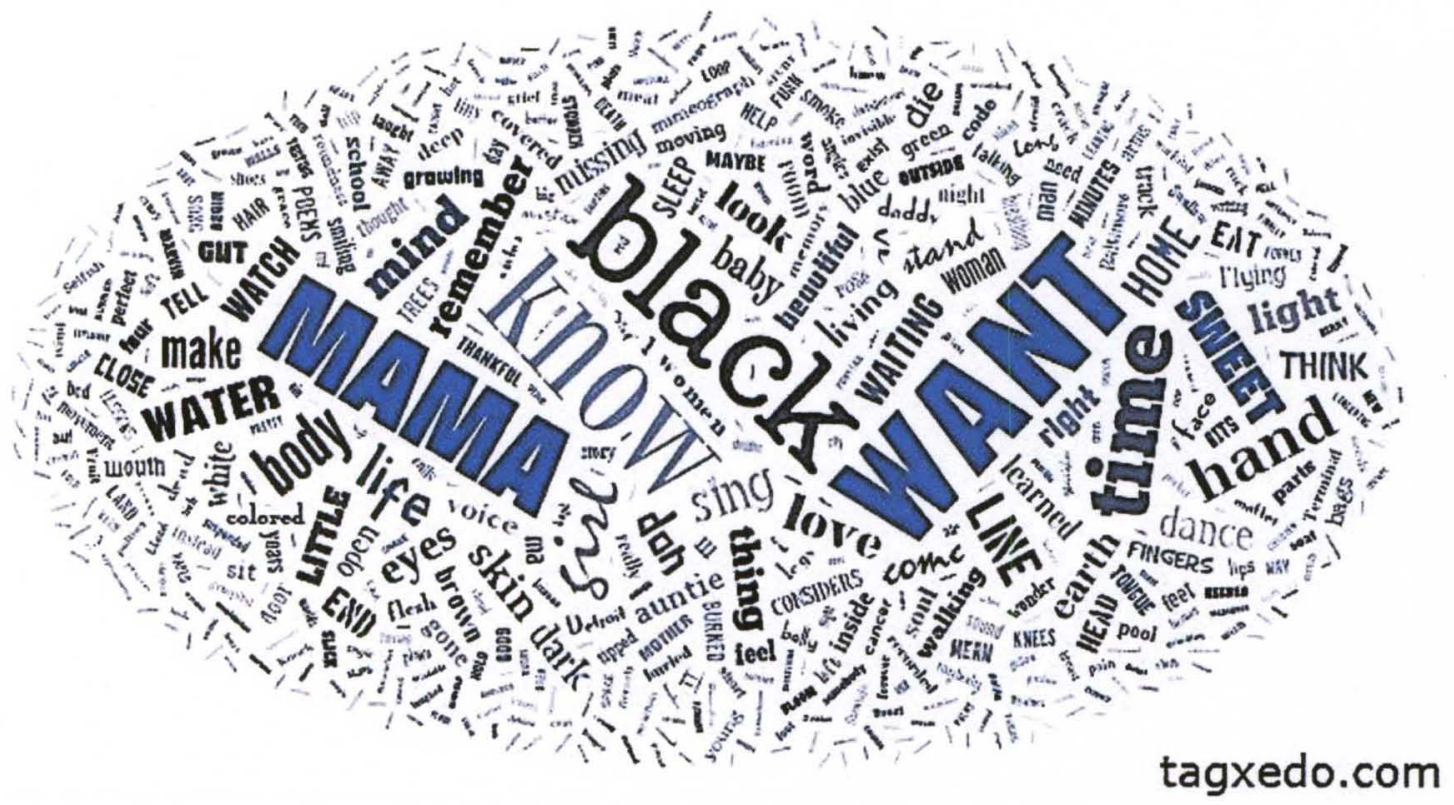

Illustration 19: Word cloud in blue. Contains the top 600 words in the manuscript.

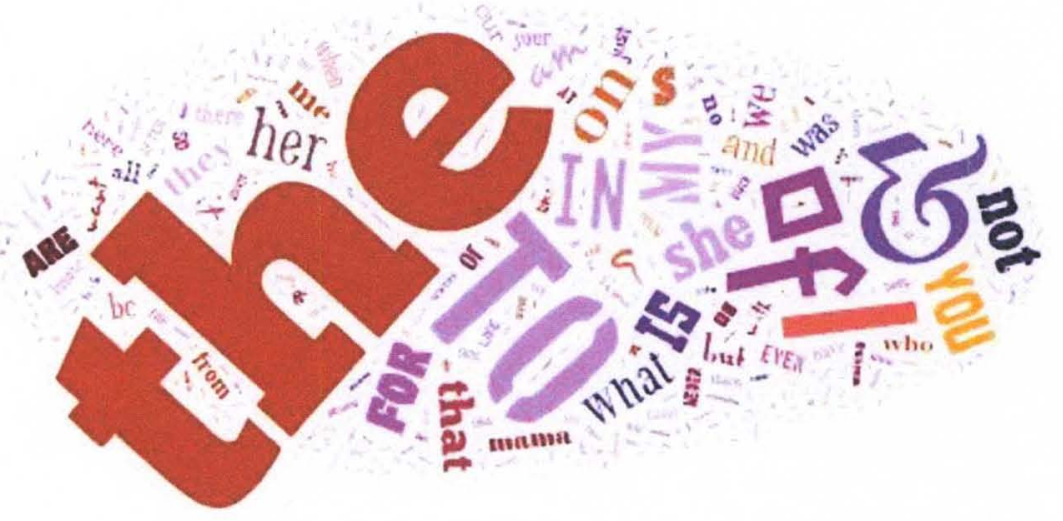

tagxedo.com

Illustration 20: Word cloud depicting most prevalent words including "common" words, such as conjunctions, prepositions and articles. 


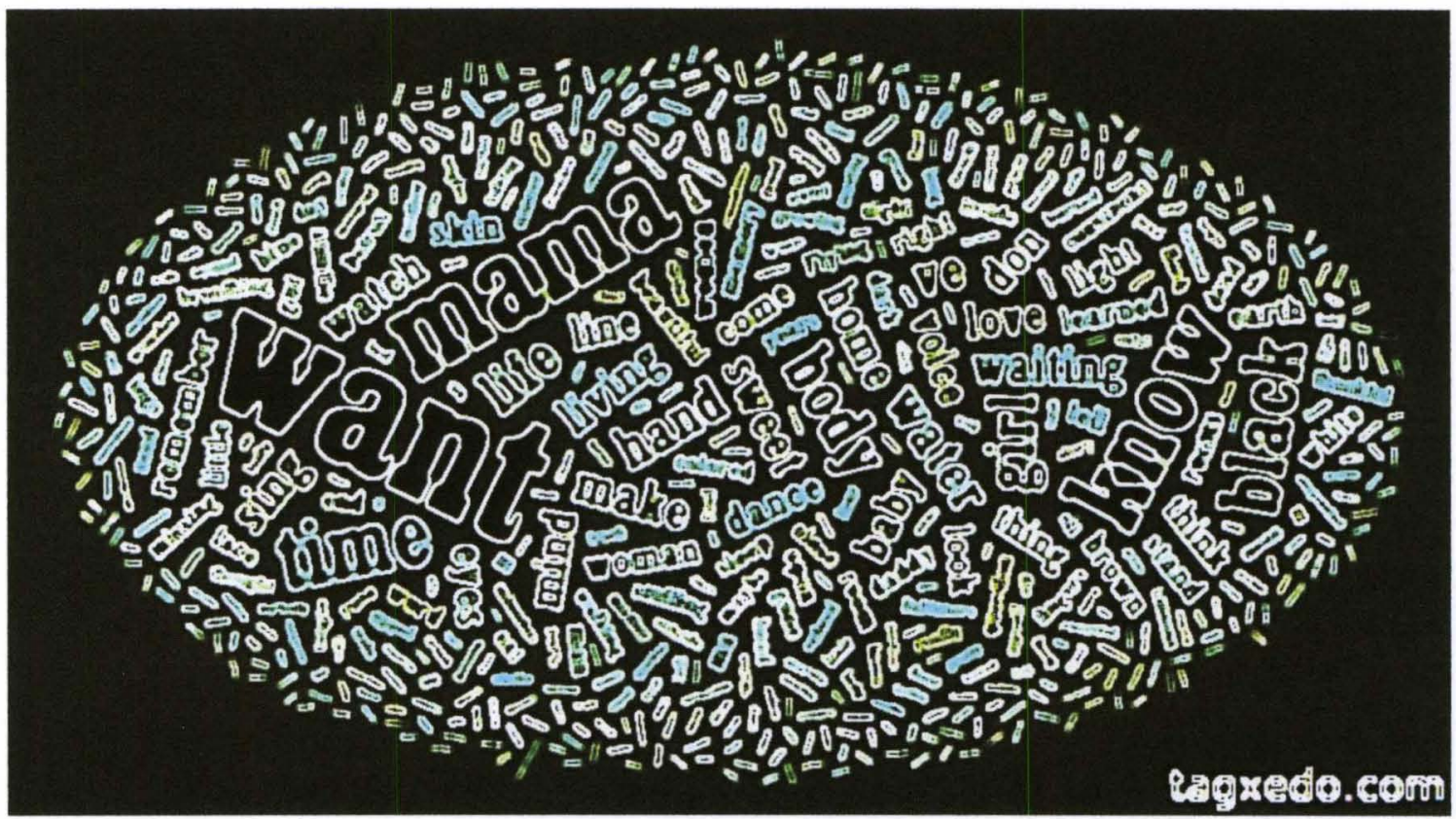

Illustration 21: Glow in the dark word cloud.

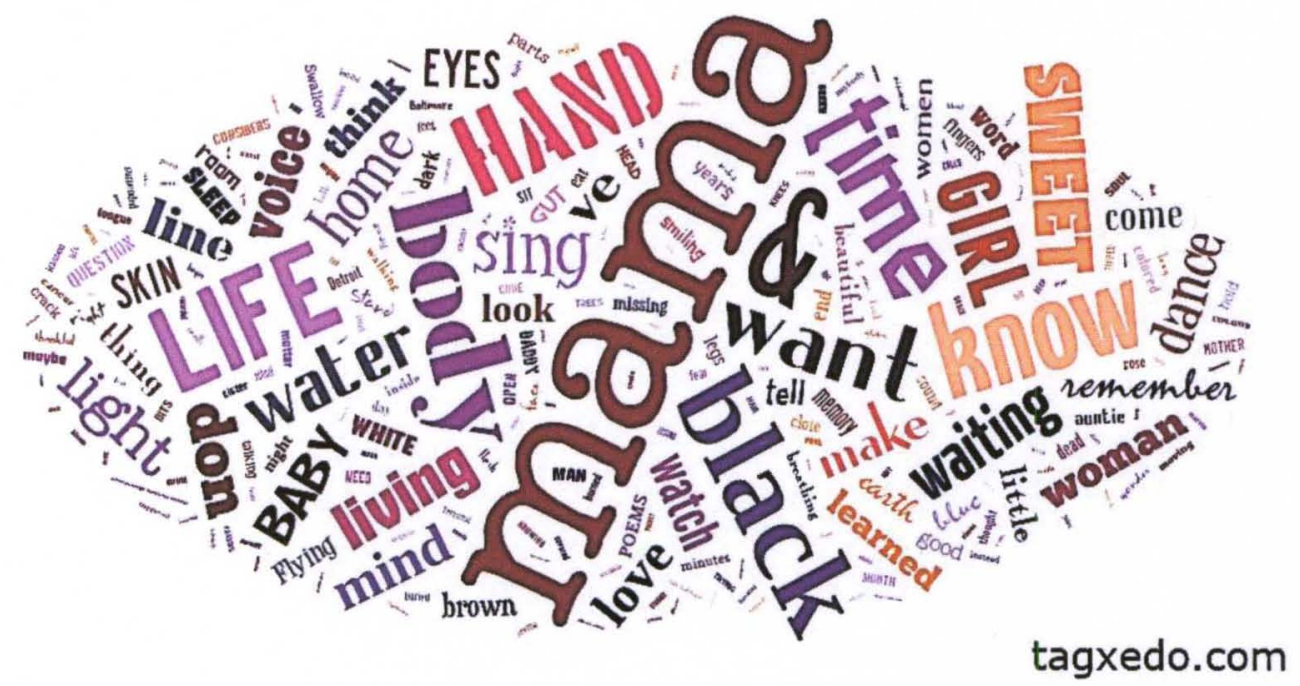

Illustration 22: In this word cloud, "mama" is the central. I think this is a particularly telling word cloud. 


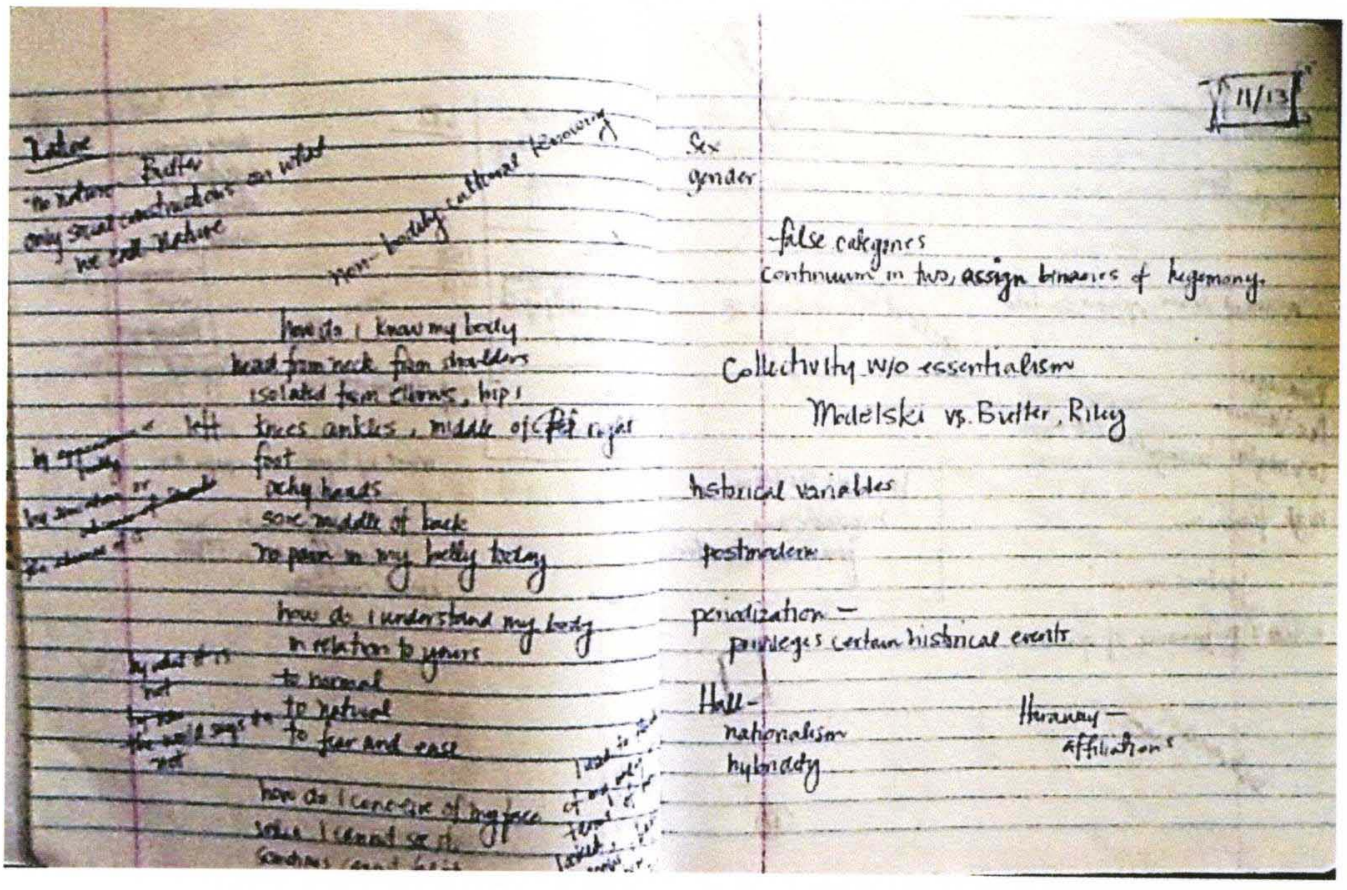

Illustration 23: "Epistemology" within the context of my class notes.

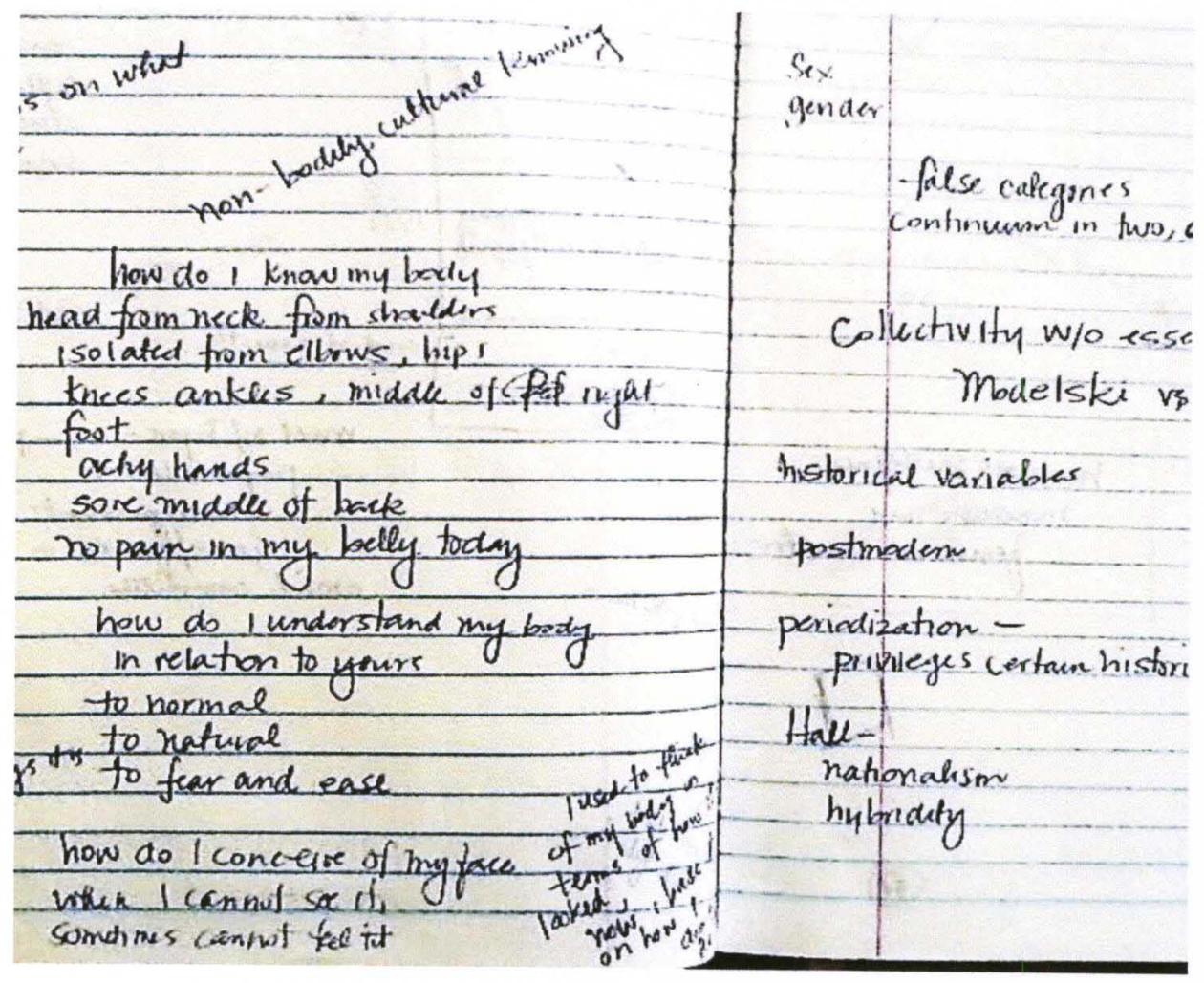

Illustration 24: Close-up of Poem Text-this is close-up shows just how closely the poem (on the left) sits with my class notes (on the right). While listening and making notes on the right, I began to think and jot (on the left). 


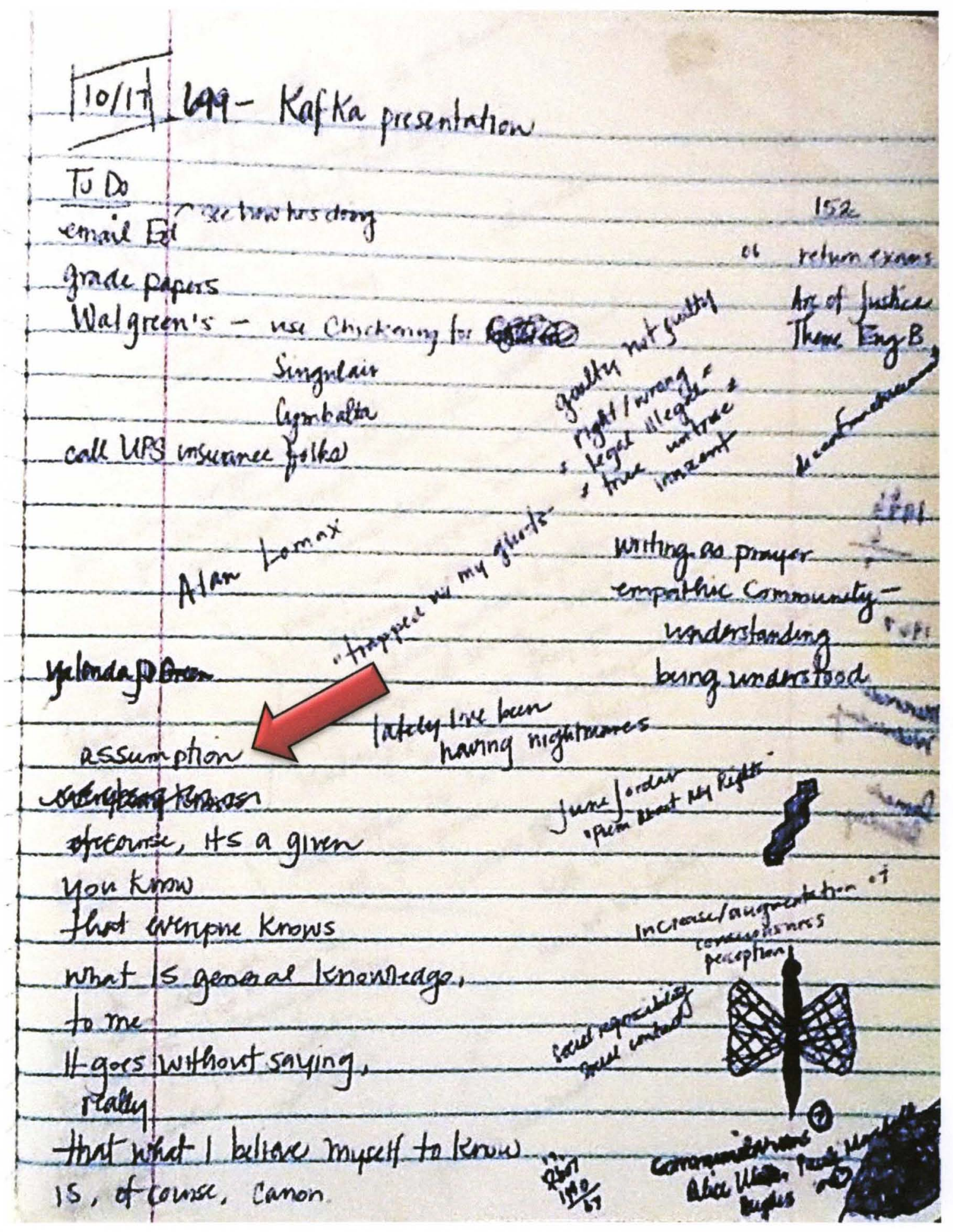

Illustration 25: Another example of a poem in its original context-the arrow shows where the poem begins. Like "Epistemology," "Assumption" is another poem that began in the middle of class, sandwiched between notes and "to do" lists, and prescriptions to refill. I remember writing the poem after a comment made in class that -I felt was condescending and grossly presumptuous. Rather than voice my disgust, I wrote the poem as it came to me. I hope that air of pomposity is preserved in the (only slightly) revised version of the piece.

219 


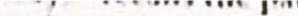

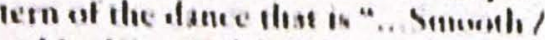

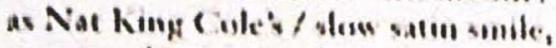
casy as takmog/ene das it a time," A

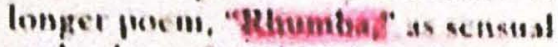
as lie dance for whele it is named, is Dove's must elaborate metging of dance and peetry in a lind uf woles. thesia of sight, musest serund. and mich:

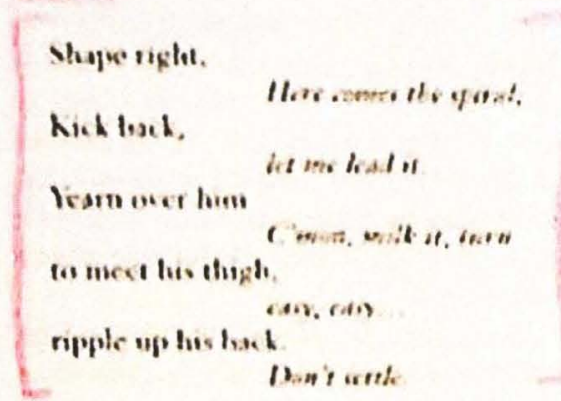

"Boy, dud I nurk en that quene"

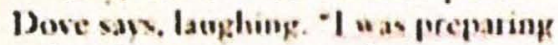
a rhumba routine tor s showcase, and it dawned on me thas I u as thinking Inyxif through it at the samc ene I was pretending not to think it tirough. I wanted to get that fecling of the rhumba's give-and-take, a tension between the lovers, the partners, a tension that is utterly smooth. So it was important that it function as two sep. arate poems at she same time that it's one interloclong pocm?

Dove's association with other art forns, especially music, is well known. Music has been a part of her life since she was a young girl growing up) in Akron, Ohio. Traned as a singer, she has performed in chroirs and occasionally sings torch songs and blues for benefits. She also plays the cello and the viola da gamba. During her tenure as peset laureate of the United States, she initiated collalsorations not just of

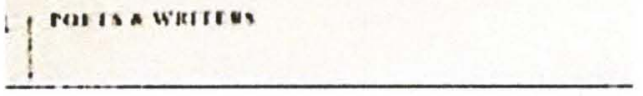

Illustration 26: Excerpted from Poets \& Writers Sept/Oct 2004, the highlighted and underlined sections were what inspired me to begin writing "Night Whispers/Hush" as a piece that could "function as two separate poems at the same time that it is one interlocking poem." This discussion of "Rhumba" by Dove made me pick up my pen to write a poem for virtually the first time since graduating from college more than two years before. 


\section{CURRICULUM VITAE}

NAME

ADDRESS

DOB

EDUCATION

\& TRAINING
Yalonda Jamel Davidson Green

900 E. Madison St.

Louisville, KY 40204

Detroit, Michigan -- June 12, 1980

BA, English Literature

Kentucky State University

1998-2002

MA, Communication

Wake Forest University

2002-2004

PhD, Humanities

University of Louisville

2005-2011

Teaching Assistantship

Department of Communication

Wake Forest University, 2003

Graduate Minority Assistantship

Humanities PhD Program

University of Louisville, 2005

Graduate Teaching Assistantship

Humanities PhD Program

University of Louisville, 2007

Cave Canem Fellowship and Poetry Retreat Greenburg, PA, 2010.
PROFESSIONAL SOCIETIES

\& AFFILATIONS
Alpha Kappa Alpha Sorority, Inc. ArtsReach and The Kentucky Center BMI

Cave Canem Poets 


\section{PUBLICATIONS}

1. "Arcanum" and "The Verb to Be" in Reverie. Fall 2008.

2. "Tending," "Struck," "Elementary Lessons," Artists in Revolution Anthology. Ed. Estella C. Majozo and David Anderson, 2009.

3. "Aphasia," "Women's Studies," and "The 6." TORCH. Spring/Summer 2010 http://torchpoetry.org/spring\%202010/yalondajdgreen.htm

4. "Flash". Mythium 1.2 (2010).

5. "Strange Fruit" and "Time (for Detroit)" in Reverie 4 (2010).

6. Diurnal Movements (2010) - album of original vocal jazz, soul, and funk music, in conjunction with E.T. Productions, Louisville, KY. http://jdgreensoul.com. Audio.

INVITED PRESENTATIONS, EXHIBITIONS,

\& PERFORMANCES

1. Paper Presentation. "THE FLESH OR THE EARTH: The (In)organic, (Un)natural Body in Nervous Conditions and The Stone Virgins." Humanities Graduate Student Colloquium "Humanities and the Arts: Cultures \& Controversies. Ekstrom Library Chao Auditorium, University of Louisville. April 3, 2009.

2. "Synapse" with Artwork by Violine Antoine. Shelter Poetry and Collaborative Art Project University of Louisville, TARC Shelter installation, March-April 2009.

3. Cave Canem Fellows Reading, $15^{\text {th }}$ Annual Cave Canem Poetry Retreat, University of Pennsylvania at Greensburg. June 22, 2010.

4. Presented Natural Beauty, a performance piece consisting of original songs and poems from my dissertation manuscript at Unspoken Truth: An Exhibit of Advocacy and Healing For Survivors of Personal Violence and Those Who Love Them. Sponsored by Seven Counties Services and The Huff Gallery at Spalding University. July 16-17, 2010.

5. Vocal Music Institute for ArtsReach, an education program of The Kentucky Center for the Performing Arts, to enable community centers to provide quality arts programming. September 16, 2010.

6. Guest Soloist. Performed a 45 minute program of traditional and original arrangements of African American spirituals for the Detroit Spiritual Festival: "After the Railroad." Bushnell Congregational Church, Sponsored by United Voices of Detroit. January 27, 2011.

7. Spirituals Workshop with The Detroit Children's Choir. Detroit Spiritual Festival. January 29. 2011.

8. Performance as "Lady in Brown" in Ntozake Shange's For Colored Girl. Directed by Rush Trowel. The Kentucky Center MeX Theater, October 6-9, 2011. 